Seleção de características: abordagem via redes neurais aplicada à segmentação de imagens

Davi Pereira dos Santos 



\section{Seleção de características: abordagem via redes neurais aplicada à segmentação de imagens}

\section{Davi Pereira dos Santos}

Orientador: Prof. Dr. João do Espírito Santo Batista Neto

Dissertação apresentada ao Instituto de Ciências Matemáticas e de Computação - ICMC-USP, como parte dos requisitos para obtenção do título de Mestre em Ciências - Ciências de Computação e Matemática Computacional.

\section{"VERSÃO REVISADA APÓS A DEFESA"}

Data da Defesa:

$21 / 03 / 2007$

Visto do Orientador:

USP - São Carlos

Março/2007 

Dedico este trabalho ao amor, e àqueles que o manifestam. 
“...

Ali onde o chão é chão as pernas, pernas

a coisa, coisa

e a palavra, nenhuma

Onde apenas se refrata a idéia

de um pensamento exaurido de movimento ,

(Francisco Alvim) 


\section{Agradecimentos}

Agradeço ao meu orientador pela confiança e amizade, agradeço à minha irmã por incentivar minha barba, agradeço ao meu irmão mais velho por me ensinar as coisas e ler (inventar) histórias em quadrinhos para mim quando eu ainda não sabia ler, agradeço ao meu irmão mais novo pela paciência e pela falta dela também, agradeço aos meus pais pelas vezes em que tiveram a coragem de acertar, agradeço à Pandora por não ter comido nenhum papel importante, agradeço ao CUME pelos momentos de lazer, agradeço às repúblicas pelas estadias e, por fim, agradeço ao Dave Matthews e Jimi Hendrix for the inspiration.

Este trabalho teve o apoio do Conselho Nacional de Desenvolvimento Científico e Tecnológico (CNPq). 


\section{Sumário}

Lista de Figuras $\quad$ xi

Lista de Tabelas $\quad$ Xv

Lista de Siglas $\quad$ xvii

Resumo xix

$\begin{array}{ll}\text { Abstract } & \text { xxi }\end{array}$

1 Introdução 1

1.1 Motivação . . . . . . . . . . . . . . . . . . . . 2

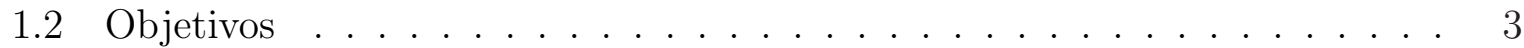

1.3 Estrutura deste documento . . . . . . . . . . . . . . . . . 3

2 Textura 4

2.1 Apreensão da textura . . . . . . . . . . . . . . . . . . 4

2.2 Análise da textura . . . . . . . . . . . . . . . . . . 6

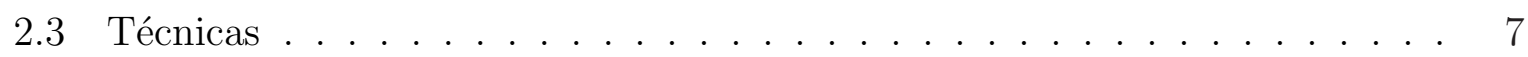

2.3.1 Métodos estatísticos . . . . . . . . . . . . . 7

2.3.2 Métodos geométricos . . . . . . . . . . . . . . . . . 99 9

2.3.3 Métodos baseados em modelos . . . . . . . . . . . . . . . . . 13

2.3.4 Métodos de processamento de sinais . . . . . . . . . . . . . . . . 15

2.4 Considerações . . . . . . . . . . . . . . . . . . . . . 16

3 Redes neurais $\quad 18$

3.1 Perceptron multicamadas (MLP) f . . . . . . . . . . . . . . . . 19

3.1 .1 Vantagens do RPROP . . . . . . . . . . . . . . . . . . . . 21

3.1 .2 Tamanho da rede . . . . . . . . . . . . . . . . . 22

3.2 Mapa auto-organizável de Kohonen . . . . . . . . . . . . . . . . . . . . 22

3.3 Considerações . . . . . . . . . . . . . . . . . . . . . . . 22

4 Reconhecimento de padrões $\quad 24$

4.1 Fundamentos . . . . . . . . . . . . . . . . . . 24

4.2 O erro e a regra de decisão de Bayes . . . . . . . . . . . . . . . . 26

4.3 Redução da dimensionalidade . . . . . . . . . . . . . . . . . . . . 28 
4.3.1 Extração de características . . . . . . . . . . . . . . . . . . 29

4.3 .2 Seleção de características . . . . . . . . . . . . . . . . 32

4.4 Classificadores . . . . . . . . . . . . . . . . . . . . . . . . . . . . . . . . . . . . .

4.4 Distância mínima . . . . . . . . . . . . . . . . . 32

4.4.2 Busca simples de clusters e k-means . . . . . . . . . . . . . 33

4.4 .3 Máxima verossimilhança . . . . . . . . . . . . . . . . . . 33

4.4 .4 Redes neurais para classificação . . . . . . . . . . . . . . . . 33

4.5 Considerações . . . . . . . . . . . . . . . . . . . 34

5 Seleção de características $\quad 35$

5.1 Seleção supervisionada de características . . . . . . . . . . . . . 36

5.1 .1 Algoritmos de busca . . . . . . . . . . . . . . 36

5.1 .2 Critérios de busca . . . . . . . . . . . . . . . . . 38

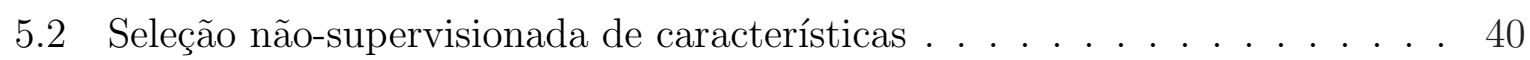

5.3 Considerações . . . . . . . . . . . . . . . . . . . . . 41

6 Metodologia $\quad 42$

6.1 Equipamentos e detalhes de implementação . . . . . . . . . . . . . . . . . . 44

6.1.1 Multithreading. . . . . . . . . . . . . . 44

6.1.2 Normalização das características de textura . . . . . . . . . . . 45

6.1.3 Distância de Bhattacharyya . . . . . . . . . . . . . . . 47

6.1 .4 Perceptron Multicamadas . . . . . . . . . . . . . . 47

6.2 CMET - Combinação de métodos de extração de textura . . . . . . . . . . 48

6.2.1 SS - Seleção por saliência . . . . . . . . . . . . . . . . 48

6.2.2 SJM - Seleção ótima pela distância de Jeffrey-Matusita . . . . . . . 50

6.2.3 Problema dimensionado . . . . . . . . . . . . . . . 51

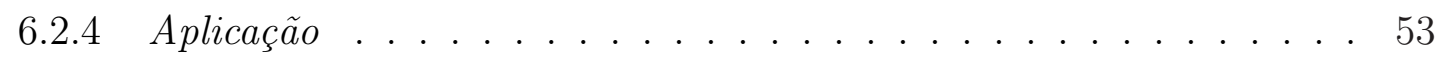

6.3 DMET - Descarte de métodos de extração de textura . . . . . . . . . . . 54

6.4 Equalização da entrada . . . . . . . . . . . . . . . . . 55

6.5 Considerações . . . . . . . . . . . . . . . . . . . . 55

$\begin{array}{lll}7 & \text { Resultados e discussão } & \mathbf{5 7}\end{array}$

7.1 CMET: Problema dimensionado . . . . . . . . . . . . . . . . 58

7.1.1 Efeito da compensação de sinal . . . . . . . . . . . . . . 58

7.1.2 Tamanho do subconjunto . . . . . . . . . . . . . . . 60

7.1 .3 Origem dos dados . . . . . . . . . . . . . . . . 60

7.1.4 SJM - seleção ótima segundo a distância de Jeffrey-Matusita . . . . 61

7.1.5 SS - Seleção do subconjunto por saliência . . . . . . . . . . . . . . 62

7.1.6 SS sem EE - Seleção do subconjunto por saliência sem equalização da entrada . . . . . . . . . . . . . . . . . . . . . . 62

7.1.7 SSOC - Seleção do subconjunto por saliência em apenas uma iteração 63

7.1.8 Comparação das abordagens . . . . . . . . . . . . . . . . . 63

7.1.9 Avaliação da qualidade das características por meio do classificador de distância mínima . . . . . . . . . . . . . . . . . . . . 65

7.1.10 Exemplo de seleção de características sem redução da taxa de acerto 66

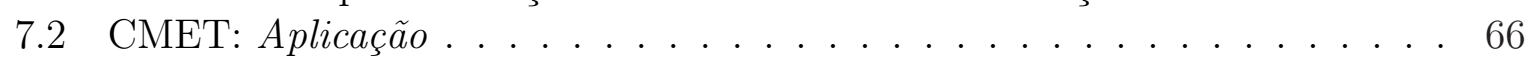

7.2 .1 Cena natural $1 \ldots \ldots \ldots$. . . . . . . . . . . . . 67

7.2 .2 Cena natural $2 \ldots \ldots \ldots$. . . . . . . . . . . . . . 67

7.2 .3 Cena natural $3 \ldots \ldots \ldots \ldots$. . . . . . . . . . . . 67 
7.3 DMET - descarte de métodos de extração de textura . . . . . . . . . . . 70

7.4 Considerações . . . . . . . . . . . . . . . . . . . . 72

8 Conclusões $\quad 73$

8.1 Contribuições . . . . . . . . . . . . . . . . . . . . 74

8.2 Publicações oriundas do trabalho . . . . . . . . . . . . . . . . . 74

8.3 Desdobramentos futuros . . . . . . . . . . . . . . . . . . . 74

$\begin{array}{ll}\text { Referências Bibliográficas } & 76\end{array}$

Apêndice A $\quad 82$

$\begin{array}{lr}\text { Apêndice B } & 84\end{array}$

$\begin{array}{ll}\text { Apêndice } \mathrm{C} & 85\end{array}$ 


\section{Lista de Figuras}

1.1 Exemplo de processo de segmentação: identificação de píxeis numa imagem de satélite. . . . . . . . . . . . . . . . . . . .

2.1 Ilusão de ótica: à primeira vista, a textura aparenta ser uniforme, porém a figura divide-se horizontalmente em três faixas (BECK; SUTTER; IVRY,

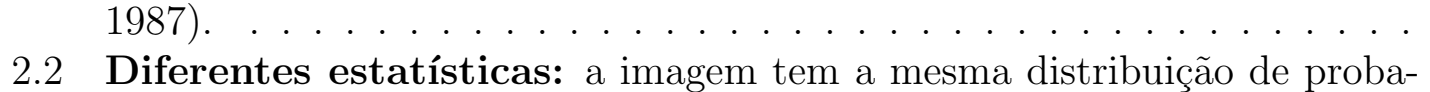
bilidade dos níveis de cinza, porém o canto inferior direito tem diferentes estatísticas de segunda ordem. . . . . . . . . . . . . . . . .

2.3 Dois polígonos de Voronoi: áreas rachuradas são as intersecções dos semi-planos. . . . . . . . . . . . . . . . . . 10

2.4 Textura estrutural: um modelo de parâmetros para a extração da textura de uma parede de tijolos (LEFEBVRE; POULIN, 2000). . . . . . . . . . 12

3.1 Diagrama exemplo de um MLP de 4 camadas: 4 entradas, 3 e 2 neurônios respectivamente nas camadas ocultas e 2 saídas. . . . . . . . . . 20

4.1 Exemplo de espaço de características: a despeito da estreita faixa de intersecção entre as diferentes categorias, é possível inferir uma regra geral de diferenciação entre homens e mulheres baseando-se nas medidas de massa corporal e muscular (JANSSEN et al., 2000). . . . . . . . . . . . . . 26

4.2 Funções de densidade de probabilidade: os eixos do espaço de características são dados espectrais e cada classe tem sua probabilidade de ocorrência aproximada por uma superfície gaussiana (RICHARDS, 1995). . . 27

4.3 Exemplo de simplificação não contemplada por PCA: com uma única dimensão pode-se descrever, simplificadamente, o comportamento dos pontos.

4.4 Topologia de uma AANN: 5 camadas: entrada, mapping, bottleneck, demapping e saída. . . . . . . . . . . . . . . . . . 31

5.1 Taxonomia dos principais métodos de seleção de características: alguns termos não foram traduzidos para não descaracterizar os métodos (JAIN; ZONGKER, 1997). . . . . . . . . . . . . . . . 36

6.1 Esquema de segmentação adotado: etapas principais desde a modelagem até o uso. . . . . . . . . . . . . . . . . . . 
6.2 Esquemas das duas abordagens distintas: a) combinação de métodos de extração de textura (CMET) com treinamento independente de classificador; b) descarte de métodos de extração de textura (DMET) dependente do classificador MLP. . . . . . . . . . . . . . . . . . . . . . 43

6.3 Experimento de métodos combinados: seleção por saliência (SS) . . . . 48

6.4 Compensação de sinal: comportamento dos pesos com relação às intensidades de entrada. . . . . . . . . . . . . . . . . . 50

6.5 Experimento de métodos combinados: seleção por distância JM (SJM). 50

6.6 Sete texturas: conjunto de treinamento (imagens parciais da amostra de 122.316 píxeis) (BRODATZ, 1966). . . . . . . . . . . . . . . . . . 51

6.7 Influência da quantidade de características na distância de Jeffrey-Matusita: no eixo $x$, cada dígito representa uma das dez características de Run Lengths; $1=$ selecionada, $0=$ descartada.

6.8 Influência da quantidade de características na taxa de acerto no treinamento: a variação entre as três execuções é devida à escolha de diferentes subconjuntos e condições iniciais das redes neurais. . . . . . . . . 52

6.9 DMET: a) treinamento; b) segmentação. . . . . . . . . . . . . . . . 54

7.1 Influência da entrada média sobre a saliência: correlação de $-0,22$ (amostra de 122.316 píxeis). O número da característica está escrito na vertical.

7.2 Nova saliência comparada com a original (dados sintéticos): a correlação com a média, originalmente de -0,54, passou a $0,19 \mathrm{com}$ a equalização (amostra de tamanho 30.624).

7.3 Nova saliência comparada com a original (dados de textura): a correlação com a média, originalmente de $-0,22$, passou a $0,06 \mathrm{com}$ a equalização (amostra de tamanho 30.624). . . . . . . . . . . . . . .

7.4 Conjunto de teste do experimento controlado: quatro imagens originais inteiras do álbum de Brodatz concatenadas (amostra de tamanho 1.607.824), os retângulos indicam as áreas usadas para treinamento (amostra de tamanho 20.416).

7.5 Distâncias de Jeffrey-Matusita: até quatro características, o método é viável computacionalmente (amostra de tamanho 30.624) . . . . . . . . . . . 62

7.6 Segmentação para o problema dimensionado: resultado da melhor das execuções baseada na SS.

7.7 Cena natural 1: os retângulos indicam as duas regiões tomadas para treinamento (amostra de 8.512 píxeis) . . . . . . . . . . . . . . 67

7.8 Cena natural 1 segmentada: cada nível de cinza representa uma classe. 68

7.9 Cena natural 1 com mais classes: os retângulos indicam as áreas tomadas para treinamento (amostra de 30.800 píxeis) . . . . . . . . . . . . . 68

7.10 Cena natural 1 segmentada em quatro classes: cada nível de cinza representa uma classe, a cor preta indica classe desconhecida. . . . . . . . . 69

7.11 Cena natural 2: os retângulos indicam as áreas tomadas para treinamento (amostra de 17.952 píxeis). . . . . . . . . . . . . . . . .

7.12 Cena natural 2 segmentada: cada nível de cinza representa uma classe, a cor preta indica classe desconhecida.

7.13 Cena natural 3: os retângulos indicam as áreas tomadas para treinamento (amostra de 15.552 píxeis). 
7.14 Cena natural 3 segmentada: cada nível de cinza representa uma classe, a cor preta indica classe desconhecida. . . . . . . . . . . . . . . . 71

7.15 Segmentação do mosaico por três abordagens: a) conjuntos de treinamento (amostra de 122.316 píxeis); b) segmentação por DMET; c) segmentação por Matrizes de Coocorrência; d) segmentação por média e variância do nível de cinza; e) imagem utilizada. . . . . . . . . . . . . . . . 72

8.1 Comparação entre as taxas de acerto com e sem retreino parcial: taxas de acerto muito próximas . . . . . . . . . . . . . . . 84

8.2 Mapa de Kohonen: em cima: é localizado o neurônio mais parecido com o padrão (neurônio vencedor); no meio: é calculada a área de influência do neurônio vencedor; em baixo: é feito o ajuste dos neurônios envolvidos . . . 86 


\section{Lista de Tabelas}

7.1 Comparação das abordagens: acerto para o conjunto de treinamento, tempo consumido com a seleção e memória utilizada. O desvio padrão é dado entre parêntesis e o tempo é dado em segundos. . . . . . . . . . . . 63

7.2 Comparação das abordagens com classificador de distância minima: taxas de acerto para treinamento e teste. Não há desvio padrão por ser um processo determinístico. . . . . . . . . . . . . 65

7.3 Comparação dos resultados para as diferentes imagens: os tempos são dados em segundos. O tempo de seleção é a soma das três execuções. 69 


\section{Lista de Siglas}

AANN - Autoassociative Neural Network

ART - Adaptive Resonance Theory

CMET - Combinação de Métodos de Extração de características de Textura

CUME - Centro Universitário de Montanhismo e Escalada

DMET - Descarte de Métodos de Extração de características de Textura

EE - Equalização da Entrada

EM - Expectation Maximization

ICMC - Instituto de Ciências Matemáticas e de Computação

JM - Jeffrey-Matusita

MLP - Multi-Layer Perceptron

NLPCA - Nonlinear Principal Component Analisys

$\mathrm{O}()$ - Ordem de complexidade do algoritmo

PCA - Principal Component Analysis

PTA - Plus l - Take Away $r$

RAM - Random Access Memory

RPROP - Resilient Backpropagation

SBFS -Sequential Backward Floating Selection

SFFS - Sequential Forward Floating Selection

SJM - Seleção por distância de Jeffrey-Matusita

SOM - Self-Organizing Map

SS - Seleção por Saliência

SSE - Sum of Squared Errors

SSOC - Seleção por Saliência de Ordem Constante

USP - Universidade de São Paulo 
SANTOS, D. P. Seleção de características: abordagem via redes neurais aplicada à segmentação de imagens, São Carlos, 2007. (Dissertação de Mestrado) - Instituto de Ciências Matemáticas e de Computação - ICMC-USP.

\section{Resumo}

A segmentação de imagens é fundamental para a visão computacional. Com essa finalidade, a textura tem sido uma propriedade bastante explorada por pesquisadores. Porém, a existência de diversos métodos de extração de textura, muitas vezes específicos para determinadas aplicações, dificulta a implementação de sistemas de escopo mais geral. Tendo esse contexto como motivação e inspirado no sucesso dos sistemas de visão naturais e em sua generalidade, este trabalho propõe a combinação de métodos por meio da seleção de características baseada na saliência das sinapses de um perceptron multicamadas (MLP). É proposto, também, um método alternativo baseado na capacidade do MLP de apreender textura que dispensa o uso de técnicas de extração de textura. Como principal contribuição, além da comparação da heurística de seleção proposta frente à busca exaustiva segundo o critério da distância de Jeffrey-Matusita, foi introduzida a técnica de Equalização da Entrada, que melhorou consideravelmente a qualidade da medida de saliência. É também apresentada a segmentação de imagens de cenas naturais, como exemplo de aplicação.

Palavras-chave: seleção de características, perceptron multicamadas, distância de Jeffrey-Matusita, equalização da entrada, textura, segmentação. 


\section{Abstract}

Segmentation is a crucial step in Computer Vision. Texture has been a property largely employed by many researchers to achieve segmentation. The existence of a large amount of texture extraction methods is, sometimes, a hurdle to overcome when it comes to modeling systems for more general problems. Inside this context and following the excellence of natural vision systems and their generality, this work has adopted a feature selection method based on synaptic conexions salience of a Multilayer Perceptron and a method based on its texture inference capability. As well as comparing the proposed method with exhaustive search according to the Jeffrey-Matusita distance criterion, this work also introduces, as a major contribution, the Input Equalization technique, which contributed to significantly improve the segmentation results. The segmentation of images of natural scenes has also been provided as a likely application of the method.

Keywords: feature selection, multi-layer perceptron, Jeffrey-Matusita distance, input equalization, texture, segmentation. 
Capítulo

1

\section{Introdução}

A cotidiana atividade de manusear objetos é mais complexa do que parece. Envolve diversas etapas, entre elas, a separação do objeto de seu contexto e a eventual identificação baseada em experiências prévias. Essa separação, por sua vez, requer a determinação, dentre os elementos que rodeiam o objeto em questão, daquilo que é o objeto e, também, daquilo que não é o objeto. No caso da inspeção visual, esse contraste significa, primeiramente, identificar onde termina um objeto e onde começa outro. Na área de visão computacional, essa tarefa pode ser considerada a essência da segmentação de imagens. Na figura 1.1 é ilustrada, como exemplo, a análise de um píxel ${ }^{1}$ durante o processo de segmentação de uma imagem de satélite.

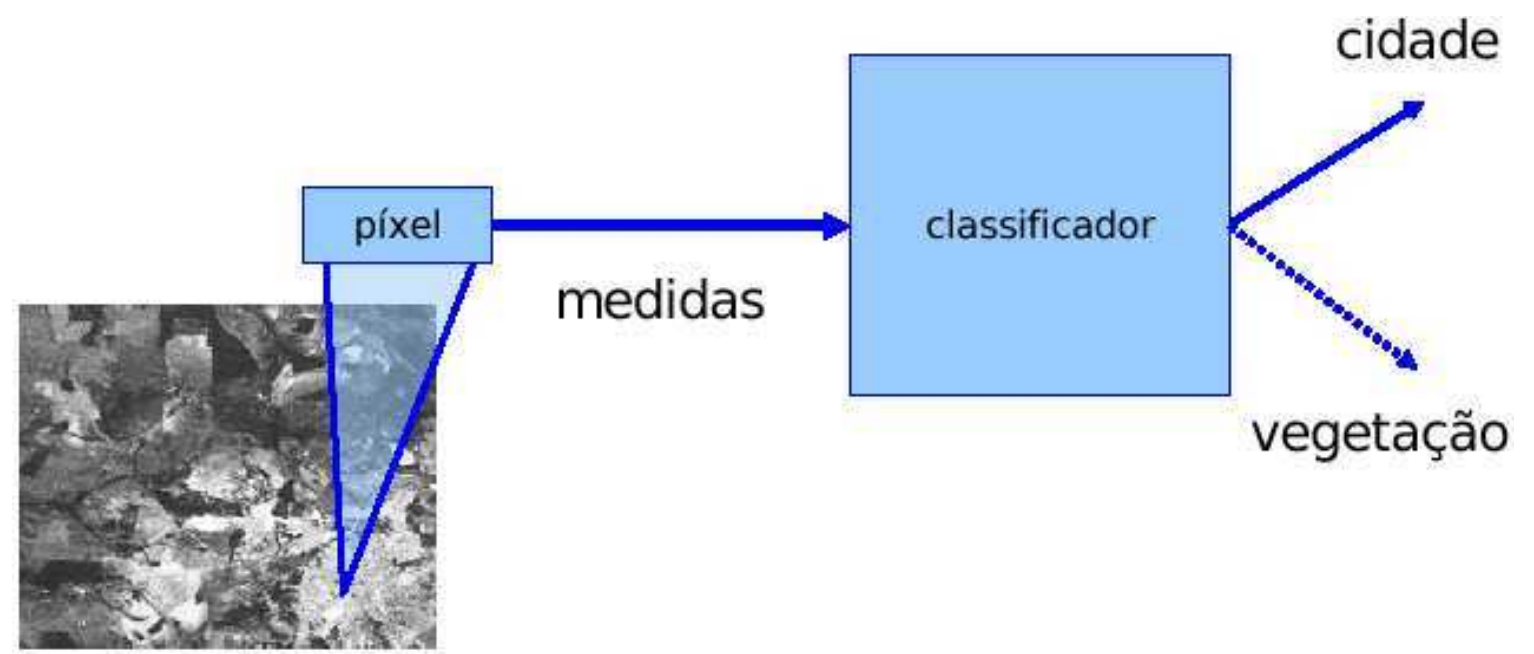

Figura 1.1: Exemplo de processo de segmentação: identificação de píxeis numa imagem de satélite.

\footnotetext{
${ }^{1}$ definição dada no capítulo 2
} 
Independentemente do objetivo, como a classificação de regiões ou a identificação de fronteiras entre elas, a textura tem sido uma propriedade bastante explorada por pesquisadores para a segmentação, e também a classificação, de imagens (TUCERYAN; JAIN, 1998; BACHOO; TAPAMO, 2005; MUNEESWARAN et al., 2006; QIN et al., 2006). Diversos métodos têm sido propostos nesse sentido. A própria natureza da textura conduz à diversidade de abordagens devido à sua subjetividade inerente. Isso decorre da ausência de uma definição formal ${ }^{2}$. Seus diferentes aspectos captados pela percepção humana, às vezes associados a um equivalente tátil (como aspereza e lisura), geométrico (como direcionalidade e regularidade) ou outro paradigma, acabam lançando as bases de modelos matemáticos diversos, sejam eles empíricos ou bioinspirados. Dependendo do enfoque, há problemas para os quais alguns métodos funcionam bem e outros não. Se forem tomados como parâmetro os sistemas de visão naturais, os modelos bioinspirados seriam aqueles capazes de funcionar bem em diferentes domínios. Esse indício foi considerado no direcionamento deste trabalho.

Redes neurais foram escolhidas para compor a parte biologicamente inspirada do sistema computacional. A primeira proposta consiste em implementar variados métodos de extração de textura e selecionar as melhores características provenientes deles. A inviabilidade computacional de se testar cada combinação possível de características é contornada pelo uso de uma heurística. Ela aproveita a inteligência contida nas sinapses de uma rede neural para identificar as melhores características. A segunda proposta é o descarte de qualquer método que envolva um modelo pré-concebido para o comportamento da textura, atribuindo, assim, essa modelagem à própria rede neural.

\subsection{Motivação}

A grande quantidade de métodos existentes que tentam mensurar textura exige uma escolha criteriosa. Na busca pela melhor solução, pode-se deparar com vantagens desejadas distribuídas em mais de um método. A simples união de diferentes métodos incorre no problema da alta dimensionalidade e das perdas sinergéticas. Essas dificuldades reforçam a necessidade de maior investigação e a busca de soluções. Também é importante o fato de ser um tema que vai além do escopo do processamento de imagens, pertencendo ao reconhecimento de padrões em geral. Assim, é fácil notar a existência de uma área de pesquisa fértil e que o trabalho será de utilidade para o laboratório no qual foi desenvolvido.

\footnotetext{
${ }^{2}$ conforme discutido no capítulo 2
} 


\subsection{Objetivos}

O objetivo principal deste trabalho é avaliar o método de seleção de características baseado na medida de saliência. Como toda seleção está associada a um problema, o problema escolhido foi a segmentação por textura. Após o estudo de diversos métodos de extração de características de textura, é proposta uma maneira viável de combiná-los. Adicionalmente é experimentada uma abordagem baseada na sÊncia de métodos de extração de textura.

Também espera-se que a produção textual e os programas computacionais desenvolvidos tenham proveito na continuidade da pesquisa com outros mestrandos e doutorandos, por isso o caráter didático de alguns capítulos e a ênfase na clareza na definição de alguns termos.

\subsection{Estrutura deste documento}

No capítulo 2 é feita uma revisão bibliográfica sobre textura, sua utilidade e as principais técnicas de extração de características texturais. No capítulo 3 são estudadas as redes neurais utilizadas no trabalho. No capítulo 4 é feita uma revisão sobre reconhecimento de padrões. São discutidas brevemente as implicações e as maneiras de se lidar com um conjunto grande de características. No capítulo 5 é aprofundado o tema da seleção de características, especificamente a heurística escolhida para o sistema proposto. No capítulo 6 são descritos os detalhes de implementação e de equipamentos e são definidos os experimentos. No capítulo 7 são apresentados e discutidos os resultados experimentais. No capítulo 8 pondera-se a respeito das implicações da pesquisa desenvolvida e sobre desdobramentos futuros. 


\section{Textura}

Mesmo que se considere apenas o trabalho com imagens, ou seja, excetuando-se, por exemplo, o aspecto tátil, o termo textura ainda é bastante amplo e engloba tópicos relacionados tanto com percepção/intuição quanto com medição instrumental. Neste capítulo introduz-se o assunto e exploram-se as inter-relações desses temas aparentemente contraditórios.

\subsection{Apreensão da textura}

A textura de um objeto é, geralmente, um atributo imediatamente distinguível para um observador humano. Apesar disso, ainda não existe uma definição formal para tal conceito (TUCERYAN; JAIN, 1998). Embora podendo ser descrita mais especificamente, porém não integralmente, em termos de granularidade, direcionalidade, aspereza, aleatoriedade, lisura, regularidade etc. (SONKA; HLAVAC; BOYLE, 1993), a textura mostra-se de natureza um tanto subjetiva. Converter valores numéricos, como as cores das imagens digitais, para as grandezas citadas é, assim, tarefa dificilmente realizada com precisão (HARALICK, 1979). Dessa forma, diversas técnicas resultam em medidas sem valor intuitivo.

Um ods diversos métodos de extração de textura, as matrizes de dependência tonal espacial $\left(\mathrm{SGLD}^{1}\right)$, por exemplo, fornecem normalmente as seguintes características: energia, entropia, correlação, inércia e homogeneidade local (JULESZ, 1962). Essa abordagem não tem relação com a nossa percepção visual (ABBADENI; ZIOU; WANG, 2000; BATTIATO; GALLO; NICOTRA, 2003), ou seja, diretamente, ela não serve para traduzir uma textura em palavras e valores compreensíveis, mas tem sido adequada para uma boa classificação automática de regiões, como no trabalho de Dai et al. (DAI; NAKANO; MIYAO, 1994).

\footnotetext{
${ }^{1}$ do inglês Spatial Gray-Level Dependence matrices
} 
Muitas vezes, cada aplicação usa um conjunto de características otimizado especificamente para ela (HE; WANG; GUIBERT, 1988), o que dificulta a generalização da solução e é uma grande desvantagem em relação aos sistemas biológicos.

Pelo fato de as soluções naturais serem capazes de distinguir boa parte das texturas existentes, outros experimentos se concentram em encontrar medidas semelhantes às da percepção humana. Amadasun e King (AMADASUn; KING, 1989) modelaram computacionalmente cinco daquelas grandezas intuitivas citadas anteriormente ${ }^{2}$ e conseguiram superar algumas das mais usadas - e pouco intuitivas - características, como segundo momento angular, contraste, entropia e correlação. Eles obtiveram um resultado melhor na análise de imagens de satélite e usaram menos memória e consumiram menos tempo de processamento. Resultados dessa espécie sugerem um viés menos empírico e mais biologicamente inspirado.

Existem também regiões texturizadas que são facilmente delimitadas por computador e que não são espontaneamente delimitadas por um observador humano. Por exemplo, não se reconhece à primeira vista a fronteira entre as três regiões da figura 2.1, embora seja um problema trivial para o processamento automático (observar a diferente disposição dos quadrados pequenos e dos quadrados grandes nas partes superior/inferior e central da figura).

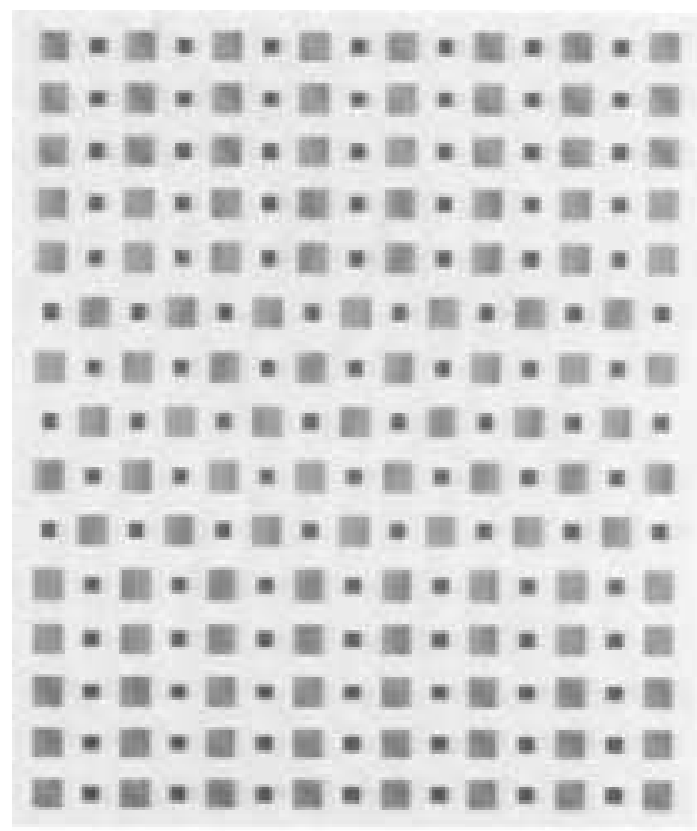

Figura 2.1: Ilusão de ótica: à primeira vista, a textura aparenta ser uniforme, porém a figura divide-se horizontalmente em três faixas (BECK; SUTTER; IVRY, 1987).

\footnotetext{
${ }^{2}$ em metade das texturas o computador classificou a textura da mesma maneira que a opinião média de oitenta e oito indivíduos
} 
Mais objetivamente, podem-se ainda fazer algumas asserções sobre a natureza da textura: ela só faz sentido para áreas, é uma propriedade contextual, envolve distribuição de tonalidades, é percebida em diferentes escalas e precisa ter um número grande de elementos componentes $\left(\right.$ textons $\left.^{3}\right)$ repetidos para não ser considerada um conjunto de objetos distintos (TUCERYAN; JAIN, 1998).

A síntese de texturas também tem sido relevante na compreensão da textura. A sua finalidade é gerar imagens no computador que simulem superfícies do mundo real. Uma tendência apontada por Gool et al. (GOOL; DEWAELE; OOSTERLINCK, 1985), e verificada em artigos mais recentes, é o encontro entre a síntese e a análise de textura. Ware e Knight (WARE; KNIGHT, 1995), por exemplo, exploram semelhanças entre os filtros de Gabor e o funcionamento do sistema visual humano. O artigo é sobre geração de textura, embora esse tipo de abordagem seja tipicamente usado na extração de textura.

\subsection{Análise da textura}

A análise de textura pode ter variados objetivos. No caso da visão humana, a textura pode, por exemplo, dar informações espaciais, facilitar a identificação de corpos ou viabilizar indiretamente outras atividades. Computacionalmente, têm-se os seguintes interesses principais (MATERKA, 1998):

- descrever numericamente as características de textura;

- identificar regiões homogêneas em termos de textura (segmentação);

- nomear regiões de acordo com um conjunto pré-estabelecido de texturas (classificação);

- reconstruir superfícies tridimensionais a partir de informações de textura;

- compactar imagens, juntamente com a síntese de textura (TUCERYAN; JAIN, 1998).

Para atingir essas metas, primeiramente extraem-se características da imagem. Essas podem ser estatísticas de determinada ordem, cuja influência foi primeiramente estudada por Julesz (JULESZ, 1962):

- de primeira ordem - medidas simples como média e variância dos valores dos píxeis ${ }^{4}$;

- de segunda ordem - é considerada a relação entre os píxeis em função da distância e orientação entre eles (por exemplo, matriz de correlação explicada mais adiante).

\footnotetext{
${ }^{3}$ os elementos que, juntos, formam a textura (do singular em inglês texton ou texel)

${ }^{4}$ neste trabalho será considerado o neologismo píxel para se referir à menor unidade de uma imagem digital - do inglês pixel - picture element
} 
Uma conjectura importante (nem sempre válida) de Julesz é que visualmente são segregadas facilmente duas regiões cujas estatísticas de segunda ordem sejam diferentes, mesmo que as estatísticas de primeira ordem sejam iguais (figura 2.2).

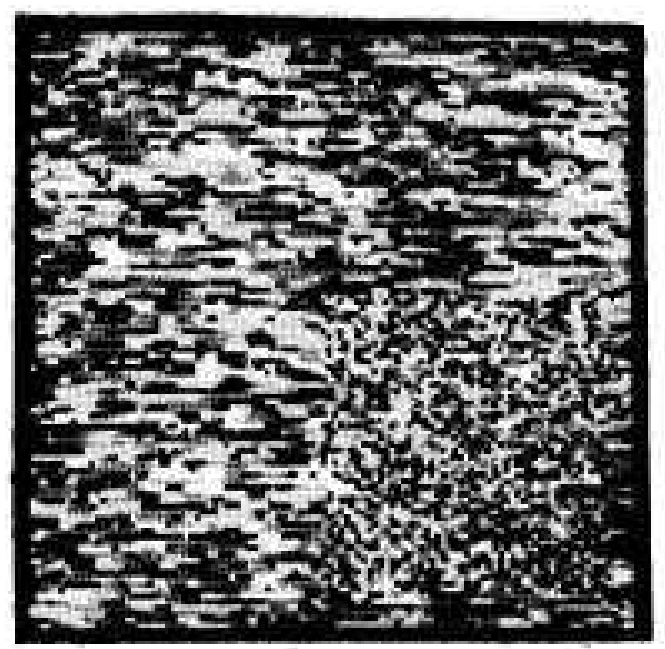

Figura 2.2: Diferentes estatísticas: a imagem tem a mesma distribuição de probabilidade dos níveis de cinza, porém o canto inferior direito tem diferentes estatísticas de segunda ordem.

Quanto às aplicações da análise de textura, existem inúmeras: avaliação do desgaste de tapetes (SIEW; HODGSON; WOOD, 1988), detecção de leucócitos (USHIZIMA-SABINO et al., 2004), pré-processamento para reconhecimento de caracteres (JAIN; BHATTACHARJEE, 1992) e sensoriamento remoto (HARALICK; SHANMUGAM; DINSTEIN, 1977).

\subsection{Técnicas}

Nesta seção é apresentada uma das taxonomias possíveis com uma breve descrição dos métodos para extração de características de textura. Geralmente se trabalha com níveis de cinza, mas neste texto usa-se o termo tonalidade visando abranger também imagens coloridas, assim como os termos intensidade e valor.

\subsubsection{Métodos estatísticos}

Medições estatísticas têm sido tomadas desde os primeiros trabalhos com textura (JULESZ, 1962). A média e a variância dos valores de tonalidade dos píxeis em uma região são medidas simples que podem discriminar uma textura. Essas estatísticas de primeira ordem foram usadas, por exemplo, no trabalho de Verma e Kulkarni (VERMA; KULKARNI, 2001). Medidas mais complexas provêm do uso das Matrizes de Coocorrência, da função de autocorrelação e dos run lengths ${ }^{5}$, por exemplo.

\footnotetext{
${ }^{5}$ comumente chamados de gray level run lengths e sem tradução precisa
} 


\section{Matrizes de Coocorrência}

As Matrizes de Coocorrência (HARALICK; SHANMUGAM; DINSTEIn, 1977) têm sido largamente estudadas e aplicadas em diversos problemas de processamento de imagens. Tratase de reproduzir em matrizes parte significativa da organização dos píxeis numa região. Para cada tonalidade há uma lista indicando a quantidade de ocorrências das outras tonalidades em cada direção e distância. Tal contagem se dá para todos os píxeis de uma certa região. Como a quantidade máxima de direções e distâncias a considerar para um único píxel é tão grande quanto toda a imagem, a complexidade da extração de características pode levar à inviabilidade computacional ${ }^{6}$. Cada característica comumente calculada das Matrizes de Coocorrência é o somatório dos resultados de uma operação matemática aplicada à todos os elementos da matriz. A operação varia conforme a característica desejada: energia, entropia, contraste, homogeneidade, correlação e outras. O resultado não é perceptualmente descritivo mas permite quantificar a diferença de textura entre duas ou mais regiões. Como a quantidade de características pode ser grande e requer algum método para selecionar as melhores, as matrizes costumam ser usadas em tarefas de classificação e não de segmentação não-supervisionada ${ }^{7}$. Isso se deve ao fato de que, normalmente, as melhores características são selecionadas visando a maximização da distinção entre as classes ${ }^{8}$. Há relação com os campos aleatórios de Markov (PICARD; ELFADEL; PENTLAND, 1991), citados posteriormente.

\section{Função de autocorrelação}

Outra abordagem estatística está na função de autocorrelação. Ela pode ser usada para avaliar a regularidade e a granularidade da textura. A função retorna um valor real para cada píxel e é calculada pela seguinte fórmula:

$$
f(x, y)=\frac{\sum_{i=0}^{L-1} \sum_{j=0}^{L-1} I(i, j) I(i+x, j+y)}{\sum_{i=0}^{L-1} \sum_{j=0}^{L-1} I^{2}(i, j)}
$$

onde

$x, y$ são as coordenadas do píxel

$L$ é a largura da imagem

$I(x, y)$ é a tonalidade do píxel localizado nas coordenadas $x, y$

\footnotetext{
${ }^{6}$ geralmente tratam-se de matrizes esparsas que permitem uma otimização adicional

${ }^{7}$ consultar a seção 4.4 sobre os diferentes tipos de classificadores

${ }^{8}$ classe e outros conceitos citados aqui e no capítulo 3 são explicados no capítulo 4, que trata sobre reconhecimento de padrões
} 
O resultado da aplicação da fórmula para todos os píxeis da imagem é um mapa de correlações que indica o quão semelhante à imagem inteira é a janela de origem em $x, y$. Há relação com o espectro de potência da transformada de Fourier (TUCERYAN; JAIN, 1998), citada posteriormente.

\section{Run lengths}

Os Run Lengths (GALLOWAY, 1975) consistem de pequenos segmentos de reta de diferentes tamanhos, tonalidades e direções. Cada matriz de Run Length corresponde a uma direção possível $\left(0^{\circ}, 45^{\circ}, 90^{\circ}\right.$ e $135^{\circ}$, por exemplo) e contém uma linha para cada tonalidade e uma coluna para cada comprimento. Assim, têm-se informações que refletem, de certa forma, o comportamento da textura. Dessa forma, podem-se extrair características calculadas analogamente às Matrizes de Coocorrência, mas que consistem de diferentes medidas: influência dos caminhos curtos, influência dos caminhos longos, grau de não-uniformidade tonal, grau de não-uniformidade dos caminhos e linearidade estrutural. Uma vantagem do método é a variação do tamanho dos Run Lengths ser proporcional à variação de escala na imagem, isso o torna invariante à escala, característica desejada em aplicações como o sensoriamento remoto, nas quais as imagens são oriundas de equipamentos com diferentes resoluções.

\section{Espectro de textura}

A idéia do espectro de textura ${ }^{9}$ (WANG; HE, 1990) é explorar todas as combinações possíveis de tonalidade numa região quadrada de píxeis de lado 3 excetuando-se o centro. Para reduzir a quantidade de combinações, reduz-se drasticamente a quantidade de tonalidades possíveis (normalmente 256) para 3. Assim, o número total é $3^{8}=6561$ combinações, 6561 unidades de textura possíveis. Como uma única textura pode ser composta de diferentes unidades de textura, é sugerido o espectro de textura. Ele consiste de um histograma que registra quantas ocorrências há de cada unidade de textura na área cuja classificação é desejada. O método revela-se mais apropriado para classificação, dada a sua necessidade de colher diversas amostras para a construção do espectro. Algumas características calculadas do espectro foram sugeridas por He e Wang (HE; WANG, 1991).

\subsubsection{Métodos geométricos}

Nos métodos geométricos considera-se que a textura é formada por primitivas - pequenos elementos individuais que, juntos, a caracterizam. Essa classe de métodos pode extrair medidas estatísticas sobre a forma desses elementos e sobre seus respectivos posicionamentos ou formular uma regra que explique a disposição das primitivas ao longo da imagem.

\footnotetext{
${ }^{9}$ do original texture spectrum
} 


\section{Segmentação usando polígonos de Voronoi}

Tüceryan e Jain (TUCERYAN; JAIN, 1990) propuseram o uso do diagrama de Voronoi para segmentar textura. É possível compreender a formação dos polígonos que integram o diagrama de Voronoi considerando-se, por simplicidade, que cada primitiva de textura é constituída de um ponto isolado. Elaborar um diagrama de Voronoi consiste em particionar o plano com um polígono para cada ponto. A partição surge das regiões resultantes ao se traçar uma reta divisória entre o ponto dado e cada um de seus vizinhos. A intersecção dos semiplanos ${ }^{10}$ resultantes que passam pelo ponto é a área interna do chamado polígono de Voronoi (figura 2.3). Depois que todos os pontos da imagem estão assim trabalhados, o diagrama está completo. O grafo de Delaunay é a representação dual dele, pois consiste em ligar com um segmento de reta cada par de pontos próximos. Os momentos de área

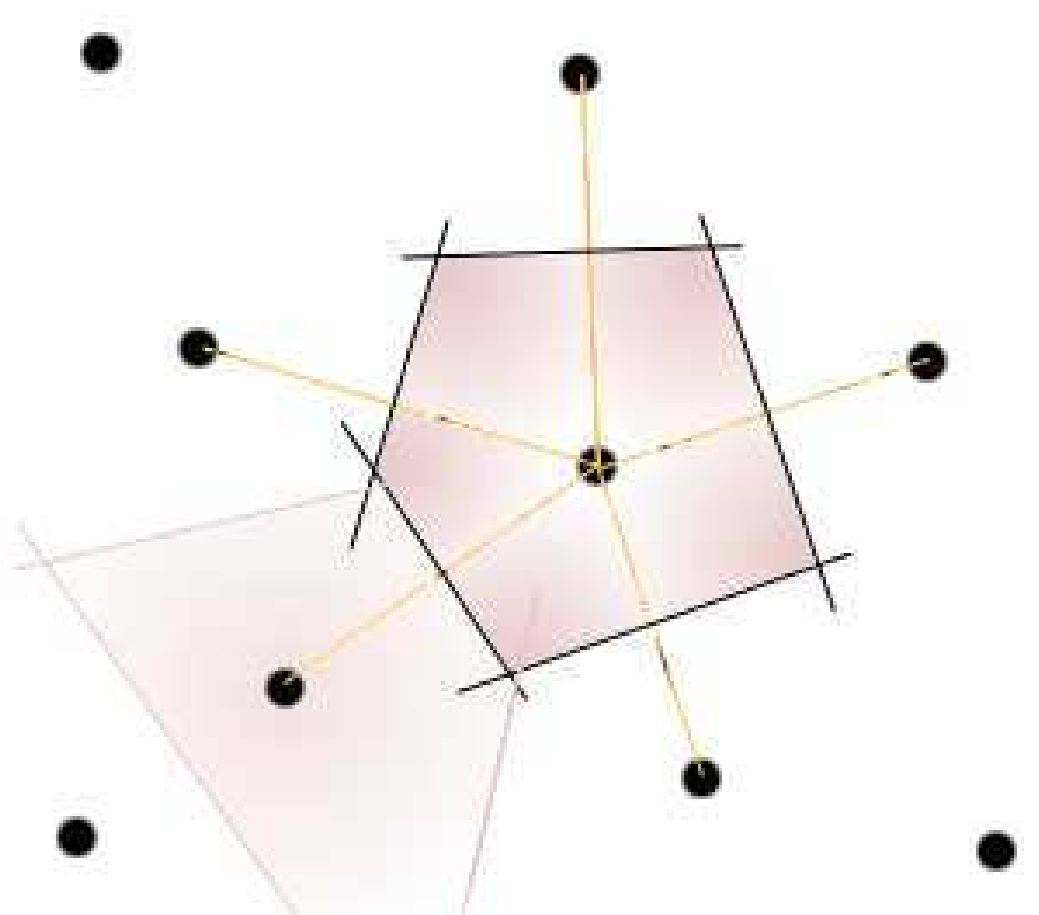

Figura 2.3: Dois polígonos de Voronoi: áreas rachuradas são as intersecções dos semiplanos.

desses polígonos são um bom conjunto de características sobre a textura, pois refletem tanto a forma quanto a distribuição espacial das primitivas. O momento de área é dado pela função abaixo:

$$
m_{p q}=\sum_{(x, y) \in R}\left(x-x_{0}\right)^{p}\left(y-y_{0}\right)^{q}
$$

\footnotetext{
${ }^{10}$ uma reta vertical, por exemplo, tem um semiplano esquerdo e um direito
} 
onde

$x_{0}, y_{0}$ são as coordenadas do píxel de referência da primitiva

$R$ é a região da primitiva

$p, q$ definem a ordem ${ }^{11}$ do momento de área; quanto maior, mais detalhada é a informação contida no resultado

Uma maneira de se adaptar uma imagem de tons de cinza para um conjunto de pontos passível de ser transformado num diagrama de Voronoi é adotar um critério de seleção de máximos locais (picos). Tüceryan e Jain (TUCERYAN; JAIN, 1998) sugerem eleger como pico todo píxel com valor mais intenso que pelo menos seis de seus oito vizinhos mais próximos. Assim, cada pico é considerado um ponto (valor 1) e o restante é tratado como fundo $^{12}$ (valor 0). A segmentação é possível porque não é necessário saber, a priori, a quantidade de texturas. Ela consiste na identificação de regiões contínuas na imagem de características resultante. Uma dificuldade dessa abordagem é quando a textura é extremamente regular e ocorrem pequenas perturbações em algumas regiões. Neste caso, elas seriam caracterizadas como texturas diferentes.

\section{Métodos estruturais}

Em geral, os métodos estruturais só funcionam para texturas bastante regulares. Eles envolvem duas etapas: extração dos elementos de textura e inferência da regra de posicionamento. Usualmente, os elementos de textura são regiões de tonalidade homogênea. Assim, pode-se usar um detector por convolução (GONZALEZ; WOODS, 1992) de regiões circulares homogêneas (na verdade uma adaptação do Laplaciano da Gaussiana ${ }^{13}$ ) para se estimar a posição e o tamanho das primitivas de textura na imagem. É o caso do algoritmo proposto por Blostein e Ahuja (BLOSTEIN; AHUJA, 1989), que procura por regiões circulares de diferentes tamanhos para estimar a orientação do plano de uma textura em perspectiva. No trabalho citado, tem-se uma matriz pré-calculada de três índices (inclinação do plano, posição e área do texton), que retorna o tamanho de primitiva esperado para cada tripla de parâmetros dada. Compara-se a área de cada texton encontrado com a área esperada dada pela matriz, assim, procura-se pela inclinação do plano que melhor represente todos os casos. Nesse método, tanto quanto na segmentação por polígonos de Voronoi, pode-se notar um forte interesse no trabalho com cada texton individualmente. Esse enfoque é praticamente inexistente nos métodos das seções 2.3.3 e 2.3.4.

\footnotetext{
${ }^{11}$ não confundir com a ordem estatística de Julesz previamente citada

12 entende-se por fundo o conjunto de todos os pontos de luminosidade nula

${ }^{13}$ normalmente usado para a detecção de bordas (fronteira entre duas regiões)
} 
Outra forma de extração dos textons, proposta por Lefebvre e Poulin (LEFEBVRE; POULIN, 2000), é realizar um pré-processamento por meio de detecção de bordas, limiarização e operações morfológicas ${ }^{14}$ para gerar uma máscara. Sobre a máscara, que pode ser refeita por ajustes no pré-processamento caso não seja considerada válida por um observador humano, aplica-se um identificador ${ }^{15}$ da freqüência com que ocorrem os textons na imagem para obter o tamanho e a orientação dos mesmos. No artigo citado, a proposta é específica para texturas de estrutura pré-modelada (figura 2.4) visando a síntese de textura, no caso, de uma parede de tijolos e de uma superfície de madeira.

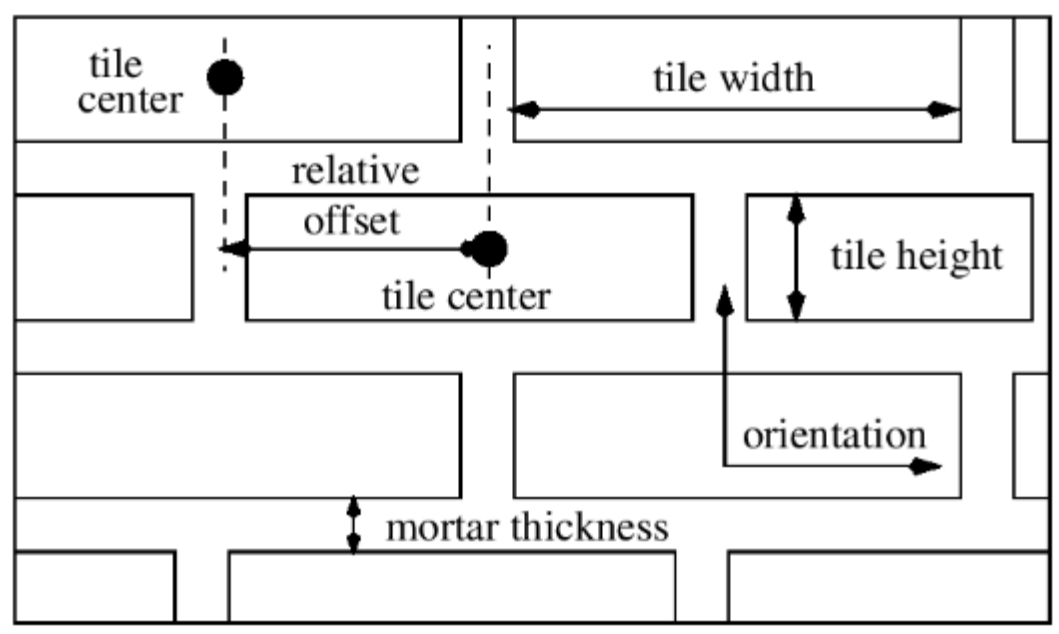

Figura 2.4: Textura estrutural: um modelo de parâmetros para a extração da textura de uma parede de tijolos (LEFEBVRE; POULIN, 2000).

Existem também os modelos gramaticais, que servem para descrever uma textura em termos de primitivas, ou seja, não são propriamente métodos de extração de textura. Uma revisão pode ser encontrada no livro de Ballard e Brown (BALLARD; BROWN, 1982). As gramáticas são compostas por poucos símbolos e um conjunto de regras, como nas linguagens formais. Sendo cada símbolo, assim, relacionado com uma classe de textons. Quando as variações naturais de um texton são representadas por probabilidades atribuídas aos diferentes símbolos, trata-se de uma gramática estocástica. Existem muitas variantes de gramática, três delas são:

\footnotetext{
${ }^{14}$ detecção de bordas, limiarização e operações morfológicas são operações básicas na literatura de processamento de imagens (GONZALEZ; WOODS, 1992)

${ }^{15}$ no caso, as freqüências mais fortes e a orientação provenientes da transformada de Fourier, que será citada no tópico sobre métodos de processamento de sinais
} 
- gramáticas de forma: os símbolos têm uma correspondência forte com os textons, precisam de mais processamento do que outras gramáticas;

- gramáticas de árvore: o primeiro nível hierárquico descreve a disposição das primitivas e o segundo as define em termos de píxeis;

- gramáticas matriciais: é semelhante às gramáticas de árvore, mas usa uma representação computacional mais conveniente.

Os modelos gramaticais, e os métodos estruturais em geral, embora não resolvam muitos dos problemas abordados pelos métodos baseados em modelos descritos a seguir (seção 2.3.3, revelam-se adequados para a síntese de texturas de superfícies construídas diretamente pelo homem como paredes azulejadas, pomares vistos de cima e telas. Há, ainda, a possibilidade de aplicá-los na síntese de texturas que surgem de forma não planejada da ação coletiva humana, como a vista áerea da ocupação da areia da praia por guarda-sóis em alta temporada, ou mesmo de certas texturas naturais tais como de um favo de mel, de tecidos celulares etc. São métodos que surgem no intercâmbio entre síntese e extração de textura, já explicitado no início do capítulo.

\subsubsection{Métodos baseados em modelos}

Diferentemente dos métodos estruturais e semelhantemente aos métodos estatísticos, os métodos descritos nesta seção tratam a textura como sendo regida por um padrão de distribuição dos píxeis e não de primitivas maiores. Realmente, existem superfícies, como um campo gramado visto de longe ou o interior de uma nuvem, nas quais os próprios seres humanos são incapazes de identificar elementos de contorno definido que se repitam por toda uma região. Ainda assim, essas superfícies possuem textura, a qual dificilmente permite a extração de primitivas. Elas são melhor trabalhadas por modelos que estudam a forma com que os píxeis são distribuídos, incluindo características espaço-contextuais e estatísticas.

\section{Campos aleatórios de Markov}

O modelo por campos aleatórios de Markov (COMER; DELP, 2000) tem sido aplicado em síntese, classificação, segmentação, restauração e compressão de imagens (TUCERYAN; JAIN, 1998). Ele assume que a intensidade de cada píxel na imagem depende probabilisticamente das intensidades dos píxeis vizinhos. Cada píxel é visto como uma variável aleatória, considerando, assim, a imagem como um campo aleatório. É possível fazer uma revisão sobre campos aleatórios com o livro de VanMarcke (VANMARCKE, 1998, 1983); também é comentado um pouco sobre estatística no capítulo 4 desta dissertação. 
Probabilidades condicionais são definidas usando-se simplesmente um píxel, um par de píxeis horizontal, vertical, triplas de píxeis etc. (tipos de clique) que estejam dentro da vizinhança do píxel em análise. Um dos critérios usados para interromper as iterações que conduzem à segmentação da imagem é a minimização da quantidade de píxeis classificados erroneamente. Dentre as dificuldades do método, está a necessidade da estimação de parâmetros da função de probabilidade (algoritmo EM - expectation maximization) quando da tarefa de segmentação. Deve-se notar que, quanto mais complexos os cliques, mais representativo é o modelo para a textura e mais complexo o algoritmo. O método tradicional baseado em campos de Markov funciona bem para microtexturas, mas apresenta problemas em texturas regulares ou muito heterogêneas.

\section{Fractais}

Muitas texturas naturais apresentam similaridade independente da escala, ou seja, para qualquer ponto, pode-se aumentar a resolução e observar a repetição da mesma textura. Essa é, resumidamente, a definição de fractal (KELLER; CHEN; CROWNOVER, 1989) e pode ser quantificada pela dimensão fractal:

$$
D=\frac{\log N}{\log \frac{1}{p}}
$$

onde

$N$ é quantidade de cópias que surgem quando se aumenta a resolução

$p$ é proporção com que se aumenta a resolução

Os fractais do mundo real apresentam, naturalmente, certa variação estatística. Logo, diversos algoritmos foram desenvolvidos para estimar a dimensão fractal, sendo que a contagem de caixas (SARKAR; CHAUDHURI, 1992) é uma das mais usadas e cobre uma faixa razoável da dimensão fractal (CHAUDHURI; SARKAR, 1995). O procedimento é simples:

- divide-se a imagem (já binarizada e com as bordas detectadas) na forma de uma grade quadriculada - é contabilizado cada quadrado (ou caixa) que contiver pelo menos um ponto (píxel de tonalidade oposta à cor de fundo);

- considerando o tamanho do quadrado e a quantidade de quadrados contabilizados como $p$ e $N$, respectivamente, citados na fórmula anterior, obteriam-se diferentes valores para a dimensão fractal; porém

- se o numerador da fórmula e o denominador forem considerados como coordenadas do plano, é possível estimar a inclinação da reta que melhor se aproxima de todos os pontos e adotar sua inclinação para a medida da dimensão fractal. 
Diversos trabalhos exploram a teoria fractal (CHAUDHURI; SARKAR; KUNDU, 1993; PELEG et al., 1984) ou alguma medida complementar como a lacunaridade (DONG, 2000) para analisar textura.

\subsubsection{Métodos de processamento de sinais}

Os métodos de processamento de sinais aqui citados detectam freqüência, que pode ser entendida como uma medida de contraste ou quantas vezes um determinado padrão se repete numa dada direção. O contraste pode também indicar a existência de bordas. Há partes do córtex visual humano especializadas na detecção de tais características (BRADLEY et al., 1987).

\section{Filtros no domínio espacial}

Os filtros no domínio espacial são uma forma bastante direta de se extrair propriedades de textura. Uma possibilidade é medir a densidade de bordas por área usando-se os operadores de Roberts ou Laplaciano (GONZALEZ; WOODS, 1992). Uma matriz 3x3, por exemplo, tem cada elemento multiplicado pela intensidade de um píxel na imagem. A soma de todas essas multiplicações corresponde a uma característica que, de certa forma, mede a textura. Isso é feito para todas as posições possíveis da matriz sobre a imagem e, assim, obtém-se um mapa que pode ser usado para segmentá-la.

\section{Transformada de Fourier}

A transformada de Fourier discreta (BRIGHAM, 1974), quando aplicada a um vetor que represente a amostragem de uma função ou sinal, retorna suas freqüências componentes no chamado domínio da freqüência. A quantidade de elementos do vetor de entrada será a quantidade de freqüências a retornar. Se, para cada freqüência, for gerada uma senóide correspondente e todas as senóides forem somadas, obtém-se o sinal original aproximado ${ }^{16}$. Zhou, Feng e Shi (ZHOU; FENG; SHI, 2001) propõem uma das formas de se aplicar a transformada para extração de característica de textura. Para cada píxel, consideram-se os oito píxeis vizinhos mais próximos como o vetor de entrada da transformada. Com esse método é possível obter informações locais sobre a variação dos níveis cinza. Intuitivamente, essas informações estão relacionadas à rugosidade da imagem.

Outra forma de se aplicar a transformada é utilizar sua versão em duas dimensões para identificar as freqüências em todas as direções de cada pequena região quadrada da imagem: divide-se o plano do domínio da freqüência em setores circulares para se obter a direção da textura e divide-se também em anéis ${ }^{17}$ para se obter a freqüência ou

\footnotetext{
${ }^{16}$ evidentemente o sinal é aproximado, pois há os efeitos da quantização e do corte abrupto nas extremidades do sinal

${ }^{17}$ intervalos entre diferentes raios
} 
rugosidade da textura (BALLARD; BROWN, 1982). A abordagem bidimensional tem a mesma dificuldade do corte abrupto do sinal nas extremidades.

\section{Filtros de Gabor}

Assim como na transformada de Fourier, os filtros de Gabor têm forte correspondência com a biologia. Trata-se de um método capaz de segmentar textura de forma compatível com a percepção visual humana (CLARK; BOVIK; GEISLER, 1987). Cada filtro de Gabor tem resposta mais intensa para uma freqüência e uma orientação específicas. Daí surgem os mapas que podem ser usados como característica de textura. Um bom desempenho é reportado nos artigos consultados - verificar o trabalho de Jain (JAIN; FARROKHNIA, 1991), por exemplo.

\section{Wavelets}

Diferentemente da transformada de Fourier, o mapa resultante da transformada Wavelet $^{18}$ (MALLAT, 1989; ZEGARRA; LEITE; TORRES, 2006) (bidimensional) contém informação espacial que é dividida em tendência e detalhe. Esse mapa é dividido em quatro quadrantes. Cada um contém um tipo de informação sobre a imagem original: detalhes, detalhes horizontais, detalhes verticais e tendência. Entende-se por tendência o mapa que contém as componentes mais fortes do sinal. Ela resulta do sinal original sem os detalhes. O nível de exclusão de detalhes pode ser aumentado aplicando-se a transformada sobre o quadrante da tendência e obtendo-se quatro novos quadrantes de resolução menor. De posse dos três quadrantes iniciais, pode-se armazenar os valores dos quatro novos quadrantes sobre o quadrante da tendência. Assim, o espaço de memória utilizada permanece o mesmo e, ainda assim, é possível reconstruir a imagem original aplicando-se a transformada inversa, independentemente da quantidade de iterações realizadas na diminuição da resolução do quadrante de tendência.

\subsection{Considerações}

Neste capítulo discorreu-se sobre a textura em seus aspectos psicofísicos e matemáticos. Foram também citadas as diferentes finalidades da análise de texturas e foram resumidas diversas técnicas pertencentes a cada uma das grandes vertentes: estatística, geométrica, baseada em modelos e de processamento de sinais. A literatura sobre textura é extensa. Para ilustrar a abundância de material existente, somente sobre métodos invariantes à translação, rotação ou perspectiva, por exemplo, podem ser citados os seguintes métodos ${ }^{19}$ (ZHANG; TAN, 2002):

\footnotetext{
${ }^{18}$ alguns traduzem por ondaleta

${ }^{19}$ neste caso, os nomes dos métodos não foram traduzidos para não descaracterizá-los
} 
- polar plots and polarograms;

- harmonic expansion;

- simultaneous autoregressive model;

- Wold-like model;

- steerable pyramid;

- perimeter contribution and compactness;

- topological texture descriptors based on Hough transform;

- iterative morphological decomposition.

Contemplou-se, assim, um conjunto embora incompleto, representativo da variedade de métodos mais usados. A visão geral proporcionada sobre o assunto e a ponderação sobre a complexidade de implementação de cada método permitiram a escolha das características de textura e a definição do sistema computacional.

Os métodos implementados foram: Run Lengths, Matrizes de Coocorrência, transformada de Fourier unidimensional e transformada de Fourier bidimensional. Foram também utilizadas estatísticas de primeira ordem, como média, desvio padrão e mediana - além do próprio valor do píxel.

O uso efetivo desses diferentes métodos em um mesmo sistema é viabilizado pelo emprego de redes neurais, que é o assunto do próximo capítulo. 


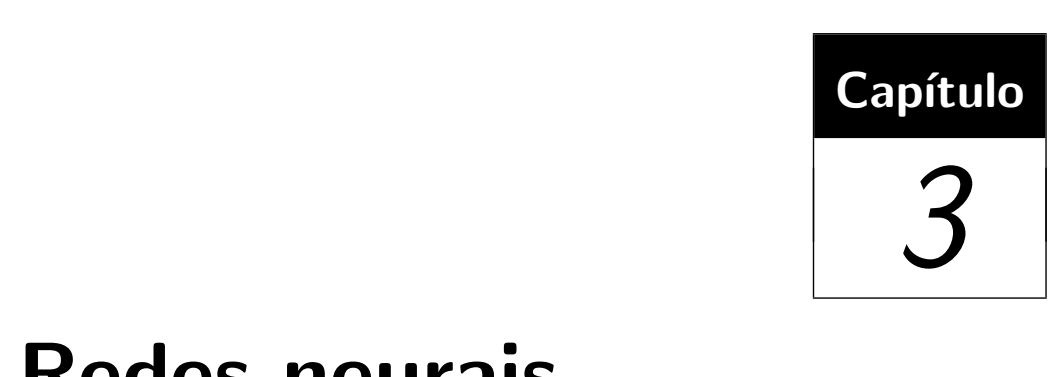

Redes neurais

Uma rede neural pode ser considerada um sistema de uma ou mais camadas que transforma dados de entrada em dados de saída e é capaz de estimar saídas para entradas desconhecidas conforme a semelhança com exemplos conhecidos. Cada camada é uma fileira de elementos que recebe valores da camada anterior, os transforma segundo uma regra simples e os transfere para um elemento na camada seguinte. Esses elementos são pequenas unidades de processamento interligadas conhecidas como neurônios artificiais. Inspirados num modelo matemático simplificado do neurônio biológico, eles são dispositivos com diversas entradas e uma saída cada - que pode ser replicada.

Apesar de terem origens díspares, as redes neurais têm forte correlação com a teoria estatística de reconhecimento de padrões (SCHÜRMANN, 1996). O termo padrão será usado neste texto com o sentido de conjunto de medidas amostradas no momento; analogamente, se todos os conjuntos de medidas extraídas de uma imagem constituíssem uma população, cada padrão seria um indivíduo. A grande vantagem das redes neurais é a sua capacidade de generalizar comportamentos complexos dos padrões de entrada. Por exemplo, se uma mesma classe se espalha em diferentes regiões desconexas no espaço de características, ou se uma classe circunda outra, tem-se então um problema não-linearmente ${ }^{1}$ separável, ou seja, inviável para um classificador de distância mínima ou outras abordagens similares ${ }^{2}$ . Dos diversos tipos de redes neurais estudados (análise de componentes independentes, ART, Hopfield, funções de base radial e aquelas que serão citadas nos tópicos 3.1 e 3.2), dois foram escolhidos levando-se em conta a robustez/simplicidade dos modelos e sua representatividade dentro das variações de redes neurais existentes. Eles são explorados

\footnotetext{
${ }^{1}$ deve-se pensar em retas ou planos dividindo o espaço de características, dependendo do número de dimensões

${ }^{2}$ na verdade, nem mesmo uma rede neural perceptron de camada simples seria capaz de encontrar a fronteira entre as classes (HAYKIN, 1999)
} 
a seguir.

\subsection{Perceptron multicamadas (MLP)}

O perceptron ${ }^{3}$ multicamadas ou MLP (Multi-Layer Perceptron em inglês) é uma rede neural que aprende por meio de treinamento supervisionado. Para cada entrada há uma saída esperada correspondente. A sucessiva apresentação de pares entrada/saída faz com que o MLP se especialize em relacionar certas entradas com determinadas saídas. Após o término do treinamento, mesmo para novos padrões, o MLP deve deduzir uma saída adequada.

Quando a saída esperada é sempre igual à entrada, o MLP é dito autoassociativo (KRAMER, 1992). Ou seja, se fornece o par entrada/entrada para treinamento em vez de se trabalhar da forma tradicional (entrada/saída). No capitulo 4, é descrita uma aplicação possível para redes neurais autoassociativas.

Durante o treinamento, a rede altera os parâmetros de seus neurônios de forma a se aproximar da classificação correta, a qual se dá na saída dos neurônios da última camada. Normalmente, cada neurônio de uma camada é conectado com pesos a todos os outros neurônios da próxima. Um padrão é apresentado à camada de entrada, processado através das camadas internas e um resultado é esperado na camada de saída. O erro - a diferença entre o valor esperado e o valor calculado - é usado na regra que altera o valor dos pesos. A disposição dos neurônios e conexões constituem a topologia da rede. Um exemplo de uma rede pequena é ilustrado na figura 3.1: 4, 3, 2 e 2 nós na camada de entrada, primeira e segunda camadas ocultas e camada de saída, respectivamente.

Cada conexão 'nó de entrada-neurônio' ou 'neurônio-neurônio' tem um peso. O conjunto de todas as entradas de um neurônio funciona como uma soma ponderada dos valores provenientes da camada anterior. Convencionalmente, a seguinte notação é usada: $w_{j i}^{(l)}$ para os pesos, onde $i$ é o número identificador do neurônio na camada $l$ e $j$ é o número identificador da entrada do neurônio. A soma ponderada é transformada por uma função logística (ou outra semelhante) que retorne resultados no intervalo ]0,1[ (ou ]-1,1[). Os pesos são ajustados por um algoritmo apropriado, como a retropropagaçã $o^{4}$ (CHAUVIN, 1995) ou RPROP - abreviação de Resilient Backpropagation (RIEDMILLER; BRAUN, 1993b). A derivada parcial do erro em função da alteração prévia de cada peso é calculada por ambos os esquemas de aprendizado. A principal diferença entre eles é que o primeiro opera de modo on-line e usa toda a informação sobre a derivada parcial e o segundo opera em lote (batch mode) e usa apenas o sinal da soma das derivadas parciais de todo o conjunto de padrões de treinamento ${ }^{5}$. A derivada parcial do erro para um dado

\footnotetext{
${ }^{3}$ nome usado por Rosenblatt para as unidades de processamento com limiar de disparo em oposição às suas predecessoras

${ }^{4}$ do inglês Backpropagation

${ }^{5}$ experimentos com diversos algoritmos, tanto on-line quanto em lote, podem ser encontrados no artigo
} 


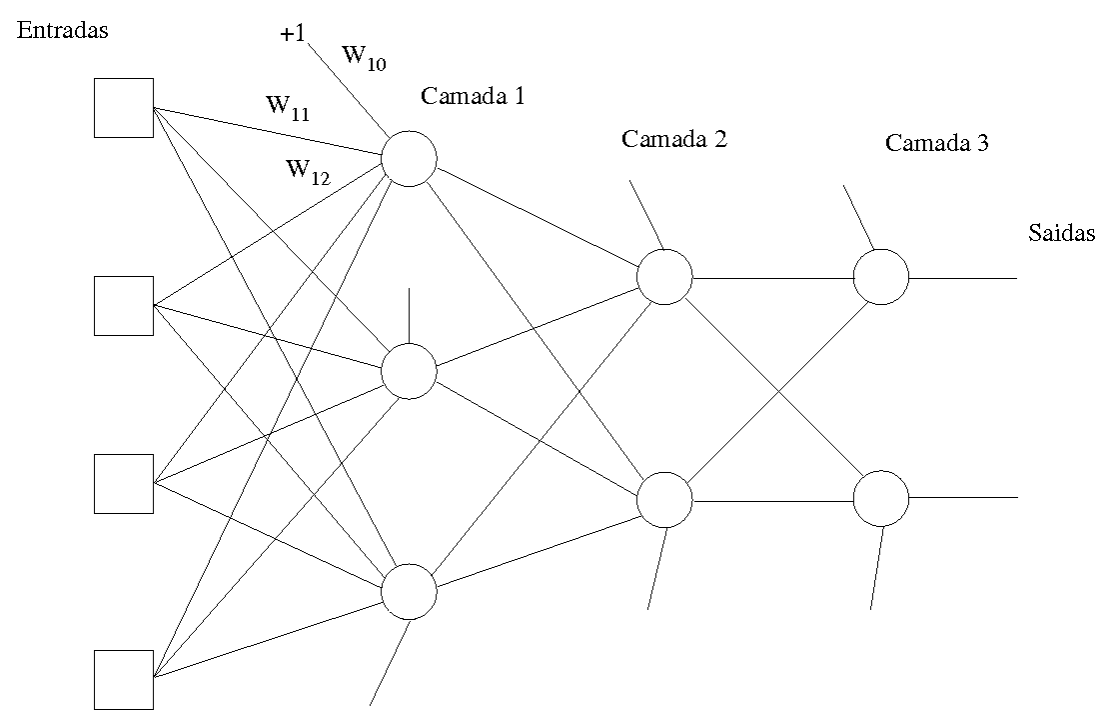

Figura 3.1: Diagrama exemplo de um MLP de 4 camadas: 4 entradas, 3 e 2 neurônios respectivamente nas camadas ocultas e 2 saídas.

peso é calculada pela fórmula:

$$
\frac{\partial E(t)}{\partial w_{j i}^{(l)}(t)}=\delta_{j}^{(l)}(t) y^{l-1}(t)
$$

onde

$$
\delta_{j}^{(l)}(t)= \begin{cases}\left(d_{j}(t)-y_{j}^{(L)}(t)\right) \varphi^{(L)}\left(v_{j}^{(l)}(t)\right) & \mathrm{I} \\ \varphi^{\prime}\left(v_{j}^{(l)}(t)\right) \Sigma_{k} \delta_{k}^{(l+1)}(t) w_{k j}^{(l+1)}(t) & \mathrm{II}\end{cases}
$$

I: o neurônio é da camada de saída

II: o neurônio é de uma camada oculta sendo que

$$
y_{j}^{(l)}(t)=\varphi_{j}^{(l)}\left(v_{j}^{(l)}(t)\right)
$$

e

$$
v_{j}^{(l)}(t)=\sum_{i=0}^{m_{l}} w_{j i}^{(l)}(t) y_{i}^{(l-1)}
$$

onde $t$ é o número da iteração, $y_{i}^{(l)}$ representa a saída do neurônio $i$ na camada $l$ (de um total de $L$ camadas), $d_{j}(t)$ é o valor esperado na saída da rede neural, $m_{l}$ é o número de neurônios na camada $l$ e $\varphi(x)=1 /\left(1+e^{-x}\right)$ é a função logística, a qual pode ser substituída por qualquer outra função cuja derivada seja conhecida e que se aproxime do modelo de disparo que simplifica o funcionamento dos neurônios naturais ${ }^{6}$. O primeiro peso de cada neurônio $\left(w_{j 0}^{(l)}(t)=b_{j}\right)$ é conectado à entrada de limiar. As entradas de de Schiffmann et al. (SCHIFFMANN; JOOST; WERNER, 1993)

${ }^{6}$ uma aproximação da função degrau 
limiar têm valor constante (1, por exemplo). Elas são necessárias para regular o ponto em que ocorre o disparo.

Para averiguar o nível de aprendizado da rede, a soma dos erros quadráticos $\left(\mathrm{SSE}^{7}\right)$ é usada:

$$
S S E(t)=\sum_{i=1}^{m_{L}}\left(d_{i}(t)-y_{i}^{(L)}(t)\right)^{2}
$$

Essa medida deve ser minimizada até atingir um valor satisfatório pré-definido ou enquanto o erro de validação seja maior que uma constante também pré-definida. $\mathrm{O}$ erro de validação é o SSE calculado usando-se um novo conjunto de padrões, que não tenha sido apresentado durante a fase de treinamento. Essa medida é importante para indicar o nível de generalização da rede, ou seja, se ela lida corretamente com novas situações do mesmo problema. O uso do erro de validação evita a especialização por treinamento excessivo (overfitting, explicado na seção 3.1.2), o que leva ao aprendizado de informações não desejadas, como o ruído. Depois de treinada, a rede é capaz de responder rapidamente às entradas apresentadas, num tempo que depende diretamente da quantidade de pesos. Outra maneira de avaliar o erro, tanto de treinamento como de validação, é recorrer diretamente à taxa de classificação. Definido um critério, por exemplo, o arredondamento dos valores de saída, pode-se contar para quantos padrões o MLP errou a resposta. Naturalmente, é uma medida mais adequada para problemas de classificação, os quais não requerem saídas de valores contínuos, tão somente uma representação binária.

\subsubsection{Vantagens do RPROP}

O algoritmo de treinamento RPROP (RIEDMILLER; BRAUN, 1993a) e seus derivados têm dado bons resultados em testes comparativos (PSTER; ROJAS, 1996). Uma vantagem do RPROP é sua melhor adequação para grandes conjuntos de treinamento, pois o treino em lote é determinístico, ou seja, os padrões não competem entre si. Num aprendizado online como o da retropropagação convencional, quanto maior o conjunto de treinamento, muito maior é a quantidade de iterações necessárias para a curva do erro estabilizar, dado o caráter estocástico dessa abordagem (HESKES; WIGERINCK, 1996). O RPROP atinge um pequeno erro de treinamento com poucas iterações. Outros fatores importantes para a escolha do RPROP é sua capacidade de generalização do aprendizado e a ausência de parâmetros, ou melhor, a existência de parâmetros que não requerem alterações, pois existe um largo intervalo funcional bem definido para os mesmos, enquanto que outros algoritmos, como a retropropagação, exigem várias tentativas antes de se encontrarem os melhores valores.

\footnotetext{
${ }^{7}$ sum of squared errors
} 


\subsubsection{Tamanho da rede}

Cada peso da rede neural é um parâmetro livre do sistema. Se houver muitos parâmetros livres, pode ocorrer do sistema aprender excessivamente a respeito do conjunto de treinamento e, conseqüentemente, não construir um modelo estatístico que represente o processo gerador dos dados de entrada. Esse fenômeno é conhecido por overfitting ${ }^{8}$. Para evitar tal problema deve-se dimensionar a topologia da rede com parcimônia. Uma regra amplamente aceita é ter uma quantidade de pesos inferior a um quinto da quantidade de padrões no conjunto de treinamento (MESSER; KITTLER, 1998). Quando o tamanho do conjunto não permite tal proporção, podem-se remover pesos durante o treinamento segundo algum critério de relevância ou saliência.

No caso deste trabalho, o número de padrões foi bastante elevado com relação ao tamanho da rede.

\subsection{Mapa auto-organizável de Kohonen}

O mapa auto-organizável de Kohonen ou SOM (do inglês Self-Organizing Map) (KOHONEN, 1995) contém uma única camada de neurônios. Que pode ser disposta em uma, duas ou mesmo três dimensões. Cada neurônio, ou grupo de neurônios próximos, se especializa em responder a um conjunto de padrões similares. Uma dificuldade é a necessidade de se definir quantos neurônios o mapa deve ter.

Maiores detalhes sobre o mapa são dados no apêndice $C$ e foram omitidos aqui pelo fato de não ser do escopo do presente trabalho, embora tenha uma importância teórica grande e tenha sido usado no experimento de um artigo elaborado durante o mestrado (SANTOS, 2006). O artigo envolveu, no caso não-supervisionado, a transformação de imagens por meio de um MLP e a posterior apresentação dos dados a um SOM. Por estar em seus estágios iniciais, optou-se por omitir o experimento não-supervisionado da dissertação.

\subsection{Considerações}

Neste capítulo foram introduzidos os fundamentos do algoritmo de treinamento e da rede neural escolhida para os experimentos. O par MLP/RPROP foi escolhido por realizar classificação supervisionada, prover um algoritmo de aprendizado bastante robusto e ser capaz de operar eficientemente de forma paralela em máquinas com mais de um processador. Foram também discutidos outros aspectos como topologia e parâmetros.

A inteligência artificial que é possível obter das redes neurais possibilita resolver problemas do mundo real. A principal restrição para isso é a modelagem do problema de

\footnotetext{
${ }^{8}$ poderia ser traduzido por superespecialização
} 
forma que possa ser apresentado a uma rede neural. Isso é assunto da área de reconhecimento de padrões e é abordado no próximo capítulo. 


\section{Capítulo \\ 4 \\ Reconhecimento de padrões}

O reconhecimento de padrões é largamente aplicado nas mais diversas áreas como inteligência de máquina e especificamente visão computacional. A inspeção de produtos manufaturados e o reconhecimento de escrita e fala, por exemplo, também requerem algum tipo de reconhecimento de padrão. Finalmente, até na medicina, os diagnósticos auxiliados por computador fazem parte de seu escopo (THEODORIDIS; KOUTROUMBAS, 1999). A revisão de Jain et al. (JAIN; DUIN; MAO, 2000) cita diversas abordagens para os principais tópicos envolvidos e apresenta taxonomias de modelos e aplicações. Neste capítulo são apresentados os fundamentos do assunto e são exploradas algumas técnicas de redução da dimensionalidade e de classificação.

\subsection{Fundamentos}

A meta do reconhecimento de padrões é a classificação de objetos do mundo real segundo diferentes categorias (classes) (THEODORIDIS; KOUTROUMBAS, 1999). Desses objetos são medidos sinais e, no presente caso, são sinais bidimensionais (imagens digitais). Tem-se nomeado na literatura, embora de tradução ambígua, cada conjunto de medidas pertencentes a um objeto como padrão ${ }^{1}$. Posteriormente, o termo padrão será usado também para o conjunto de características ${ }^{2}$ - proveniente de alguma transformação, ou seqüência de transformações, aplicada sobre uma janela na imagem.

O reconhecimento de padrões envolve, em geral, as seguintes etapas (YOUNG; FU, 1986): aquisição de sinais, normalização, estimação não-paramétrica do erro inicial, ex-

\footnotetext{
${ }^{1}$ do inglês pattern

${ }^{2}$ cada característica é o resultado de uma função aplicada ao conjunto de medidas que procura reduzí-lo a um conjunto mínimo e suficiente para diferenciar as classes
} 
tração de características, modelagem do classificador e estimação paramétrica do erro final.

Trata-se de um processo realimentado, pois, dependendo dos erros obtidos, pode-se alterar a forma de extração de características, o classificador ou mesmo recorrer a novas medições. Entende-se, aqui, o termo extração de características como a redução do total de medidas para um conjunto de dados menor e mais relevante para o reconhecimento, ou seja, implica na seleção ou combinação de medidas. É análogo ao conceito de extração de características de textura, mas, no contexto deste capítulo, as características de textura seriam a entrada do sistema, substituindo o estágio de aquisição de sinais. Deve-se ainda notar que o algoritmo reconhecedor de padrões adotado pode realizar todo o processo desde a etapa de aquisição de sinais até a etapa de classificação ${ }^{3}$ de forma simultânea, como é o caso dos campos aleatórios de Markov aplicados à segmentação de texturas (COMER; DELP, 2000).

A abordagem mais geral é a estatística (FUKUNAGA, 1990), para a qual as medidas são vistas como variáveis aleatórias e cada conjunto delas como vetores aleatórios. Normalmente, assume-se um modelo de comportamento para eles e, também, para o seu ruído oriundo, em grande parte, do próprio processo de digitalização. Uma vez que se conheça, de medições prévias, a distribuição dos vetores aleatórios, isto é, o comportamento que os padrões pertencentes à mesma classe têm em comum, é possível criar uma fronteira no espaço de características ${ }^{4}$ que separe uma categoria de objetos de outra. Nesse caso, os vetores são chamados de padrões de treinamento. Para exemplificar o conceito de fronteira no espaço de características, considerem-se, por exemplo, os dados de uma pesquisa (JANSSEN et al., 2000), na qual as medidas de massa corporal e massa muscular são obtidas de homens e mulheres. Pode-se observar na figura 4.1 que a regressão dos pontos de cada categoria (homem ou mulher), indicada por uma curva, sugere uma tendência particular.

As tendências, ou qualquer outro tipo de ordem contida na disposição dos objetos no espaço de características, viabilizam o uso de uma função discriminante que pode, por exemplo, tendo como argumentos as medidas de massa, retornar um valor positivo para indicar gênero feminino e um valor negativo para indicar gênero masculino. $O$ dispositivo capaz de detectar essa polaridade é chamado de rede de reconhecimento de padrões ou, simplesmente, classificador. A modelagem do classificador exige o estudo, para cada classe, das peculiaridades dos padrões pertencentes a ela. Essa atividade faz parte da etapa chamada de aprendizado ou treinamento quando é feita automaticamente. No sentido mais amplo, o reconhecimento de padrões pode ser considerado um problema de

\footnotetext{
${ }^{3}$ entender que, no contexto de reconhecimento de padrões, o termo não é apenas restrito a classes pré-conhecidas, mas principalmente a classes deduzidas durante o processo

${ }^{4}$ o espaço de características consiste de uma abstração na qual cada eixo contém todos os valores possíveis de uma característica (variável aleatória, no jargão estatístico)
} 


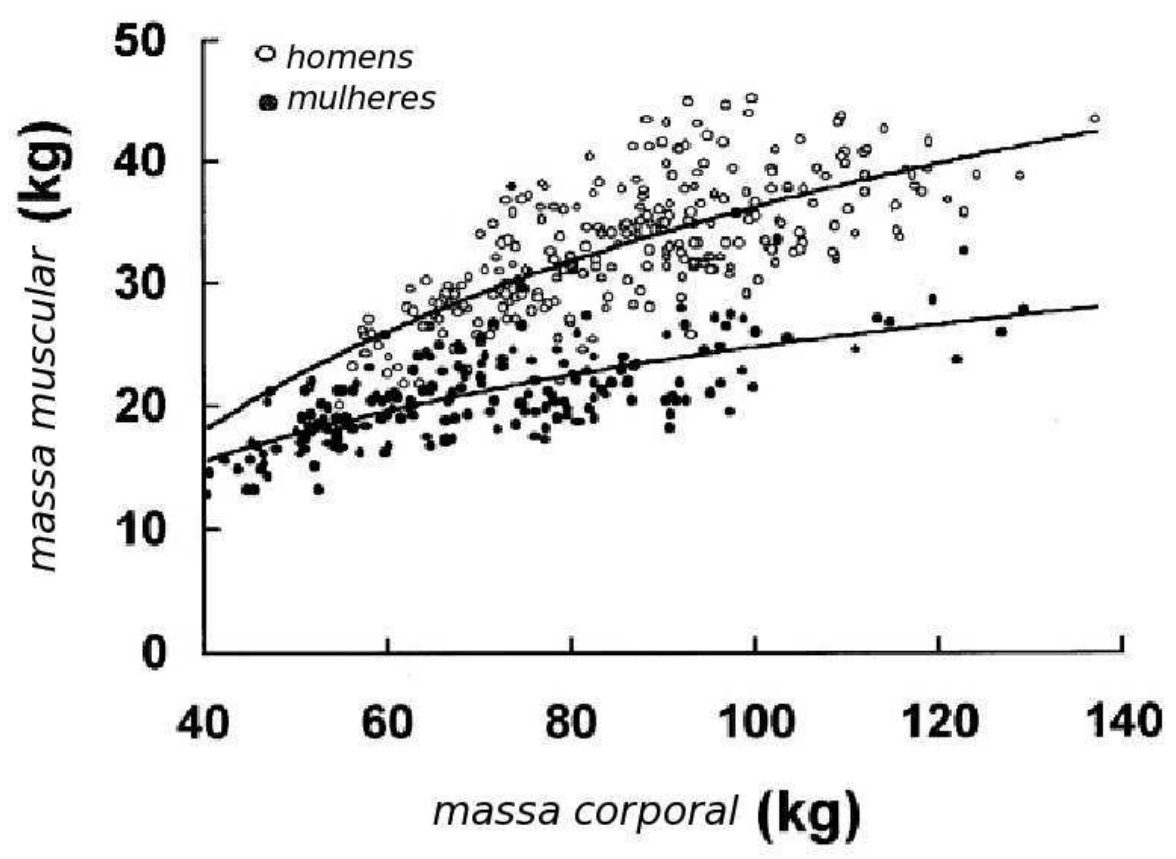

Figura 4.1: Exemplo de espaço de características: a despeito da estreita faixa de intersecção entre as diferentes categorias, é possível inferir uma regra geral de diferenciação entre homens e mulheres baseando-se nas medidas de massa corporal e muscular (JANSSEN et al., 2000).

estimação de funções de densidade em um espaço de alta dimensionalidade ${ }^{5}$ e de divisão desse espaço em regiões que correspondam a classes (FUKUNAGA, 1990). Na figura 4.2, é mostrado como se distribuem píxeis de dados de sensoreamento remoto de duas bandas conforme sua categoria.

Os fundamentos sobre o assunto vêm da estatística e a representação é simplificada com a notação de vetores da álgebra linear. Cada conjunto de medidas ou características é representado por um vetor. No caso em que imagens inteiras sejam os padrões, cada elemento do vetor equivale a um píxel.

\subsection{O erro e a regra de decisão de Bayes}

O cálculo do erro de Bayes permite estimar o quanto se perde de informação quando os dados são submetidos a uma transformação. Na seção 4.3 serão citadas algumas transformações que servem para reduzir a complexidade de um problema e que são o foco principal deste trabalho. Essa estimação é a diferença entre o erro de Bayes contido nas medidas iniciais e o erro de Bayes contido nas características transformadas e pode ser

\footnotetext{
${ }^{5}$ quantidade de dimensões
} 


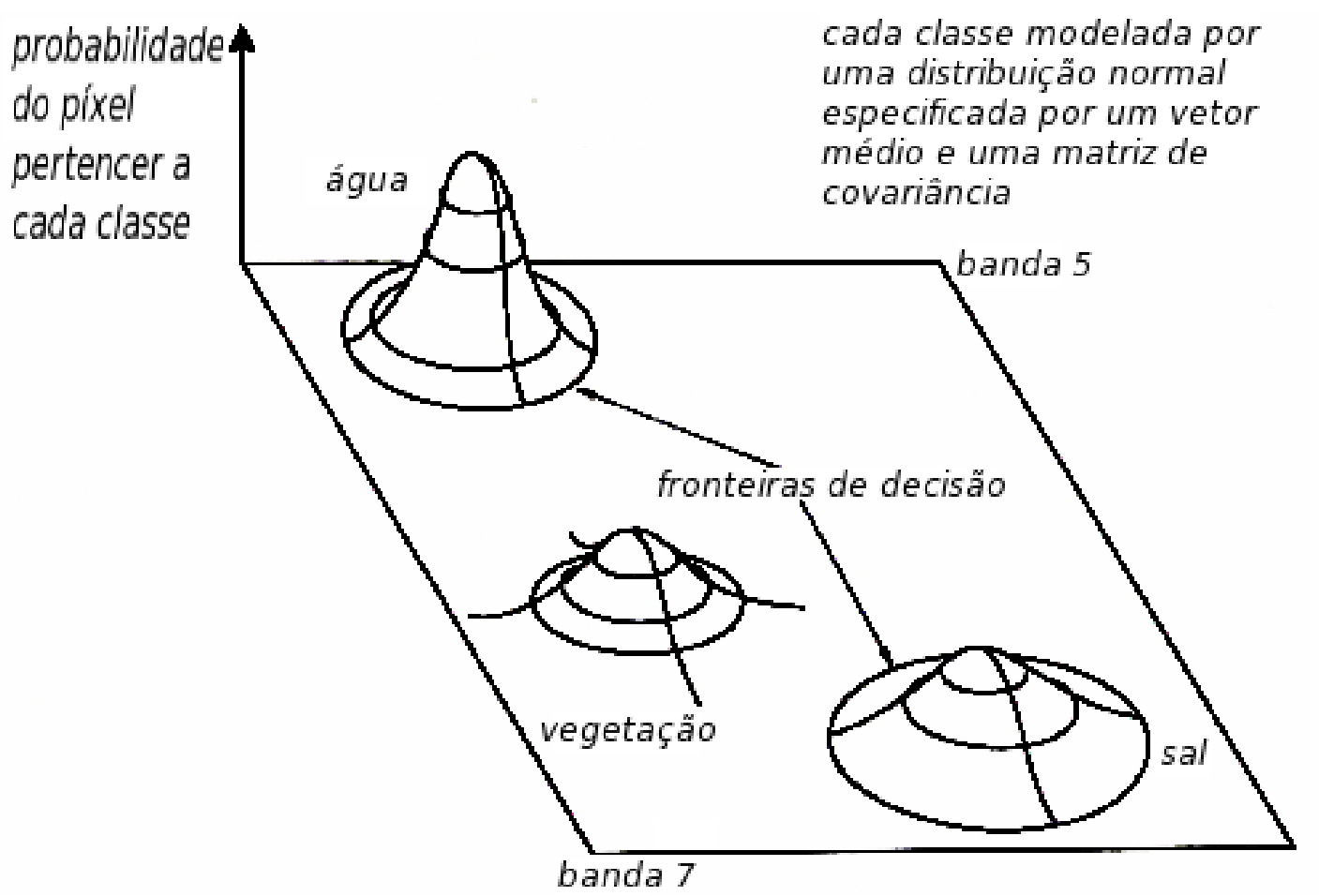

Figura 4.2: Funções de densidade de probabilidade: os eixos do espaço de características são dados espectrais e cada classe tem sua probabilidade de ocorrência aproximada por uma superfície gaussiana (RICHARDS, 1995).

usada para a redefinição do sistema, caso o aumento do erro esteja acima do estipulado. Considere-se a seguinte notação para as próximas fórmulas:

$x$ é um dado padrão

$w_{i}$ é a classe $i$, no caso, $i=1$ ou $i=2$

$P\left(w_{i} \mid x\right)$ é a probabilidade de $w_{i}$ para um padrão $x$ dado

$p\left(x \mid w_{i}\right)$ é a função de densidade de probabilidade, ou seja, é definida com base nos padrões conhecidos

$p(x)$ é a soma das probabilidades condicionais de $x$ para todas as classes ponderada pela chance de cada classe ocorrer

$P\left(w_{i}\right)$ é chance de cada classe ocorrer independentemente de outra informação

Se o problema não permite que a função de densidade de probabilidade seja expressa matematicamente em termos de parâmetros, é necessário usar algum método nãoparamétrico para estimá-la. Dois métodos existentes são: estimação de densidade de Parzen e estimação de densidade do k-ésimo vizinho mais próximo. Eles são semelhantes e dão resultados parecidos. Ambos consistem em medir localmente a densidade do espaço 
de características. A vizinhança considerada pode ser limitada por distância (Parzen) ou por número de vizinhos ( $k$-ésimo vizinho) (FUKUNAGA, 1990).

De posse da informação sobre a densidade, pode-se calcular o erro inerente de classificação dos dados e pode-se classificar os padrões segundo um critério próximo do ótimo, na medida em que as funções de densidade de probabilidade tendam a representar fielmente a distribuição estatística dos padrões (com o número de padrões tendendo a infinito, por exemplo). O erro de Bayes, num caso de duas classes, é calculado por:

$$
P(\operatorname{erro} \mid x)=\min \left[P\left(w_{1} \mid x\right), P\left(w_{2} \mid x\right)\right]
$$

$P\left(w_{i} \mid x\right)$ é calculado pelo teorema de Bayes que relaciona a probabilidade condicional ${ }^{6}$ (ou a priori) e a probabilidade marginal $^{7}$ (ou a posteriori):

$$
P\left(w_{i} \mid x\right)=\frac{p\left(x \mid w_{i}\right) P\left(w_{i}\right)}{p(x)}
$$

Uma vez que o erro esteja dentro do limite definido, o teste de Bayes (FUKUNAGA, 1990) é usado para retornar a classe mais provável. Ele pode ser feito comparando-se a taxa de verossimilhança $l(x)$,

$$
l(x)=\frac{p\left(x \mid w_{1}\right)}{p\left(x \mid w_{2}\right)}
$$

com a razão

$$
\frac{P\left(w_{1}\right)}{P\left(w_{2}\right)}
$$

Se a taxa $l(x)$ for maior que a razão $\frac{P\left(w_{1}\right)}{P\left(w_{2}\right)}$, então a classe 2 tem mais probabilidade de ser a correta. Caso contrário, considera-se a outra classe. Se a ocorrência das duas classes for equiprovável, compara-se $l(x)$ com 1.

No caso citado, trata-se de um aprendizado supervisionado, pois existe a necessidade de um observador humano treinar o computador. Logo, é preciso ter um conjunto de padrões cujas categorias sejam conhecidas de antemão. Diferentemente, o aprendizado não-supervisionado ocorre quando as categorias são inferidas automaticamente.

\subsection{Redução da dimensionalidade}

Normalmente, as medidas que compõe cada padrão (características de textura, no caso deste trabalho) apresentam certo nível de interdependência e algumas podem nem mesmo contribuir para a tarefa de discriminação entre as classes, ou seja, é desejável reduzir o

\footnotetext{
${ }^{6}$ a probabilidade condicional é a chance de um evento ocorrer dado que um evento do qual ele depende tenha ocorrido

${ }^{7}$ a probabilidade marginal é a chance de um evento ocorrer independentemente de outros acontecimentos
} 
conjunto de dados de entrada do sistema de reconhecimento de padrões a um conjunto mínimo segundo um critério ótimo (BANKS, 1990). A dificuldade mais evidente de se trabalhar com um espaço de características de dimensionalidade muito alta é o custo computacional, nomeadamente, memória e processamento. Outro problema é o mal da dimensionalidade, embora sua influência dependa da dimensionalidade intrínseca dos da$\operatorname{dos}^{8}$ (KORN; PAGEL; FALOUTSOS, 2001). O mal da dimensionalidade é o fato de o espaço de características se tornar cada vez mais esparso na medida em que, para um mesmo número de padrões de treinamento, a quantidade de dimensões for cada vez maior. Numa situação limite, um padrão cuja classe se deseje conhecer não teria vizinhos conhecidos suficientes para isso.

A redução da dimensionalidade é um tipo de pré-processamento (BISHOP, 1995) que antecipa-se à apresentação dos padrões ao classificador. Esse pré-processamento pode se beneficiar de conhecimentos a priori sobre os padrões. É sabido, por exemplo, que alguns tipos de medidas são invariantes à rotação ou mudança de escala. Essas informações adicionais facilitam a escolha das melhores características e das transformações adequadas para o pré-processamento. Se o conhecimento a priori não for suficiente, recorre-se a um redutor automático de dimensionalidade. O redutor pode transformar ou apenas descartar características. No primeiro caso, o processo é chamado de extração de características, e permanece o mesmo em todas as fases do reconhecimento de padrões, desde o aprendizado do classificador até o uso definitivo. No segundo caso, o processo chama-se seleção de características, e diferencia por ser um procedimento usado apenas na modelagem do sistema de reconhecimento de padrões. Uma vez selecionadas as características relevantes, o treinamento e o uso final do sistema não envolvem qualquer seleção posterior sobre o conjunto de características.

Quando a redução da dimensionalidade é não-supervisionada, corre-se o risco de ignorar alguma característica boa, pois o critério de seleção, nesse caso, desconhece a informação de classe. Ele apenas procura reduzir a dimensionalidade às custas da perda de um pouco de informação. Se as medidas existentes não forem suficientemente boas, uma informação aparentemente desprezível pode ser descartada dependendo do critério de seleção. Tais alterações no conjunto de características, podem diminuir o potencial de classificação do sistema de reconhecimento de padrões. Diferentes formas de seleção e extração de características serão explicadas nos próximos tópicos.

\subsubsection{Extração de características}

Nesta seção são apresentadas formas de extração de características baseadas em PCA (do inglês Principal Component Analysis), MLP autoassociativo e SOM.

\footnotetext{
${ }^{8}$ a dimensionalidade intrínseca seria a quantidade de dimensões suficiente para representar os padrões
} 


\section{Análise de componentes principais}

A análise de componentes principais é bastante usada para reduzir a dimensionalidade de forma não-supervisionada. Ela consiste em mudar a base ortonormal dos dados de forma a maximizar a independência entre as características e reduzir a quantidade de dimensões apenas às relevantes. Uma vantagem é que o erro do procedimento pode ser calculado. Um argumento contra essa abordagem é que ela se baseia em combinações lineares, ou seja, não considera formas mais complexas de descrição dos pontos no espaço de características. Na figura 4.3 podem-se observar pontos espalhados de forma ordenada sobre o plano. A transformação necessária para transpô-los para um espaço unidimensional vai além de uma simples combinação linear. Visualmente, nota-se que os dados encontram-se "alinhados" numa circunferência e poderiam ser "esticados" sobre uma reta. Essa tarefa não é realizada por PCA. Outros métodos também apresentam tal dificuldade, mas não se trata de uma dificuldade intrínseca teórica dos modelos como acontece com a PCA.

Métodos baseados em equações lineares, em autovalores/autovetores, que é o caso de PCA, nem sempre funcionam, mesmo para problemas com classes linearmente separáveis (MARTINEZ; ZHU, 2005).

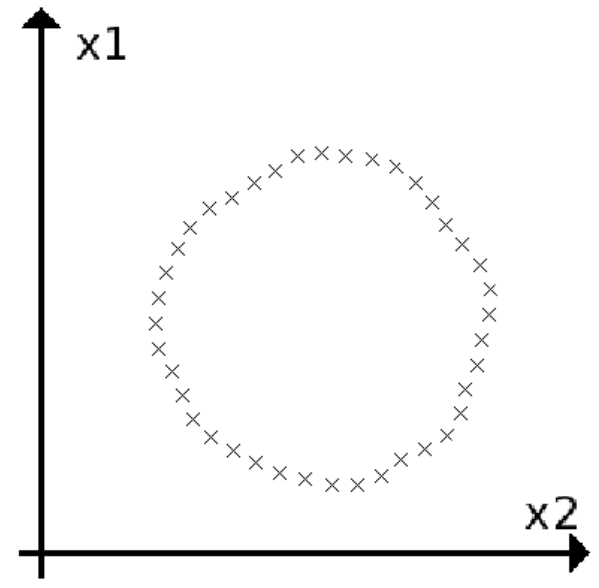

Figura 4.3: Exemplo de simplificação não contemplada por PCA: com uma única dimensão pode-se descrever, simplificadamente, o comportamento dos pontos.

Pode-se usar PCA para o dimensionamento da camada oculta de um MLP (LERNER et al., 1994). Uma vez definido um limiar para os autovalores, é possível determinar quantos componentes são suficientes para representar os dados. Esse número de componentes é uma boa estimativa para a quantidade de neurônios da camada oculta. Essa maneira pode ser considerada conservadora, uma vez que a rede neural pode analisar os dados de forma não-linear e, talvez, representá-los com ainda menos componentes. 


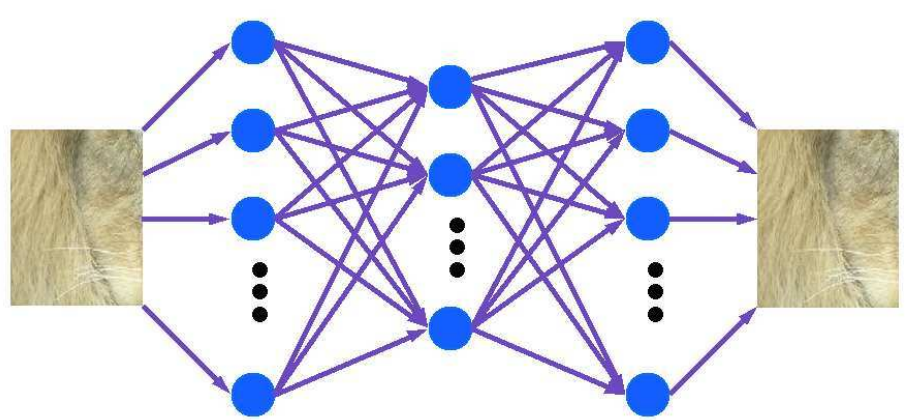

Figura 4.4: Topologia de uma AANN: 5 camadas: entrada, mapping, bottleneck, demapping e saída.

\section{Perceptron multicamadas auto-associativo}

No capítulo 3, as redes neurais foram vistas com maior profundidade. Para o presente tópico e o seguinte é importante a noção de que redes neurais são sistemas em camadas que transformam dados de entrada em dados de saída por meio de transformações aplicadas sucessivamente. O tempo de treinamento pode ser a porção crítica do custo computacional.

Uma rede neural autoassociativa $\left(\mathrm{AANN}^{9}\right)$ pode realizar a análise linear e não-linear de componentes principais $\left(\mathrm{NLPCA}^{10}\right)$ sem restrições, ou seja, ela é capaz de identificar correlações muito complexas entre variáveis (KRAMER, 1991). Se satisfizer certas propriedades, um MLP tradicional se torna uma rede neural autoassociativa. Os requisitos são: o MLP precisa ter pelo menos cinco camadas, a camada do meio precisa ser menor que a quantidade de características em questão e a rede deve esperar na saída os mesmos valores fornecidos na entrada. A camada do meio, também chamada de bottleneck ${ }^{11}$ (KRAMER, 1991) força a rede a representar os dados de entrada de forma compacta. Depois do treinamento, a redução de dimensionalidade é obtida considerando-se os valores das saídas dos neurônios da bottleneck como o novo conjunto de características.

A análise não-linear só é possível devido à existência das outras duas camadas ocultas, chamadas mapping e demapping ${ }^{12}$. Elas completam o número teórico mínimo de camadas necessárias para realizar qualquer mapeamento não-linear, tanto na compactação dos dados, quanto na decodificação. Na ausência da primeira camada oculta, por exemplo, a transformação das variáveis de entrada nas variáveis do bottleneck teria, no máximo, a complexidade de um sistema linear, com o somatório interno de cada neurônio equivalendo a uma equação do sistema. O mesmo vale para a camada de demapping. A topologia de um perceptron multi-camadas autoassociativo é mostrada na figura 4.4

Se o treinamento atingir o ponto em que a diferença entre a saída e a entrada da

\footnotetext{
${ }^{9}$ autoassociative neural network

${ }^{10}$ nonlinear principal component analisys

${ }^{11}$ poderia ser traduzido por gargalo ou camada de estreitamento

${ }^{12}$ os termos poderiam ser traduzidos por codificação e decodificação respectivamente
} 
rede (erro) esteja abaixo de um limite aceitável, isso significa que os dados da camada intermediária contêm ainda parte significativa da informação. Essa é uma das vantagens do método: ele retorna o erro proveniente da redução da dimensionalidade. Uma desvantagem é a necessidade de se definir previamente a quantidade de dimensões desejada para o espaço resultante. O trabalho de Kulkarni e Verma (VERMA; KULKARNI, 2001) é um exemplo bastante simples de aplicação no pré-processamento para a classificação de textura.

\section{Mapa auto-organizável de Kohonen}

O mapa auto-organizável de Kohonen, quando usado para a extração de características, é como uma generalização do PCA capaz de encontrar relações mais complexas nos dados (HAYKIN, 1999). Sua única camada de neurônios equivale ao espaço de características resultante. Mais informações sobre o mapa são dadas no apêndice $C$.

\subsubsection{Seleção de características}

Por ser o assunto central deste trabalho, a seleção de características é abordada separadamente no capítulo 5 .

\subsection{Classificadores}

Conforme já citado, a necessidade de se adotar o aprendizado supervisionado ou o aprendizado não-supervisionado decorre diretamente da existência ou não da informação de classe, isto é, existindo um conjunto de treinamento, se os padrões nele contidos estão previamente classificados ou não. É explorado, a seguir, pelo menos um classificador de cada tipo para os dois grandes paradigmas de classificação estudados: estatístico e conexionista (redes neurais).

\subsubsection{Distância mínima}

O classificador de distância mínima (GONZALEZ; WOODS, 1992) funciona de forma supervisionada. Primeiramente é calculado o ponto médio de cada classe e definido como o protótipo da classe. Depois de obtidos os protótipos, cada novo padrão, cuja classe se deseja descobrir, é comparado em termos de distância com cada um deles. A menor distância indicará, possivelmente, a classe à qual o padrão pertence. 


\subsubsection{Busca simples de clusters e $k$-means}

A busca simples de clusters $^{13}$ e o k-means $^{14}$ são ambos algoritmos não-supervisionados (BANKS, 1990). O primeiro não requer o conhecimento prévio da quantidade de classes, enquanto que o segundo depende dessa informação. A busca simples de clusters segue os seguintes passos: baseando-se em algum conhecimento sobre o problema, define-se o raio que os clusters terão; escolhe-se um padrão aleatoriamente para ser o centro do primeiro cluster; procura-se o próximo padrão que não esteja contido nesse cluster; os padrões que não se enquadraram no critério da etapa anterior passam a fazer parte do primeiro cluster; o padrão selecionado se torna o centro do segundo cluster. Repetem-se os passos citados, exceto o primeiro, para todos os padrões que não estiverem dentro de nenhum cluster. Claramente, o raio e a ordem com que os padrões são pesquisados interferem no resultado.

O algoritmo $k$-means consiste das seguintes etapas: define-se a quantidade $k$ de clusters esperada; atribuem-se as coordenadas de um padrão escolhido ao acaso para cada cluster; marca-se cada um dos padrões como pertencente ao seu cluster mais próximo; recalculase o centro de todos os clusters baseando-se na média dos padrões que lhes pertencem. Repetem-se os passos anteriores, exceto o primeiro, até que os centros se estabilizem. O resultado depende da ordem em que se pesquisam os padrões, do número de classes e da escolha inicial dos clusters. Há casos especiais em que o algoritmo não converge.

\subsubsection{Máxima verossimilhança}

A máxima verossimilhança baseia-se nas medidas de média e variânca de cada classe dos padrões de treinamento. A distribuição normal é adotada para estimar a função de densidade de cada classe e usa-se o critério bayesiano para decidir a qual classe os padrões não classificados pertencem.

\subsubsection{Redes neurais para classificação}

No capítulo 3 foram dados os fundamentos sobre redes neurais. O MLP é uma rede neural que é treinada de forma supervisionada e seu uso mais comum é como classificador. O SOM, diferentemente do MLP, é treinado de forma não-supervisionada e pode ser usado como classificador, embora sua gama de aplicações seja vasta.

\footnotetext{
${ }^{13}$ agrupamentos de padrões no espaço de características

${ }^{14}$ em português $k$-médias
} 


\subsection{Considerações}

Neste capítulo foram introduzidos os fundamentos estatísticos do reconhecimento de padrões e foram descritos alguns dos classificadores existentes tanto supervisionados quanto não-supervisionados, e citados dois tipos de redes neurais. Também foram mencionadas algumas técnicas de redução da quantidade de características sem perda considerável de informação. O classificador de distância mínima tem importância especial neste trabalho por ser mais simples que o MLP, e, por isso, servir de indicador da qualidade de características. Em outras palavras, o MLP geralmente extrai relações mais complexas dos padrões e consegue, assim, tirar proveito até mesmo de características ruins. Essa diferença entre os classificadores é importante para avaliar métodos de seleção de características, cuja exposição é feita no próximo capítulo. 


\section{Capítulo \\ 5 \\ Seleção de características}

O sucesso de um sistema de reconhecimento de padrões pode depender da seleção de características. A seleção de características é usada para reduzir o custo de aquisição de medidas e também para aumentar a precisão do sistema de classificação (JAIN; ZONGKER, 1997). Ela não cria novas características, apenas seleciona as medidas mais representativas. Por ser um método que permite descartar medidas menos importantes, ele pode ser usado para a combinação de muitos métodos geradores de características, principal objetivo deste trabalho. Neste capítulo é apresentada uma tradicional medida estatística que permite a seleção ótima de características e uma heurística que será usada no método proposto. Ambas são comparadas no capítulo 7. Uma possível taxonomia dos principais métodos existentes é ilustrada na figura 5.1.

Além dos métodos que aparecem na figura, existem outros algoritmos. A busca para a frente e a busca para trás (forward e backward), por exemplo, estão entre as mais simples. Alguns esclarecimentos sobre as siglas que aparecem na figura: PTA $(1, r)$ significa algo como adiciona com uma mão (esquerda) e retira com a outra (direita) ${ }^{1}$, SFFS significa busca seqüencial para a frente flutuante ${ }^{2}$ e SBFS significa busca seqüencial para trás flutuante $^{3}$. As considerações deste capítulo são majoritariamente direcionadas ao caso supervisionado. Todavia, poderiam ser aplicadas ao caso não-supervisionado em muitas situações. A seção 5.2 trata do segundo tema mais especificamente.

\footnotetext{
${ }^{1}$ Plus 1 - take away $\mathrm{r}$

${ }^{2}$ do inglês sequential forward floating selection

${ }^{3}$ do inglês sequential backward floating selection
} 


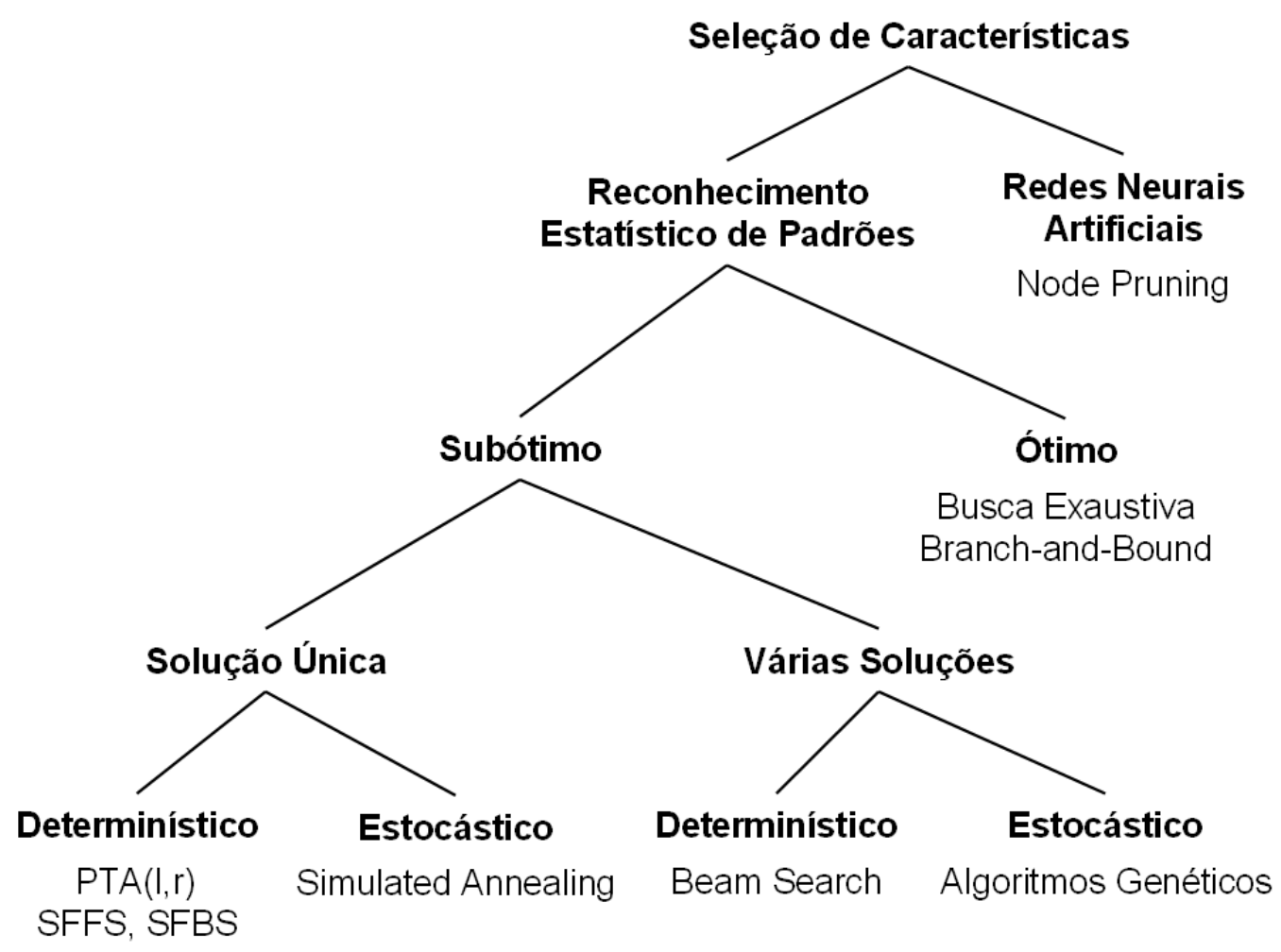

Figura 5.1: Taxonomia dos principais métodos de seleção de características: alguns termos não foram traduzidos para não descaracterizar os métodos (JAIN; ZONGKER, 1997).

\subsection{Seleção supervisionada de características}

Kudo e Sklansky (KUDO; SKLANSKY, 2000) apresentam uma revisão dos principais métodos ótimos, de busca e um algoritmo genético. A revisão também oferece uma boa discussão sobre as implicações teóricas envolvidas em cada opção e que serão brevemente mencionadas a seguir. Neste tópico serão discutidos métodos ótimos e heurísticos para a seleção de características. Como, geralmente, os métodos são constituídos de um algoritmo de busca e de um critério, essas duas partes serão apresentadas separadamente.

\subsubsection{Algoritmos de busca}

\section{Busca exaustiva}

No caso exaustivo, todas as combinações possíveis de características são testadas para se determinar qual é o subconjunto mais relevante. O problema desse procedimento é sua inviabilidade computacional para muitas medidas: sendo $n$ o número de medidas, a quantidade de iterações é $2^{n}-1$. Num sistema com 50 valores de entrada, o total de 
combinações possíveis é superior a $10^{15}$. Quando a quantidade de características desejadas $m$ é fixada, o número de combinações se reduz a $\left(\begin{array}{c}n \\ m\end{array}\right)$ ou $\mathrm{O}\left(n^{m}\right)$.

Uma heurística que pode ser usada é a seleção das medidas que individualmente têm o maior poder discriminante ou excluir sucessivamente as que causem menor impacto no sistema. Esse método tem a dificuldade de não dar garantias de retorno do melhor conjunto de medidas, pois trata-se de um algoritmo guloso ${ }^{4}$. O único método ótimo que não é exaustivo é o Branch and Bound ${ }^{5}$ (FUKUNAGA, 1990) cujo um dos últimos aperfeiçoamentos foi feito por Chen (CHEN, 2003) e que consistiu em eliminar ainda mais caminhos desnecessários na árvore de busca.

\section{Seleção Branch and Bound}

A seleção Branch and Bound usa um critério de similaridade interclasses para direcionar a busca no espaço de soluções. A similaridade pode ser calculada por medidas de distância como Mahalanobis ou Bhattacharyya (THEODORIDIS; KOUTROUMBAS, 1999). Tais medidas podem ser usadas para a determinação do melhor subconjunto de características por busca exaustiva. Caso a medida, como ocorre em geral com métricas de distância, cresça monotonicamente com o aumento da dimensionalidade, é possível evitar a busca exaustiva. Isso é viável por meio do método Branch and Bound. Ele se baseia na asserção de que o acréscimo de uma característica a um subconjunto sempre aumenta a acurácia do sistema (segundo o critério de distância). Logo, considerando-se as combinações possíveis de características numa estrutura de árvore e partindo-se dos subconjuntos maiores (pais) para os menores (filhos), pode-se, por exemplo, descartar toda a descendência dos pais que pontuem menos que qualquer combinação-folha da árvore. O pior caso do método Branch and Bound se realiza entre $2^{n}-1$ e $\left(\begin{array}{c}n \\ m\end{array}\right)$ iterações. Embora não seja o que ocorre na prática, ele pode ser mais lento que a busca exaustiva, pois faz comparações também para subconjuntos maiores que o desejado.

Mesmo para critérios não-monotônicos, o método Branch and Bound, normalmente, retorna bons resultados.

\section{Busca para trás}

A busca para trás consiste em avaliar um conjunto de características segundo algum critério e eliminar a pior delas. Iniciando-se com o conjunto completo de características e aplicando-se essa regra, há um momento em que resta apenas um subconjunto com o tamanho desejado. No capítulo 6 é proposta uma abordagem que faz uso da busca para trás.

\footnotetext{
${ }^{4}$ O algoritmo guloso sempre busca a solução que, à primeira vista, parece ser a mais vantajosa, não explorando, assim, a maior parte das possibilidades

${ }^{5}$ poderia ser traduzido por ramificar e limitar
} 


\section{Considerações sobre redes neurais}

Partindo-se de um MLP treinado, dependendo do critério, poder-se-iam eliminar várias características de uma só vez e fazer um novo treinamento com aquelas restantes. Leray e Gallinari (LERAY; GALLINARI, 1998) sugerem a remoção de apenas uma característica por vez e o imediato retreino. Isso é importante para permitir que correlações entre as características sejam identificadas. Caso contrário, pares de medidas - por exemplo - poderiam ser eliminados em conjunto, sendo que uma delas poderia se mostrar útil na ausência da outra. Sucessivos treinamentos aumentam consideravelmente o custo computacional. Laar et al. (LAAR; HESKES; GIELEN, 1997; LAAR; GIELEN; HESKES, 1997b) sugerem o retreino parcial, ou seja, assumem que o valor dos pesos da rede anterior contém informação ainda pertinente para a rede atual. Conseqüentemente, pode-se adotá-los como valores iniciais do novo treinamento para reduzir seu tempo de convergência.

\subsubsection{Critérios de busca}

O critério de busca mede a qualidade do subconjunto escolhido e permite que o algoritmo decida como prosseguir. Para isso, existem vários critérios diferentes. Eles podem se basear diretamente na taxa de acerto do classificador, na determinação estatística da separabilidade entre as classes ou em alguma avaliação indireta da relevância das características.

\section{Distâncias de Bhattacharyya e de Jeffrey-Matusita}

Uma medida largamente usada para medir a separabilidade entre duas classes ( $h$ e $k$ na fórmula abaixo) é a distância de Jeffrey-Matusita (JM) (HUBER; DUTRA, 1998), que depende da distância de Bhattacharyya (FUKUNAGA, 1990):

$$
\begin{gathered}
J M_{h, k}=\sqrt{2\left(1-\exp \left(-B_{h, k}\right)\right)} \\
B_{h, k}=\frac{1}{8}\left(M_{h}-M_{k}\right)^{T}\left(\frac{C_{h}+C_{k}}{2}\right)^{-1}\left(M_{h}-M_{k}\right)+\frac{1}{2} \ln \left(\frac{\left.\mid \frac{C_{h}+C_{k} \mid}{2}\right)}{\sqrt{\left|C_{h}\right|\left|C_{k}\right|}}\right)
\end{gathered}
$$

onde $M_{i}$ e $C_{i}$ são, respectivamente, o vetor médio dos padrões e a matriz de covariância da classe $i$. Embora a teoria envolvida trate de distribuições gaussianas, tem-se aplicado tal critério satisfatoriamente em aplicações sem qualquer garantia de gaussianidade (HUBER; DUTRA, 1998). Pode-se indicar dois aspectos da medida de Bhattacharyya que correspondem aos seus dois termos (fatores da soma). O primeiro termo tem o numerador atrelado à diferença entre os vetores médios das duas classes. Essa diferença está relacionada com a distância entre os centróides das distribuições. O denominador (na verdade a matriz inversa) é a matriz média de covariâncias, logo, quanto menor a variabi- 
lidade das classes, maior o primeiro termo. No caso do segundo termo, ele aumenta com o aumento da variabilidade das classes. Assim, a distância de Bhattacharyya combina uma medida de afastamento interclasses e uma medida de dispersão.

No caso de mais de duas classes, é usual somar as distâncias de todos os pares de classes ponderando pelas probabilidades a priori $\left(P_{i}\right)$ :

$$
J M=2 \sum_{i, j} P_{i} P_{j} J M_{i, j}
$$

Quando as probabilidades a priori são muito diferentes e o erro para as classes menos prováveis não pode ser alto, existe uma extensão mais adequada proposta por Bruzzone et al. (BRUZZONE; SERPICO, 1995). No presente trabalho tais considerações de probabilidade não se aplicam, pois as áreas correspondentes às classes são de tamanho igual ou próximo e não têm custos diferenciados de classificação.

\section{Erro de classificação/validação}

Quando se dispõe de um sistema classificador que seja viável computacionalmente para a realização de vários treinamentos, pode-se determinar o melhor subconjunto de características diretamente pela taxa de acerto. Uma desvantagem desse critério é que o classificador pode demorar para ser treinado. E, mesmo se não for o caso, quando há muitas características, o número de combinações possíveis de subconjuntos torna qualquer método exaustivo proibitivo. Uma heurística comumente adotada é verificar para qual exclusão de característica obtém-se o menor erro e prosseguir com as demais. Tal procedimento, para a escolha do subconjunto final de características, é de ordem quadrática $\left(O\left(n^{2}\right)\right)$.

\section{Saliência}

Aproveitando que as redes neurais não fazem qualquer suposição prévia sobre as funções de distribuição de probabilidade dos dados, pesquisadores passaram a utilizá-las como alternativa aos métodos estatísticos, evitando assim suas condições restritivas (CASTELLANO; FANELLI, 2000). Garson (GARSON, 1991) propôs uma medida de saliência para as entradas de uma rede neural que se mostrou viável para a seleção de características quando comparada a métodos tradicionais (NATH; RAJAGOPALAN; RYKER, 1997). Tratase de uma estimativa da importância de cada entrada baseada no custo dos diferentes caminhos de conexões possíveis até as saídas. Primeiramente, é calculado um fator de normalização $N_{o}$ para cada neurônio o oculto que consiste da soma do módulo de suas 
conexões $w_{e, o}^{\text {camadaOculta }}$ (o índice $e$ corresponde ao número do nó de entrada) ${ }^{6}$ :

$$
N_{o}=\sum_{e}\left|w_{e, o}^{\text {camadaOculta }}\right|
$$

Cada combinação de caminhos possíveis (acrescentando-se à notação a variável $s$ para neurônios de saída) retorna um determinado valor $w *_{e, o, s}$ baseado no peso normalizado da entrada e no valor do peso de saída:

$$
w *_{e, o, s}=\frac{\left|w_{e, o}^{\text {camadaOculta }}\right|\left|w_{o, s}^{\text {camadaDeSaida }}\right|}{N_{o}}
$$

Assim, a medida de saliência $S_{e, s}$ da entrada $e$ para a saída $s$ é dada por:

$$
S_{e, s}=\sum_{o} w *_{e, o, s}
$$

e a saliência total $S T_{e}$ da entrada $e$ é dada por:

$$
S T_{e}=\sum_{s} \frac{S_{e, s}}{\sum_{f} S_{f, s}}
$$

O artigo de Nath et al (NATH; RAJAGOPALAN; RYKER, 1997) só aborda o problema de duas classes, ou seja, uma única saída. Assim, o cálculo de $S T$ aqui proposto é apenas uma das soluções possíveis.

Com a medida de saliência, é possível excluir diretamente uma característica sem recorrer ao erro de classificação, o que poupa o procedimento de treinar a rede várias vezes em busca da característica menos relevante. Essa escolha imediata reduz consideravelmente a complexidade da busca pelo subconjunto final, resultando num algoritmo de ordem linear $(O(n))$, mais especificamente $O(n-m)$, pois ao obter as $m$ caracterísitcas restantes o algoritmo acaba.

\subsection{Seleção não-supervisionada de características}

Na seleção não-supervisionada, não há como medir o poder discriminatório de cada característica para a diferenciação entre as classes, pois essas não são conhecidas a priori. Dessa forma, o critério de seleção se baseia unicamente nas relações existentes nos dados de treinamento. Duas características altamente correlacionadas, por exemplo, podem ser substituídas por apenas uma. Uma característica cujo valor é constante, por outro lado, pode ser descartada de imediato. Qualquer tipo de dependência entre as características deve ser explorada na busca de um conjunto reduzido menos redundante.

\footnotetext{
${ }^{6}$ Por conveniência, a notação simplificada $\sum_{x}$ é usada e representa a soma para cada $x$ existente.
} 
Dy e Brodley (DY; BRODLEY, 2004) constataram pouco interesse na área e enunciaram a seguinte definição: "A meta da seleção não-supervisionada de características é encontrar o menor subconjunto de características que melhor revele agrupamentos naturais (clusters) de interesse nos dados de acordo com um determinado critério" ${ }^{7}$. Note-se que a definição amarra o processo de busca de classes com a seleção de características. Eles usaram a busca para frente (forward search) em seus experimentos.

\subsection{Considerações}

A seleção de características foi explorada neste capítulo. Foram apresentados algoritmos básicos de busca (busca exaustiva, Branch and Bound, forward e backward) e importantes critérios de avaliação de subconjuntos de características (distâncias de Bhattacharyya e de Jeffrey-Matusita, erro de classificação/validação e saliência). Também foi abordado o tema da seleção não-supervisionada de características cujo interesse tem se intensificado mais recentemente. Por ser um método ótimo e bastante conhecido, a combinação busca exaustiva/distância de Jeffrey-Matusita foi escolhida para servir de parâmetro quando da avaliação do método proposto composto pelo do par busca para trás/medida de saliência. É especificado no capítulo 6 como foram implementadas, neste trabalho, a seleção por saliência e variações.

\footnotetext{
${ }^{7}$ No original: "The goal of feature selection for unsupervised learning is to find the smallest feature subset that best uncovers interesting natural groupings (clusters) from data according to the chosen criterion."
} 


\section{Metodologia}

O esquema de segmentação adotado envolve três etapas, conforme ilustrado na figura 6.1. Neste trabalho, entende-se por segmentação a tarefa de rotulação de cada píxel da imagem de interesse. Essa tarefa é a classificação do píxel segundo categorias pré-definidas.

Visando contornar o problema da escolha de um dentre os diferentes métodos de extração de textura existentes, duas soluções bioinspiradas foram propostas:

- combinar os métodos por meio da seleção de características baseada na saliência dos pesos de um classificador MLP;

- delegar a tarefa de apreensão da textura à inteligência do classificador, que passa a substituir o ser humano na tarefa de modelar a estrutura subjacente da textura.

A primeira requereu a implementação dos métodos de extração de textura citados na seção 2.3, sendo que todas as características correspondentes foram agrupadas para gerar os padrões de treinamento. Essa proposta é, neste trabalho, referenciada pela sigla CMET (combinação de métodos de extração de textura). A segunda precisou apenas da definição do tamanho da janela de píxeis que seria apresentada como padrão, sendo cada elemento da janela uma "característica". Essa abordagem não faz uso de qualquer método de extração de textura. Por isso, é denominada neste texto de DMET (descarte de métodos de extração de textura).

Na figura 6.2 é possível ver as duas formas de obtenção do conjunto de características para o treinamento.

Na figura 6.2.a, pode-se notar a existência de uma etapa que transforma os píxeis e uma etapa de seleção que reduz o total de características que alcançam a etapa de treinamento. Por outro lado, na figura 6.2.b, os píxeis não sofrem qualquer transformação 


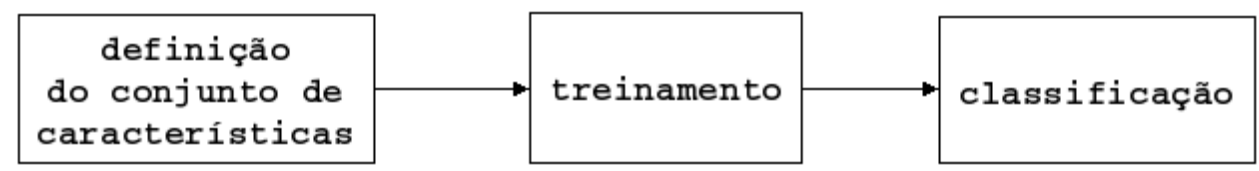

Figura 6.1: Esquema de segmentação adotado: etapas principais desde a modelagem até o uso.

\section{a)}

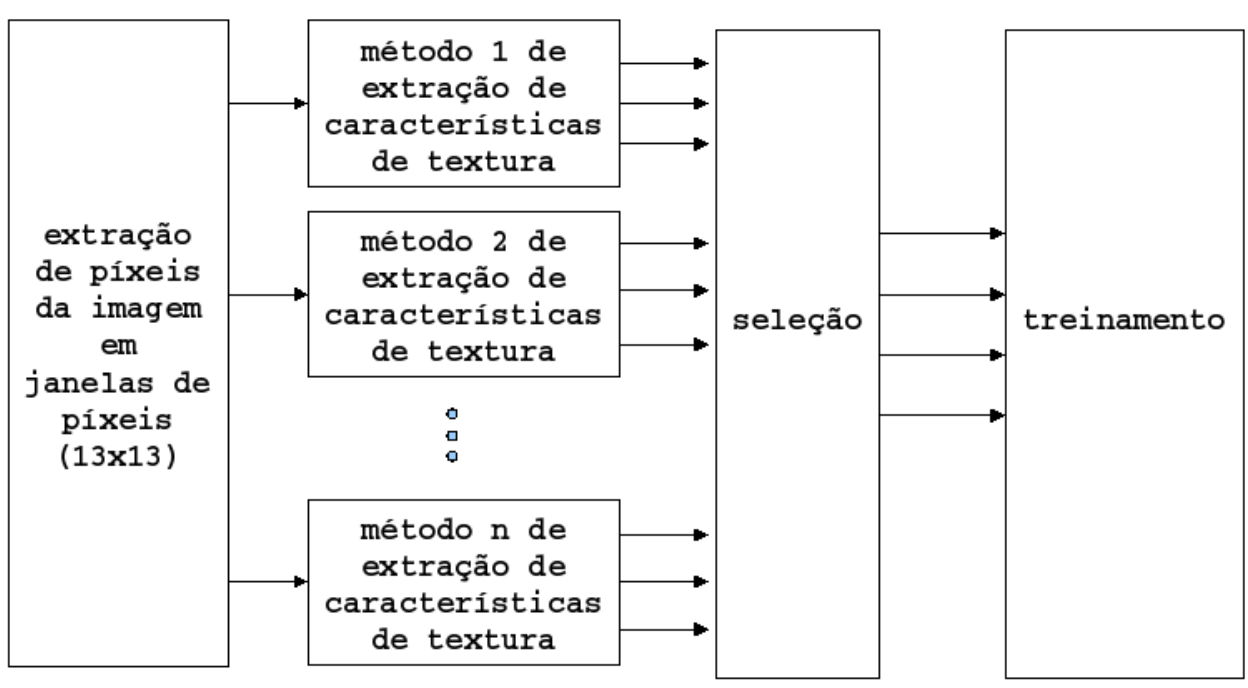

\section{b)}

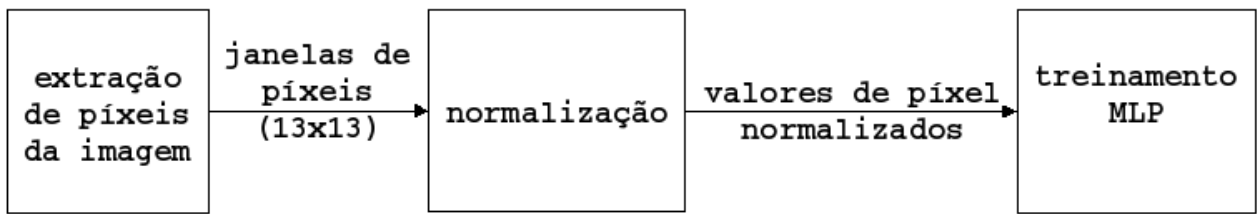

Figura 6.2: Esquemas das duas abordagens distintas: a) combinação de métodos de extração de textura (CMET) com treinamento independente de classificador; b) descarte de métodos de extração de textura (DMET) dependente do classificador MLP.

relevante antes de atingirem a etapa de treinamento, para a qual são considerados como características.

No primeiro caso (CMET), tanto a extração e a seleção de características quanto o treinamento do classificador são independentes entre si. Isso permite que a seleção por saliência, que é a principal contribuição deste trabalho, seja avaliada separadamente. Tal avaliação consiste na comparação com a seleção ótima segundo a métrica de separabilidade interclasses conhecida por distância de Jeffrey-Matusita e apresentada no capítulo 5. Duas variações da seleção por saliência também são sugeridas.

No segundo caso (DMET), trata-se de um experimento secundário, de caráter ilustrativo, conseqüência dos estudos do capítulo 2. O objetivo desse experimento é demonstrar 
a viabilidade de se delegar a apreensão da textura diretamente à inteligência artificial. Isso significa permitir que o modelo de extração seja construído pelo próprio MLP em suas conexões internas e, assim, prescinda de qualquer etapa de transformação ou seleção dos dados - excetuando-se a normalização (seção 6.1.2), a qual não agrega qualquer tipo de conhecimento. A confirmação da hipótese é dada pela inspeção visual da segmentação supervisionada de um mosaico de texturas.

O presente capítulo é dividido em três seções principais, a primeira, 6.1, contém detalhes de ambas as abordagens com relação a equipamentos e codificação. As seções 6.2 e 6.3 tratam dos experimentos baseados na CMET e DMET, respectivamente.

\subsection{Equipamentos e detalhes de implementação}

Esta seção descreve detalhes da implementação dos métodos para extração de características de textura, dos seletores de características e dos classificadores. A linguagem de programação usada foi $C++$ com compilador $g++3.3 .2$ e sistema operacional Solaris 2.10 x86. A máquina usada foi uma Sun $V 40 z$ com quatro processadores Opteron 64 Dual Core com $24 \mathrm{~GB}$ de memória $\mathrm{RAM}^{1}$ e $3.2 \mathrm{~TB}$ de disco rígido. Todo o sistema desenvolvido é completamente portável para as outras plataformas, como Linux e Windows. O sistema implementado é flexível, ou seja, aceita diferentes quantidades de classes, características e padrões sem necessidade de alterações no código.

\subsubsection{Multithreading}

A programação em Multithreading ${ }^{2}$ foi feita com a criação de 8 threads (subprogramas idênticos) a partir da biblioteca PThread que é baseada no padrão IEEE POSIX 1003.1c. A adoção do paralelismo implicou em algumas mudanças no uso da memória volátil: as variáveis referentes ao treinamento da rede neural como as variações dos pesos do MLP, as derivadas parciais do RPROP etc. foram replicadas 8 vezes; os dados dos padrões de entrada foram divididos igualmente entre as threads; foram criadas exclusões mútuas (TANENBAUM, 1992) para proteger a numeração das threads e o somatório das contribuições de cada thread quanto ao cálculo da derivada parcial do erro (importante para o RPROP).

As Matrizes de Coocorrência também foram implementadas em Multithreading seguindo o mesmo procedimento de dividir em 8 o conjunto de dados e replicar as variáveis de cálculo temporário.

\footnotetext{
${ }^{1}$ do inglês Random Access Memory

${ }^{2}$ modo de programação que permite a criação de subprogramas que executam simultaneamente em vários processadores da mesma máquina
} 


\subsubsection{Normalização das características de textura}

Foram implementados seis métodos de extração de características de textura para uma janela de 169 píxeis (13 de largura). O tamanho da janela foi definido baseado numa estimativa visual de qual seria o maior têxton possível dentro das imagens escolhidas. Seguem os métodos escolhidos: Run Lengths (GALLOWAY, 1975), estatísticas de primeira ordem (média, desvio padrão e mediana), valor do píxel ${ }^{3}$, Matrizes de Coocorrência (HARALICK; SHANMUGAM; DINSTEIN, 1977), transformada de Fourier unidimensional (ZHOU; FENG; SHI, 2001) e transformada de Fourier bidimensional (BALLARD; BROWN, 1982). Os seis métodos totalizaram 71 características numeradas e listadas no apêndice $A$. Uma dificuldade relacionada com a maioria delas é a normalização dos dados para o intervalo $[0 ; 1]$.

A restrição do MLP de que os valores das entradas precisam situar-se num intervalo exigiu a determinação, ora teórica e ora empírica, de fatores de normalização. Eles foram escolhidos de forma a maximizar o intervalo útil de cada característica. Para a determinação empírica, a rede foi treinada com imagens de diferentes domínios: de vegetação, de construções, de animais e têxteis.

No caso do CMET, as distribuições resultantes da normalização mostraram-se de grande importância e são abordadas no tópico sobre a compensação de sinal na seção 6.2.1. Seguem os detalhes sobre a normalização e os parâmetros usados em cada método. Os termos foram mantidos em inglês para facilitar a referência aos originais e à respectiva literatura decorrente.

\section{Run Lengths}

Foram implementadas as seguintes características: short runs emphasis, long runs emphasis, gray level nonuniformity, run length nonuniformity e run percentage. O nível de cinza dos píxeis foi quantizado em oito faixas e foram calculadas matrizes para quatro direções. Para cada característica foram calculados a média e o desvio padrão das quatro direções, resultando em cinco médias que foram divididas por 64, e cinco desvios padrões, divididos por 128.

\section{Estatísticas de primeira ordem}

Foi calculada a média, o desvio padrão e a mediana dos valores dos píxeis contidos na janela. A normalização consistiu em dividir os valores por 255.

\footnotetext{
${ }^{3} \operatorname{logicamente}$ aqui não se trata de uma janela, mas tão somente de um píxel
} 


\section{Valor do píxel}

O nível de cinza foi usado diretamente como característica de textura dividindo-se o valor do píxel por 255 .

\section{Matrizes de Coocorrência}

As matrizes usadas não foram simétricas, para aumentar a informação de direcionalidade da textura. Posteriormente, com a decisão de reduzir a quantidade de características do sistema por meio do cálculo da média das quatro direções (assim como foi feito com o método Run Lengths), é possível que o efeito do uso de matrizes assimétricas tenha se perdido. Como tal implementação atingiu um excelente desempenho em testes de validação do código, optou-se por mantê-la.

Das medidas sugeridas no artigo original (HARALICK; SHANMUGAM; DINSTEIN, 1977), foram implementadas: angular second moment, contrast, correlation, variance, inverse difference moment, sum average, sum variance, sum entropy, entropy, difference variance, difference entropy. Foram contabilizados pares distanciados de um e dois píxeis. Quatro direções foram consideradas e as imagens foram quantizadas para oito faixas de cinza. A normalização se deu da seguinte maneira:

- foi calculada a raíz ${ }^{4}$ de todas as médias para a atenuação dos picos;

- o valor resultante das medidas contrast, correlation, variance, sum average, sum variance, sum entropy, entropy e difference entropy para ocorrências de comprimento 1 e 2 foram divididas por 4, 255, 8, 4, 8, 2, 2 e 2, respectivamente;

- os valores correspondentes às ocorrências de comprimento 2 ainda foram multiplicadas pelo fator 0.6 ;

- os desvios padrões das medidas contrast, correlation, variance e sum variance para ocorrências de comprimento 1 e 2 foram divididos por 4, 255, 8 e 8, respectivamente.

\section{Transformada de Fourier unidimensional}

A janela, nesse caso, foi de três píxeis, restrição intrínseca do método. Foram consideradas duas voltas em torno do píxel central, ou seja, a transformada foi aplicada sobre 16 números. Foi calculada a raíz da média de cada dois números do espectro de potência, resultando num total de 8 características. A normalização final se deu com os seguintes denominadores: 64 para a freqüência mais intensa e 32 para as restantes.

\footnotetext{
${ }^{4}$ foi extraída duas vezes a raíz da média da medida correlation para que fosse suficientemente atenuada
} 


\section{Transformada de Fourier bidimensional}

A janela, nesse caso, foi de oito píxeis de largura porque a transformada exige potências de dois. A origem da janela se iniciou quatro píxeis acima e à esquerda do píxel de interesse (aquele cuja informação de textura se desejava extrair) e três abaixo e à direita. A linha superior e a coluna da esquerda foram desprezadas no espaço de Fourier para que a origem se situasse no meio da matriz. Foi calculada a energia total do espectro de potência nas faixas circulares (anéis em torno do centro) de raios $0,1,2,3$ e 4 . Um quarto de cada um dos quatro valores é acrescentado à contribuição das outras três janelas de forma a compensar o deslocamento citado no início deste parágrafo. Os valores finais foram normalizados por 128 .

\subsubsection{Distância de Bhattacharyya}

Como visto no capítulo 5, a distância de Bhattacharyya depende do cálculo de uma matriz inversa e vários determinantes. Além da otimização mais óbvia que foi armazenar os valores que se repetem para evitar cálculos redundantes, foi possível explorar o fato de que matrizes de covariância são simétricas não-negativas definidas, ou seja, podem ser trabalhadas mais rapidamente pelo método de Cholesky no cálculo da matriz inversa e do determinante (PRESS, 1990). Outra vantagem é que o método evita o problema da propagação de erros de arredondamento. Ainda assim foram utilizadas variáveis do tipo double para contemplar os determinantes muito próximos de zero ${ }^{5}$.

\subsubsection{Perceptron Multicamadas}

A adoção do RPROP (seção 3.1.1) poupou a modelagem do sistema do ajuste de parâmetros de aprendizado e permitiu a otimização dos recursos computacionais. A topologia foi definida da seguinte maneira para o CMET: 4 entradas, pois correspondem às 4 características de textura selecionadas; 5 neurônios na camada oculta, pois foi o tamanho mínimo necessário para que o treinamento do MLP atingisse 100\% de acerto com o conjunto completo de características; e 4 neurônios de saída, cada um representando uma classe. Na etapa de seleção por saliência do CMET, a topologia foi a mesma, exceto para a entrada que varia entre 71 e 4 conforme a iteração do processo.

\section{Regra de aprendizado}

O RPROP foi implementado em multithreading para minimizar o tempo de treinamento, aproveitando, assim, plenamente a capacidade da máquina multiprocessada. A redução do tempo de processamento acarretou num aumento pouco significativo na ocupação da memória RAM, dada a magnitude da memória ocupada pelos padrões de treinamento.

\footnotetext{
${ }^{5}$ aqueles menores que $10^{-65}$ foram considerados zero
} 
Como conseqüência obteve-se um processamento pelo menos 7 vezes mais rápido que a versão monoprocessada. Os tempos de processamento relatados no capítulo 7 levam em conta a ocupação do processador, ou seja, é considerado o tempo de processador que os programas consumiriam numa máquina monoprocessada. Tal critério foi adotado para contornar o problema da oscilação na disponibilidade da máquina devido aos programas de outros usuários.

\section{Topologia da rede}

A escolha da topologia foi guiada pela parcimônia: o número de camadas foi definido conforme o mínimo teórico de camadas necessárias para a solução de problemas nãolineares, ou seja, três; o tamanho da camada oculta foi aumentado durante um treinamento preliminar até que a curva do erro acelerasse sua convergência. O valor escolhido foi de cinco neurônios. É possível que com mais neurônios, o classificador aumentasse a taxa de acerto, porém, como se pode notar no capítulo 7, com uma camada oculta de tamanho cinco, o erro de validação já é bastante inferior ao erro de treinamento, um possível sinal do início de overfitting (seção 3.1.2).

\subsection{CMET - Combinação de métodos de extração de textura}

O objetivo do experimento é avaliar a seleção por saliência, que é uma heurística, frente à seleção ótima segundo a distância de Jeffrey-Matusita. As duas abordagens são explicadas a seguir. Ambas serão referenciadas doravante por SS e SJM, respectivamente.

\subsubsection{SS - Seleção por saliência}

A combinação de diferentes métodos de extração de características de textura, por meio da SS, foi estruturada conforme ilustrado na figura 6.3. O comnjunto completo de carac-

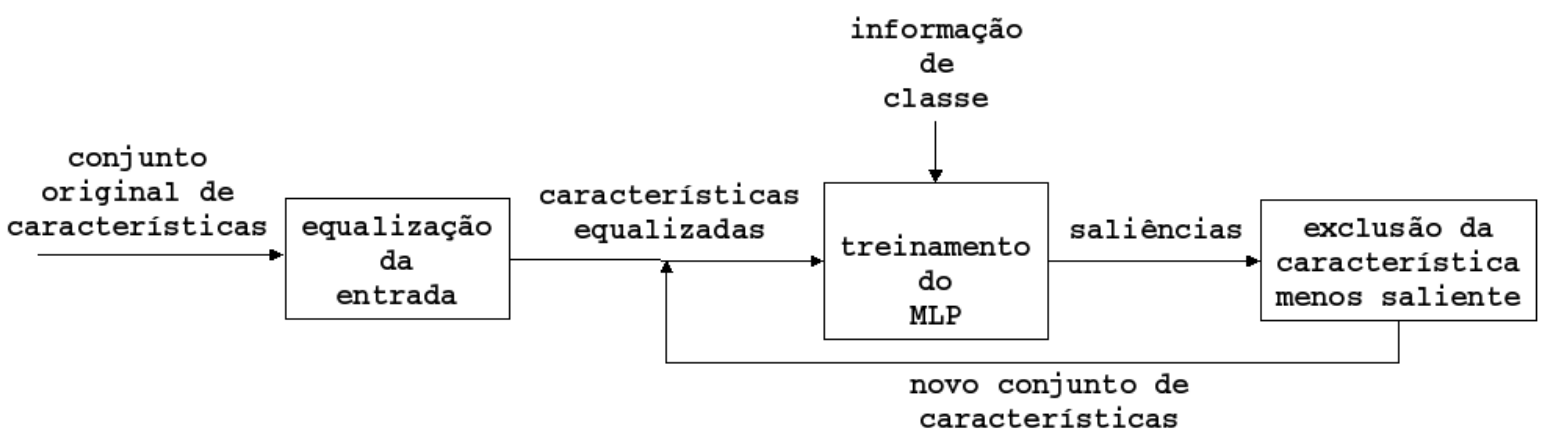

Figura 6.3: Experimento de métodos combinados: seleção por saliência (SS). 
terísticas é apresentado, após passar pela etapa de equalização que será explicada oportunamente (seção 6.4), ao MLP para treinamento. Assim, após o término do treinamento, a característica com a menor saliência é removida e a rede passa a ter 70 entradas. Esse novo conjunto de características é apresentado ao MLP para um novo treinamento e o processo continua sucessivamente até que reste apenas a quantidade características desejada. Pode-se notar que o esquema adotado foi de busca para trás, ou seja, de eliminação de uma característica por vez - a menos saliente.

Uma variação da SS foi também experimentada. Ela consistiu na interrupção do processo após a primeira iteração. As melhores saliências apontariam, assim, diretamente as melhores características. É evidente a redução drástica na complexidade da seleção, de ordem linear para constante: $\mathrm{O}(1)$. Essa variação é referenciada por SSOC (seleção por saliência de ordem constante).

Dois temas que envolvem diretamente o desempenho da SS e da SSOC são: retreino parcial (seção 6.2.1) e a compensação de sinal (seção 6.2.1).

\section{Retreino parcial}

Para acelerar a seleção, foi adotada a técnica de retreino parcial citada no capítulo 5, pois mostrou-se com um custo computacional 1,4 vezes menor do que se o MLP tivesse seus pesos reiniciados a cada iteração. As taxas de acerto foram muito próximas nos dois casos. Essas informações foram obtidas no experimento descrito no apêndice $B$.

\section{Compensação de sinal}

Tendo em vista o trabalho de Ruck et al., que cita a influência do intervalo útil da característica sobre a saliência (RUCK; ROGERS; KABRISKY, 1990), suspeitou-se da fragilidade dessa medida diante de características tão díspares, provavelmente, com distribuições abrangendo diferentes faixas e médias. Supõe-se que ocorra uma compensação de sinal no MLP que corrompe o cálculo da saliência. Essa suposição se baseia no fato de que os pesos conectados à entrada da rede neural têm influência direta no cálculo da saliência. Eles são representados por $w_{e, o}^{c a m a d a O c u l t a}$ nas fórmulas 5.4 e 5.5. Na figura 6.4, a largura de cada seta que entra na rede representa a intensidade média da característica. A largura das conexões internas à rede representam os valores dos pesos. Deve-se notar que, para a entrada de valor mais intenso, os pesos diretamente conectados têm os valores mais baixos.

Para investigação, foi treinado um MLP com todas as características disponíveis com o intuito de comparar as suas saliências com os seus respectivos valores médios. Na seção 7.1.1 do capítulo de resultados, são apresentados os experimentos a respeito dos efeitos da compensação de sinal. A equalização da entrada é uma técnica proposta neste trabalho para resolver esse problema e será apresentada na seção 6.4. 


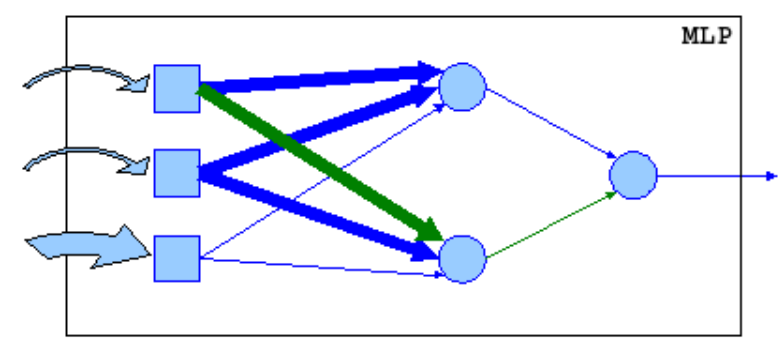

Figura 6.4: Compensação de sinal: comportamento dos pesos com relação às intensidades de entrada.

\subsubsection{SJM - Seleção ótima pela distância de Jeffrey-Matusita}

A combinação de diferentes métodos de extração de características de textura, por meio da seleção ótima por métrica de distância, é esquematizada na figura 6.5. Sendo $m$ o

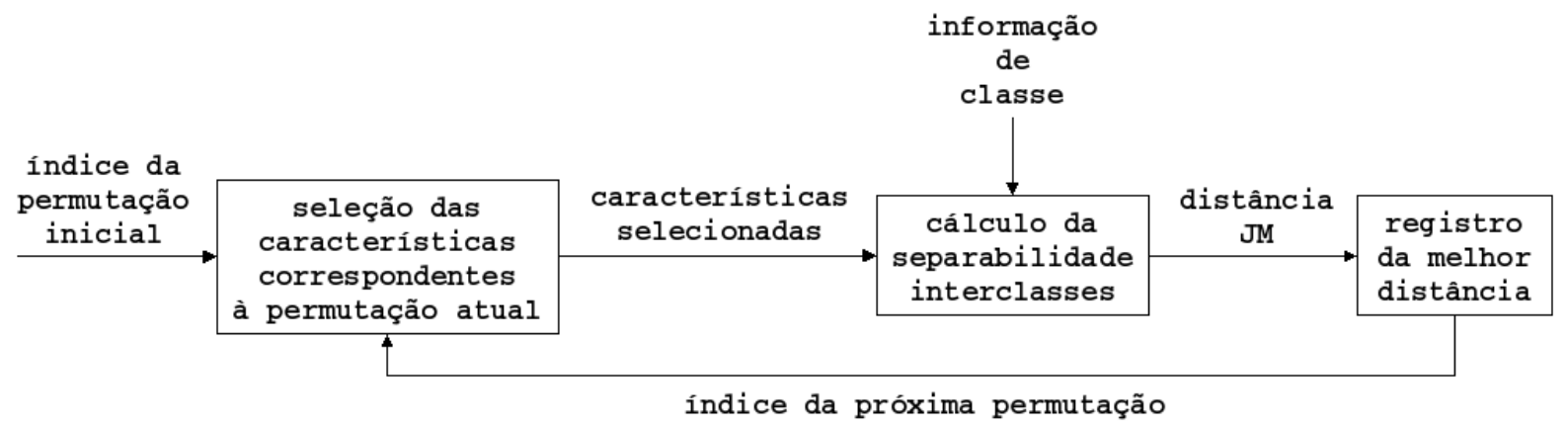

Figura 6.5: Experimento de métodos combinados: seleção por distância JM (SJM).

tamanho do subconjunto desejado, parte-se de uma seleção inicial de $m$ características e testam-se todas as outras combinações de tamanho $m$. Durante o processo é armazenado o subconjunto que obteve a maior distância JM. Claramente, o esquema adotado foi de busca exaustiva $^{6}$, ou seja, todas as permutações possíveis de subconjuntos para um dado tamanho fixo foram exploradas.

Pela alta ordem de complexidade do método ótimo escolhido como referência, foi necessário dimensionar um problema de acordo com os recursos disponíveis. Ele foi denominado problema dimensionado e foi fundamental para avaliar o método proposto do ponto de vista comparativo. Quanto à sua aplicabilidade em problemas do mundo real, optou-se pela inspeção visual da segmentação de imagens de paisagens naturais. O experimento que englobou esse tipo de problema é denominado de aplicação neste capítulo e no capítulo 7 .

O problema dimensionado foi abordado por SS, SSOC e SJM para comparação. A aplicação foi abordada por SS somente.

\footnotetext{
${ }^{6}$ o algoritmo Branch and Bound será adotado numa publicação futura
} 


\subsubsection{Problema dimensionado}

O problema dimensionado consistiu na segmentação de um mosaico de quatro imagens inteiras retiradas do álbum de Brodatz (BRODATZ, 1966). A imagem original e os resultados são expostos no capítulo 7. O tamanho do conjunto de treinamento foi escolhido com base em testes preliminares que demonstrassem o comportamento dos programas desenvolvidos, principalmente em termos de custo computacional.

\section{Testes preliminares}

Para determinar que experimentos seriam viáveis computacionalmente e possíveis dificuldades, foi realizado um teste apenas com as dez características do método Run Lengths. Foram utilizadas sete texturas do álbum de Brodatz (BRODATZ, 1966) apresentadas parcialmente na figura 6.6, correspondendo a 122.316 padrões para treinamento (122.316 vetores com 10 dimensões cada). Note-se que algumas foram escolhidas justamente pela similaridade que apresentam, visando diminuir a separabilidade entre as classes.
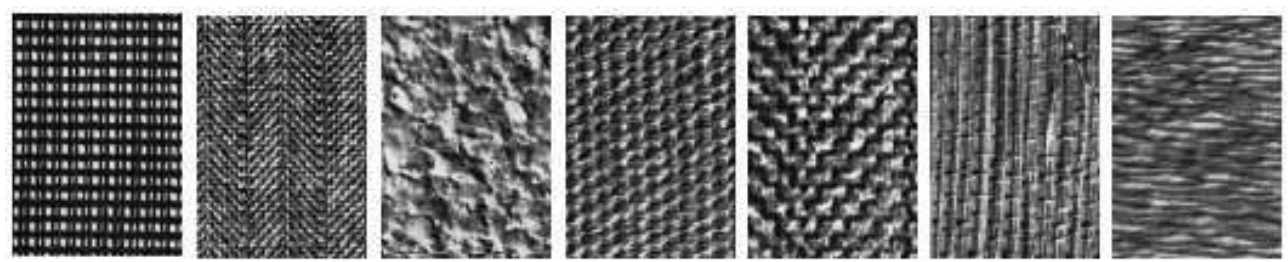

Figura 6.6: Sete texturas: conjunto de treinamento (imagens parciais da amostra de 122.316 píxeis) (BRODATZ, 1966).

Na figura 6.7, é mostrada a evolução da separabilidade interclasses segundo a distância de Jeffrey-Matusita. O processo durou 88 segundos. Somente uma execução foi necessária, pois o método é determinístico.

Naturalmente, o resultado experimental respeita a monotonicidade própria de seleções baseadas em medidas de distância. O valor indicador da qualidade do subconjunto selecionado é o valor da distância JM normalizada.

Dado o não-determinismo do MLP ocasionado pelo sorteio inicial dos pesos, três execuções foram feitas para a abordagem baseada na saliência. Na figura 6.8, são indicadas três curvas que correspondem às três diferentes inicializações aleatórias dos pesos da rede neural.

Nesse caso não há uma métrica de separabilidade, por isso o desempenho é indicado pela taxa de acerto no treinamento. Deve-se notar a não-monotonicidade das curvas, o que pode indicar a existência de características cuja presença prejudica a classificação. O ponto de parada do treinamento ${ }^{7}$ também pode alterar os resultados. Como houve divergência na escolha dos subconjuntos nas três execuções, optou-se por exibir apenas o

\footnotetext{
${ }^{7}$ depois de 100 ciclos sem redução de pelo menos $1 \%$ na soma de erros quadráticos
} 


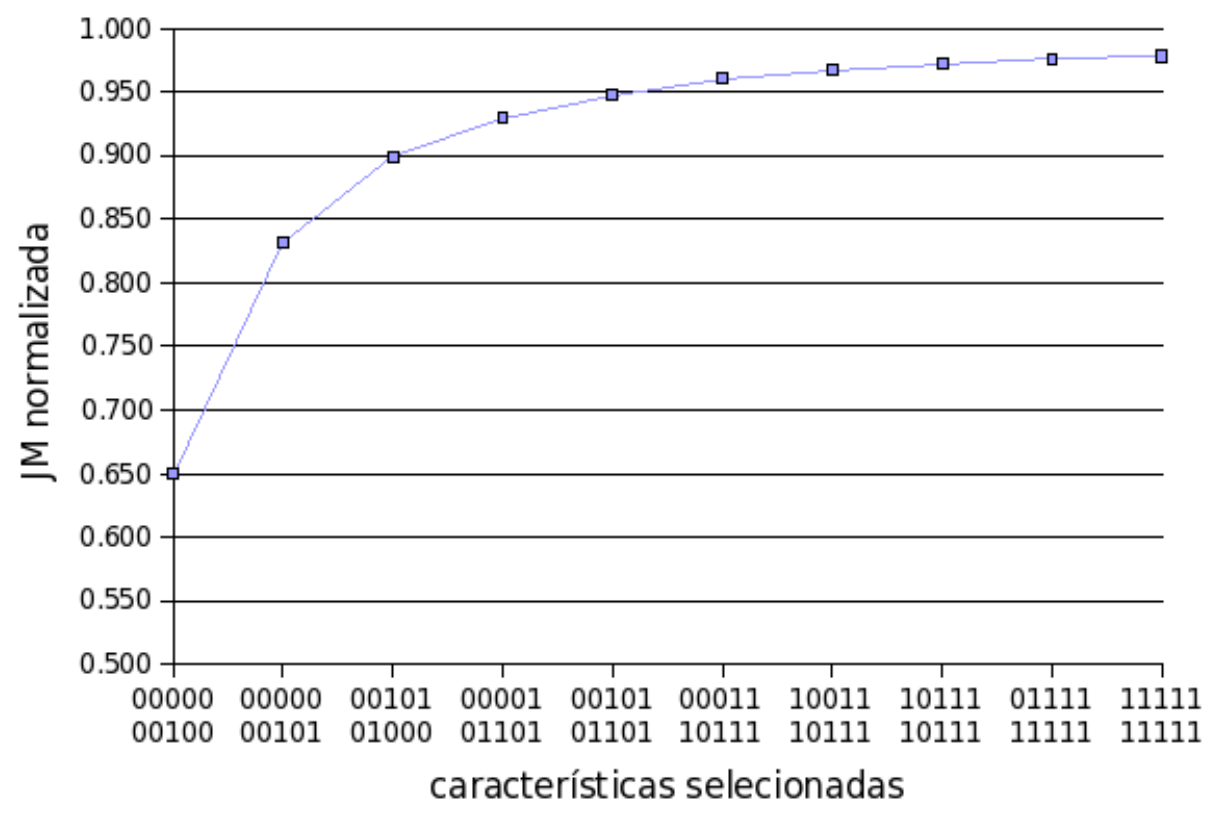

Figura 6.7: Influência da quantidade de características na distância de JeffreyMatusita: no eixo $x$, cada dígito representa uma das dez características de Run Lengths; $1=$ selecionada, $0=$ descartada.

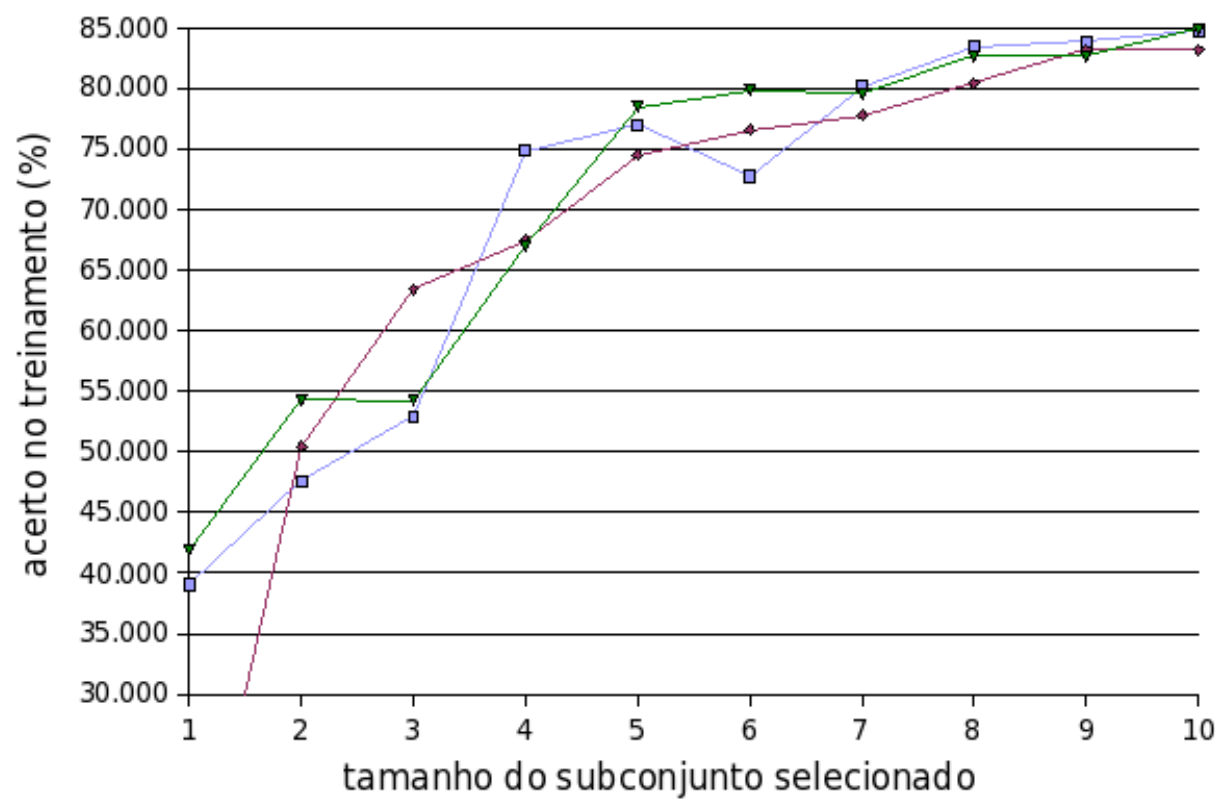

Figura 6.8: Influência da quantidade de características na taxa de acerto no treinamento: a variação entre as três execuções é devida à escolha de diferentes subconjuntos e condições iniciais das redes neurais.

tamanho de cada subconjunto. O treino da rede completa (com todas as características) durou aproximadamente $9400 \mathrm{~s}$ nos três casos e a busca/retreino parcial da rede para os subconjuntos durou entre 4800 e $6000 s$. 


\section{Observações}

Considerando a divergência de soluções e a demora dos processos, optou-se por reduzir as imagens de entrada para possibilitar a realização de uma quantidade de execuções (5) mais significativa estatisticamente. Outra decisão foi fixar o tamanho do subconjunto desejado com o intuito de simplificar a comparação entre os métodos. Isso foi feito observando-se em que ponto da curva o acréscimo de características passa a ser menos relevante. $\mathrm{Na}$ figura 6.8, por exemplo, esse ponto corresponde a cinco características.

\section{Decisões}

A busca exaustiva testou $2^{10}$ combinações de subconjuntos em $88 s$, ou seja, aproximadamente $0,14 \mathrm{~s}$ por teste. Para 71 características, fixando o tamanho do subconjunto em 5 , o total combinações seria de $\left(\begin{array}{c}71 \\ 5\end{array}\right)$, superior a $1,3.10^{7}$ e equivalendo a mais de 500 horas de busca. Para diminuir o tempo de processamento, o tamanho da amostra foi reduzido de 122.316 para 20.416 e o número de classes de 6 para 4. Como a abordagem heurística também esteve sujeita a essa escolha, a nova quantidade de padrões precisou respeitar o limite $^{8}$ de ser pelo menos cinco vezes superior ao total de parâmetros livres da rede neural. Esse limite $L$ foi calculado como segue:

$$
L=5\left(\left(N_{e}+1\right) N_{o}+\left(N_{o}+1\right) N_{s}\right)
$$

sendo $N_{e}$ o número de entradas, $N_{o}$ o número de neurônios ocultos e $N_{s}$ o número de neurônios de saída. Substituindo pelos valores adotados:

$$
\begin{gathered}
L=5((71+1) 5+(5+1) 4) \\
L=1920
\end{gathered}
$$

Como se pode notar, mesmo reduzido, o total de padrões de treinamento continuou plenamente satisfatório: $20.416>>1.290$.

Finalmente, dois classificadores diferentes (um simples e um complexo) são usados visando a comparação dos efeitos do subconjunto selecionado sobre os mesmos: classificador de distância mínima e MLP.

\subsubsection{Aplicação}

Para avaliar a aplicabilidade do método de seleção baseado em saliência, três imagens de cenas naturais foram obtidas em repositório na internet (WANG, 2003). De cada imagem foram selecionadas pequenas regiões para representar as classes e compor o conjunto de

\footnotetext{
${ }^{8}$ citado no capítulo 3
} 
treinamento. O resultado das segmentações e mais detalhes são apresentados no capítulo 7.

\subsection{DMET - Descarte de métodos de extração de tex- tura}

O esquema do sistema que descarta métodos tradicionais de textura é apresentado na figura 6.9. Na figura 6.9.a é possível ver que cada janela extraída contém 169 píxeis.

\section{a)}

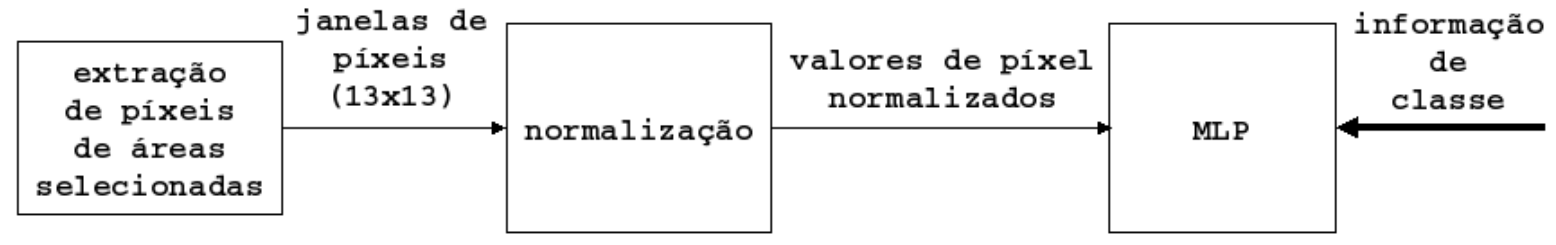

\section{b)}

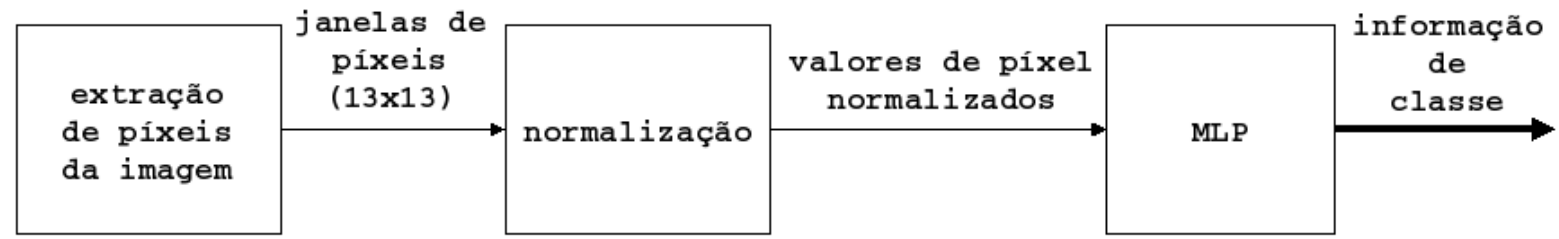

Figura 6.9: DMET: a) treinamento; b) segmentação.

Eles são normalizados para o intervalo [0;1] e apresentados às 169 entradas do MLP. O treinamento é realizado com todas as janelas até que o treinamento atinja o critério de parada (1000 ciclos sem redução de $1 \%$ no erro). A janela é uma região quadrada de lado 13 centrada no ponto de interesse. O ponto de interesse é a posição do píxel que está sob treinamento ou classificação. Dessa foram, o único parâmetro que precisou ser ajustado foi o tamanho da janela de píxeis, o que depende basicamente da granularidade da textura e da resolução da imagem. O tamanho da janela afeta, evidentemente, o tempo de processamento e a taxa de acerto do sistema.

As texturas utilizadas foram as mesmas dos testes preliminares da seção 6.2.3.

Para comparação foram treinados outros dois MLPs (camada oculta de tamanho 5) com diferentes entradas: matrizes de coocorrência (44 entradas); e estatísticas de primeira ordem (2 entradas). A comparação com as estatísticas de primeira ordem é importante para assegurar-se de quão complexa é a segmentação. 


\subsection{Equalização da entrada}

A equalização proposta consiste em transformar os dados de forma que todas as características passem a ter a mesma média $(0,5)$ e sejam alterados em escala para otimizar a ocupação do intervalo [0;1]. Trata-se de uma combinação das técnicas centering e scaling - normalmente usadas para acelerar o treinamento de MLPs (MASTERS, 1994). Dessa forma, os novos valores $v(1)$ de cada classe foram deslocados segundo a seguinte fórmula:

$$
\begin{gathered}
v(1)=\frac{v(0)-\mu}{2 m}+0,5 \\
m=\left\{\begin{array}{l}
|\min -\mu|, \text { se }|\min -\mu|>|\max -\mu|, \\
|\max -\mu|, \text { se }|\max -\mu|>|\min -\mu| .
\end{array}\right.
\end{gathered}
$$

onde $v(0)$ é o valor original e $\mu, \max$ e min são a média e os valores máximo e mínimo da característica em questão, respectivamente. Essa normalização especial foi denominada neste trabalho de equalização da entrada e é referenciada abreviadamente por EE. Essa técnica é avaliada e validada nas seções 7.1.1 e 7.1.1.

\subsection{Considerações}

A metodologia foi definida de forma a maximizar o proveito dos algoritmos implementados, levando-se em conta as limitações computacionais e de cronograma. A maior parte dos experimentos diz respeito ao CMET, especialmente quanto à avaliação da SS e das variações propostas. As seguintes etapas foram definidas para constituir a parte experimental deste trabalho:

- confirmação da influência da compensação de sinal sobre a saliência;

- definição e validação de uma forma de atenuação do efeito da compensação de sinal;

- determinação de um tamanho fixo para o subconjunto de características;

- seleção do melhor subconjunto para o problema dimensionado pelos três métodos: SJM, SS e SSOC;

- comparação de desempenho dos três subconjuntos;

- avaliação da qualidade dos subconjuntos por meio do classificador de distância mínima;

- aplicação da SS em cenas naturais;

- teste do DMET. 
Os resultados de tais experimentos e respectiva discussão são apresentados no próximo capítulo. 


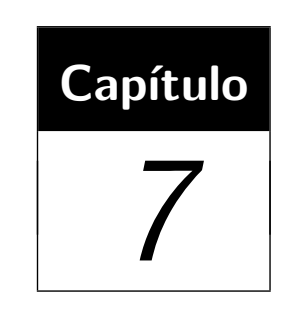

\section{Resultados e discussão}

Este capítulo apresenta, primeiramente, a investigação a respeito dos efeitos da compensação de sinal sobre a saliência e a respectiva solução ideal encontrada denominada de equalização da entrada ou EE. É também justificada a escolha do tamanho final desejado para o subconjunto de características.

Posteriormente, é feita uma seleção do melhor subconjunto por SS e, para comparação, são selecionados também os melhores subconjuntos segundo a SJM e a alteração SSOC do método proposto. Para averiguar a importância da EE, é encontrado também o melhor subconjunto da SS sem a EE. Todas as abordagens são comparadas em termos de acerto na classificação e custo computacional. A quantidade de píxeis cuja classe foi indicada corretamente pelo classificador dividida pelo total de píxeis é taxa de acerto utilizada. A taxa de erro é calculada com total restante de píxeis.

Com um classificador de distância mínima foi avaliado qual subconjunto, da SS ou SJM, obteve maior ganho de desempenho frente ao conjunto original de características. Finalmente, a SS é usada para segmentar fotos do mundo real e avaliada qualitativamente pela inspeção visual das imagens resultantes.

Todos os experimentos acima citados são aplicados ao problema dimensionado. Em seguida, o método de SS é aplicado a imagens de cenas naturais.

Adicionalmente, é apresentado o resultado da segmentação segundo o esquema DMET. Em todos os experimentos, o critério para determinar qual classe é indicada nas saídas do MLP, foi o neurônio com valor acima de 0,5. Caso houvesse mais de uma saída nesse estado ou nenhuma, então a classe era considerada desconhecida.

Os tempos de processamento são sempre dados em segundos de ocupação do processador, ou seja, processos em paralelo têm seus tempos somados. 


\subsection{CMET: Problema dimensionado}

O problema dimensionado e os experimentos relacionados foram planejados conforme as decisões baseadas nos testes preliminares citados no capítulo 6. Antes da apresentação dos resultados, segue a investigação a respeito da compensação de sinal.

\subsubsection{Efeito da compensação de sinal}

Todos os experimentos preliminares resultaram, após a estabilização da curva de erro, na mesma disposição de curvas da figura 7.1. Uma das curvas corresponde aos valores de saliência obtidos para cada característica. A outra contém o valor médio de cada característica no treinamento ${ }^{1}$. É possível notar certa correlação inversa entre as curvas, a qual se deve à compensação de sinal realizada pelo MLP. Se duas entradas têm o mesmo grau de importância na tarefa de discriminação de classes, mas uma delas tem um valor médio menor, a camada de entrada se adapta durante o treinamento para fazer a compensação. Assim, os pesos conectados às entradas "mais fracas" passam a ter valores mais altos do que teriam se não houvesse discrepância nos valores médios. Essa mudança afeta diretamente a saliência, conforme mostra a fórmula no tópico 5.1.2. A seguir será melhor averiguada a influência da compensação de sinal nas medidas de saliência e demonstrado o resultado da aplicação da equalização da entrada para neutralizá-la.

\section{Avaliação}

Para que todas as características passassem a ter a mesma média $(0,5)$, foi aplicada a de equalização da entrada (seção 6.4). Com o intuito de avaliar o efeito dos valores médios isoladamente, isto é, sem a influência de qualquer distribuição específica, uma MLP foi treinada com 100 características (e 7 saídas aleatórias) cujas médias fossem proporcionais aos números das características. Naturalmente, a curva das médias passaria a ser uma reta e a curva da saliência baseada nas características transformadas se tornaria, esperava-se, mais independente. Isso se confirmou, conforme ilustrado na figura 7.2, onde é possível também comparar as medidas de saliência antes e depois da equalização.

\section{Validação da técnica de equalização da entrada}

A MLP foi retreinada com todas as características de textura, produzindo o resultado mostrado na figura 7.3. Pode-se notar que a baixa correlação entre a média original e a nova saliência indica que realmente havia uma influência e, dependendo da situação, poderia alterar o resultado da seleção do subconjunto de entradas.

\footnotetext{
${ }^{1}$ no caso da figura 7.1, o conjunto de treinamento foi o mesmo dos experimentos preliminares citados no capítulo 6
} 


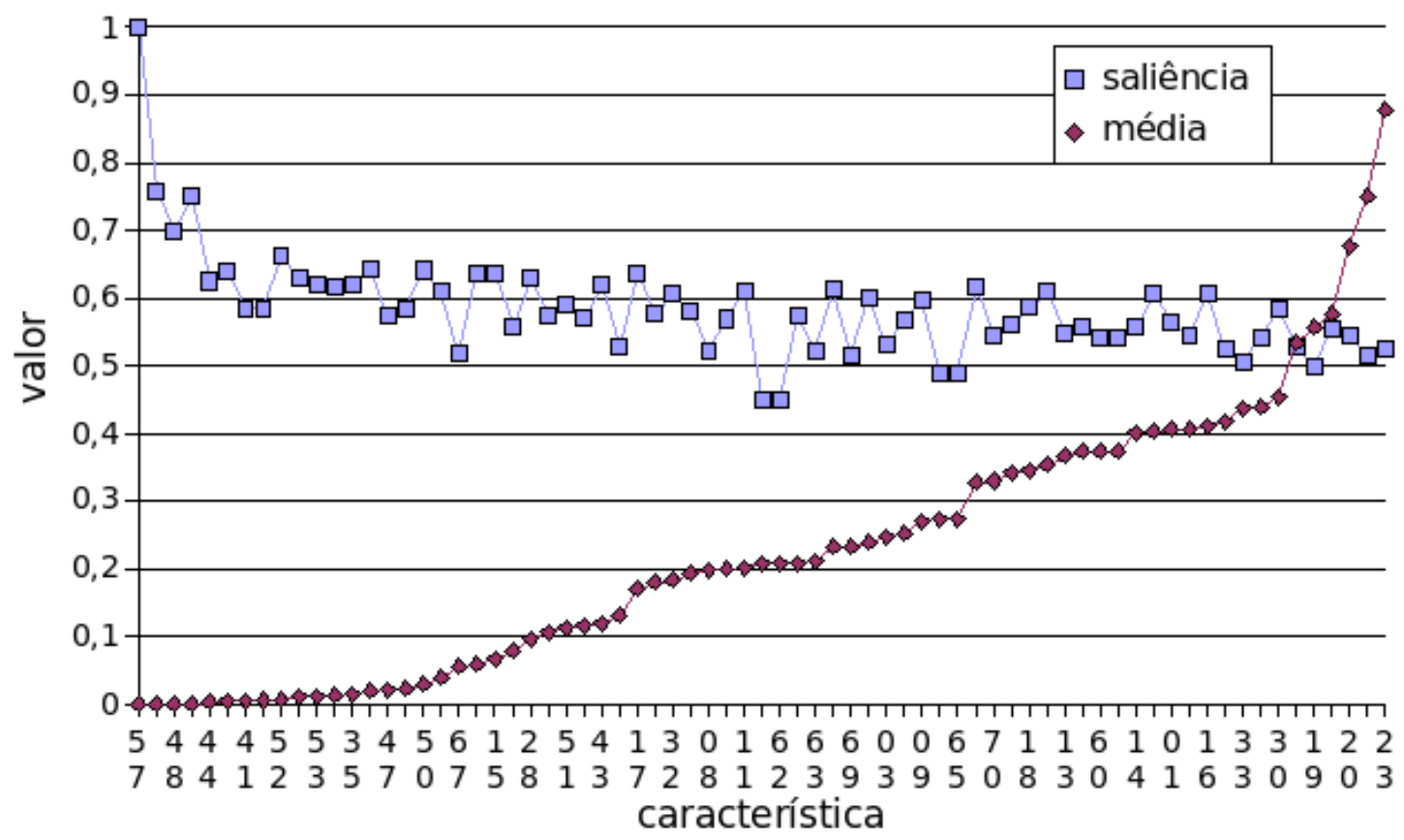

Figura 7.1: Influência da entrada média sobre a saliência: correlação de $-0,22$ (amostra de 122.316 píxeis). O número da característica está escrito na vertical.

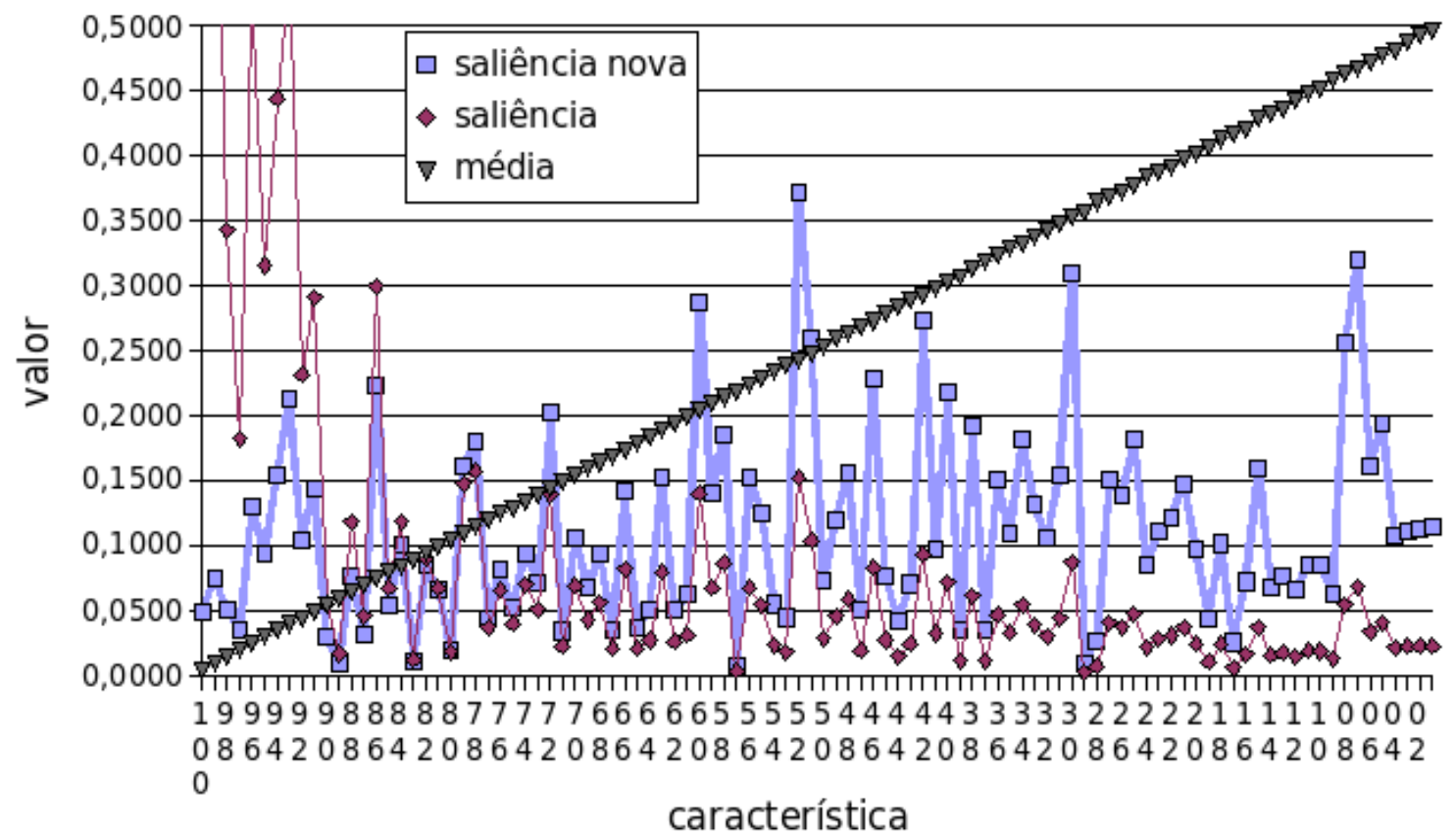

Figura 7.2: Nova saliência comparada com a original (dados sintéticos): a correlação com a média, originalmente de $-0,54$, passou a 0,19 com a equalização (amostra de tamanho 30.624).

Além de possibilitar a obtenção de medidas de saliência mais puras, a equalização faz com que as características passem a aproveitar melhor seu intervalo válido, facilitando os sucessivos treinamentos da rede. Uma desvantagem é que a equalização é especifica 


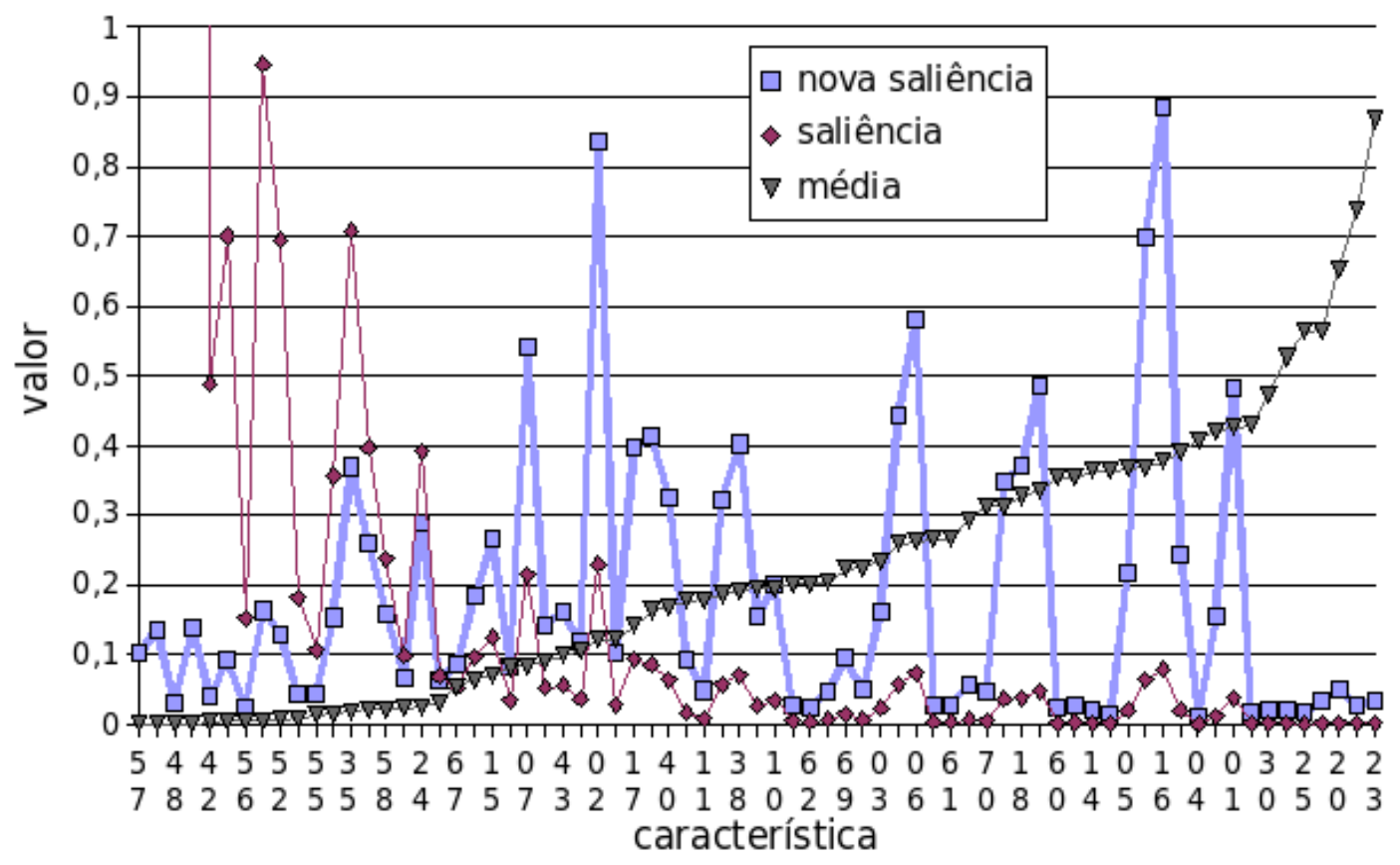

Figura 7.3: Nova saliência comparada com a original (dados de textura): a correlação com a média, originalmente de $-0,22$, passou a 0,06 com a equalização (amostra de tamanho 30.624).

para os dados de treinamento, o que descaracteriza os valores em relação ao conjunto de teste. Assim, os pesos obtidos com o processo de seleção devem ser descartados. Logo, o resultado final do processo passa a ser somente a indicação das melhores características, restando a tarefa de um novo treinamento para um classificador à parte. Essa desvantagem pode ser contornada se os parâmetros da equalização forem armazenados e sempre aplicados aos novos dados.

\subsubsection{Tamanho do subconjunto}

Levando em conta as ponderações do capítulo 6 quanto à quantidade de permutações possíveis para um subconjunto com 5 características e a constatação, como se pode verificar nos experimentos que se seguem, que com 4 características já é possível atingir um erro de treinamento acima de $95 \%$, o tamanho do subconjunto foi assim fixado, ou seja, foram necessárias $\left(\begin{array}{c}71 \\ 4\end{array}\right)=97.163$ combinações para a busca exaustiva.

\subsubsection{Origem dos dados}

Uma amostra de 1.607.824 padrões foi usada para gerar os conjuntos de treinamento e de teste. Ela é proveniente de quatro imagens originais inteiras do álbum de Brodatz concatenadas conforme dispõe a figura 7.4. Dessa forma, o conjunto de teste é 52 vezes maior que o conjunto de treinamento, o que exige uma forte capacidade de generalização 
por parte do classificador.

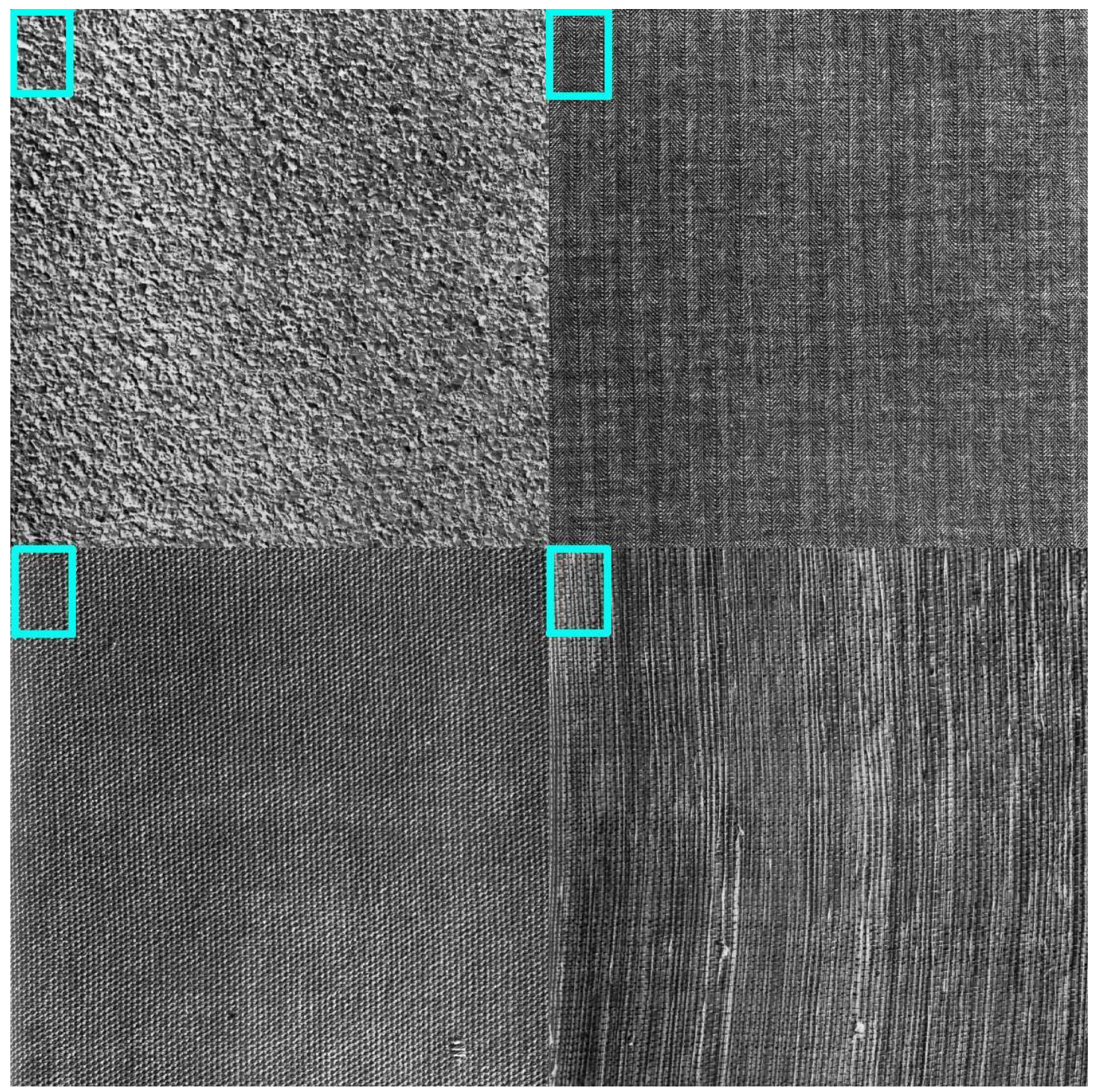

Figura 7.4: Conjunto de teste do experimento controlado: quatro imagens originais inteiras do álbum de Brodatz concatenadas (amostra de tamanho 1.607.824), os retângulos indicam as áreas usadas para treinamento (amostra de tamanho 20.416).

\subsubsection{SJM - seleção ótima segundo a distância de Jeffrey- Matusita}

A SJM apontou as características 10, 12, 19 e 22 como o melhor subconjunto. Ou seja, parte dos métodos Run Length, Matrizes de Coocorrência e o desvio padrão dos valores dos píxeis foi usada na constituição do melhor conjunto de características. O valor obtido da distância JM normalizada foi 0,983772 e foi calculado em 8.857s. Foram descartadas as combinações que envolviam matrizes com determinante zero (conforme especificado 
no capítulo 6). É possível comparar a evolução da distância JM com o aumento do tamanho do subconjunto (figura 7.5). A seleção de quantidades maiores de características inviabilizaria o cálculo.

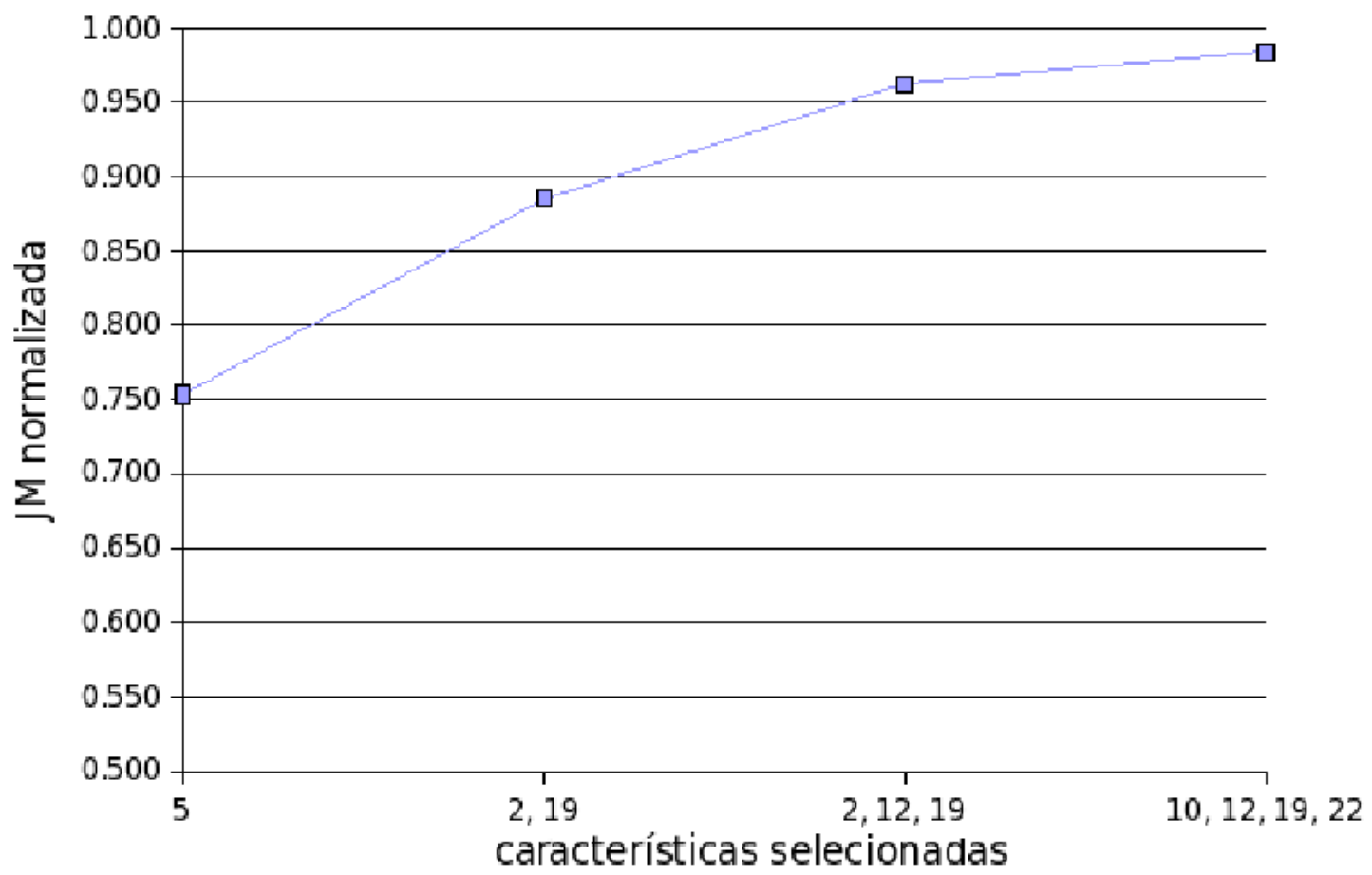

Figura 7.5: Distâncias de Jeffrey-Matusita: até quatro características, o método é viável computacionalmente (amostra de tamanho 30.624).

\subsubsection{SS - Seleção do subconjunto por saliência}

Foram treinadas 5 redes MLP inicialmente com todas as características de textura. $\mathrm{Na}$ medida em que o erro de treinamento estabilizava conforme o critério citado no capítulo 6 , a característica de saliência mais baixa era removida. Quando o tamanho do subconjunto restante atingia 4 características, o processo era interrompido.

A melhor das execuções obteve uma taxa de acerto de treinamento de 98,0\%. Ela resultou nas características: 12, 16, 36 e 52 (desvio padrão dos valores dos píxeis e Matrizes de Coocorrência).

\subsubsection{SS sem EE - Seleção do subconjunto por saliência sem equalização da entrada}

A SS sem EE foi executada 5 vezes. O subconjunto com melhor acerto foi escolhido e atingiu $70,8 \%$ de erro de treinamento. O subconjunto escolhido foi: 37, 48, 52 e 57 (apenas Matrizes de Coocorrência). 


\subsubsection{SSOC - Seleção do subconjunto por saliência em apenas uma iteração}

Como há uma informação de saliência disponível para cada característica logo na primeira iteração, optou-se por realizar um experimento aproveitando essa possibilidade de reduzir drasticamente a ordem de complexidade da SS. A SSOC consistiu apenas em escolher as quatro características mais salientes após a primeira iteração.

Na primeira iteração, todas as características estão presentes. Isso explica o fato de que todas as taxas de acerto na seleção foram 100\%. Assim, o critério para escolher o melhor subconjunto, dentre os resultados de 5 execuções, foi realizar um treinamento para cada uma delas e escolher o subconjunto que atingisse o menor erro de treinamento (96,0\%). Esse treinamento é equivalente à última iteração do processo de seleção do experimento da seção 7.1.5.

O seguinte subconjunto foi selecionado: 7, 19, 20 e 52 (Run Length e Matrizes de Coocorrência).

\subsubsection{Comparação das abordagens}

O mesmo conjunto de dados da etapa de seleção de características foi usado para treinamento $^{2}$ de cada um dos subconjuntos selecionados: SJM, SS, SS sem EE e SSOC.

Independentemente da abordagem, o tempo médio de treinamento do MLP foi de $922 \mathrm{~s}$ (desvio padrão de 1.776) e o tempo de segmentação foi, em média, 4, $6 s$ (desvio padrão de $0,07 s)$. A extração das características de textura consumiu $17 \mathrm{~s}$ para o conjunto de treinamento, enquanto que para o conjunto de teste ela consumiu $840 \mathrm{~s}$. Na figura 7.6 é apresentado o resultado da segmentação baseada na SS.

Na tabela 7.1 são indicadas as taxas de acerto e os tempos das quatro abordagens. $\mathrm{O}$ tempo total é a soma de todas as cinco seleções usadas na escolha do melhor subconjunto.

\begin{tabular}{|l|l|l|l|l|}
\hline método & SJM & SS & SS sem EE & SSOC \\
\hline \% acerto & $86,2(0,57)$ & $86,6(0,64)$ & $71,0(1,69)$ & $86,4(0,61)$ \\
\hline tempo de seleção & 8.857 & $16.548(3.672)$ & $18.882(3.641)$ & $2.052(348)$ \\
\hline tempo total & 8.857 & 82.740 & 94.410 & 10.260 \\
\hline memória utilizada & $1.6 \mathrm{~GB}$ & $624 \mathrm{MB}$ & $624 \mathrm{MB}$ & $624 \mathrm{MB}$ \\
\hline
\end{tabular}

Tabela 7.1: Comparação das abordagens: acerto para o conjunto de treinamento, tempo consumido com a seleção e memória utilizada. O desvio padrão é dado entre parêntesis e o tempo é dado em segundos.

Claramente, SSOC apresenta-se como a melhor alternativa dentre os métodos baseados em saliência para a imagem e o classificador usados, pois apresenta uma taxa de

\footnotetext{
2a interrupção do treinamento foi alterada para ocorrer depois de 1000 ciclos sem redução de pelo menos $1 \%$ na soma de erros quadráticos
} 


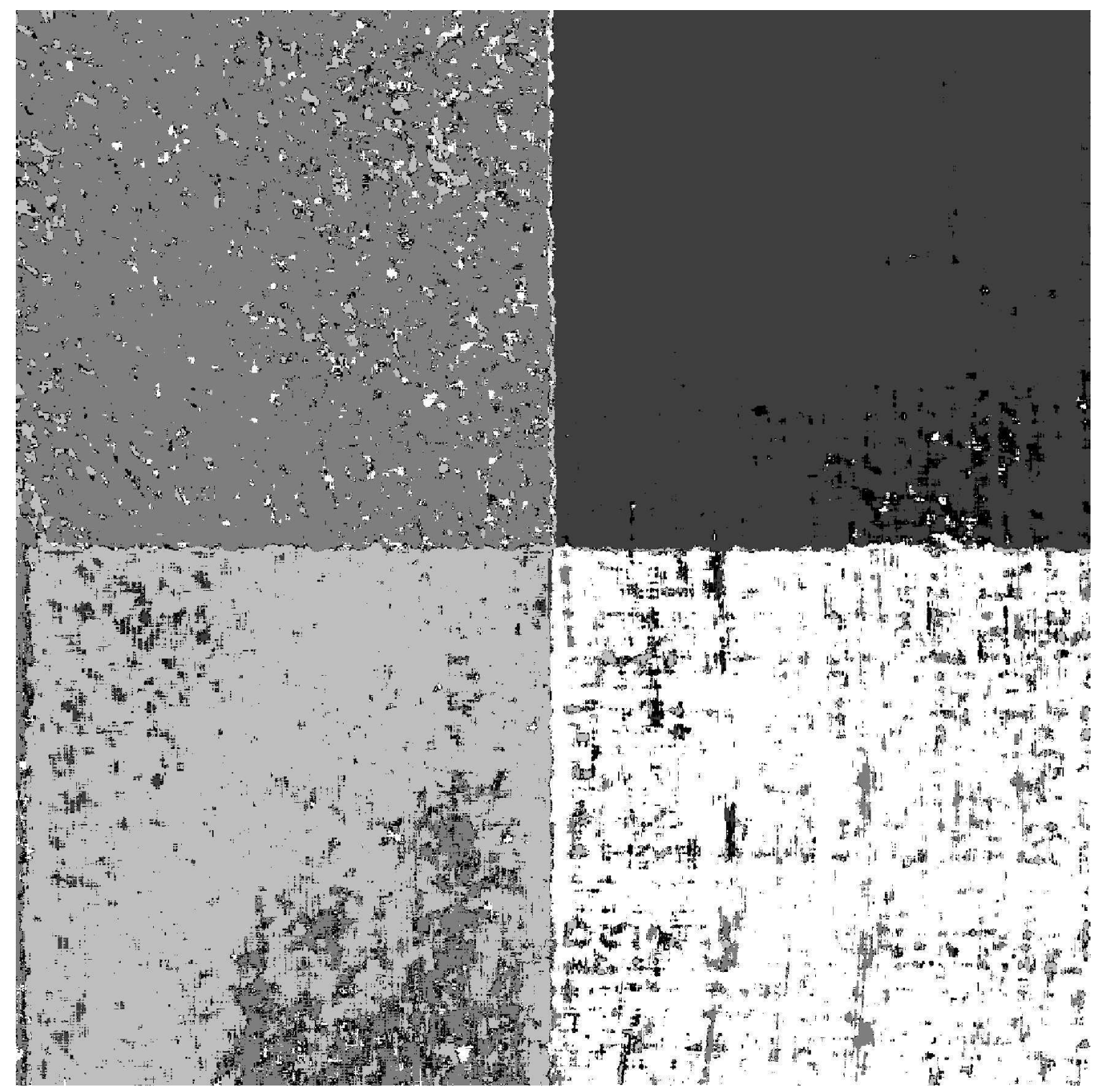

Figura 7.6: Segmentação para o problema dimensionado: resultado da melhor das execuções baseada na SS.

acerto muito próxima da melhor e tem um tempo de seleção bastante inferior aos outros de seleção por saliência. Na comparação com a SJM, o acréscimo de apenas uma característica ao tamanho do subconjunto desejado tornaria a SJM inviável para a busca exaustiva. O acréscimo de uma ou duas dezenas no tamanho do subconjunto tornaria a SJM inviável para o branch and bound. Enquanto que, para a SSOC, o custo computacional permaneceria o mesmo. Para a SS vale quase a mesma regra, a diferença é que cada característica a mais no subconjunto implica em uma iteração a menos na seleção.

Os tempos poderiam ser reduzidos optando-se por menos execuções ou antecipando-se a interrupção do treinamento que ocorre em cada iteração do processo de seleção. O critério de parada adotado neste trabalho é certamente conservador, pois a SSE (sum of squared errors, mencionada no capítulo 3) atingia sempre valores próximos de $10^{-31}$, 
quando, na realidade, uma SSE de 1, 0 era suficiente para classificar corretamente 99, 995\% dos padrões. É possível que um melhor critério de parada seja obtido usando o erro de classificação e não a SSE. Outra forma de se reduzir o tempo é aproveitar os valores dos pesos do MLP seletor para servirem de valor inicial dos pesos do MLP classificador. Isso reduz o tempo de treinamento do clasificador, o que somente não é possível com SJM, dentre os métodos em questão.

Pode-se também notar que a EE, usada tanto na SS quanto na SSOC, contribui consideravelmente com a taxa de acerto do sistema.

Os resultados foram muito parecidos. Isso é conseqüência da alta capacidade de generalização do MLP e também em sua vocação em encontrar relações complexas nos dados. Para avaliar mais a qualidade da seleção do que a complexidade do classificador, foi empreendido um experimento adicional.

\subsubsection{Avaliação da qualidade das características por meio do classificador de distância minima}

Uma regra geralmente válida no reconhecimento de padrões é que quanto melhores forem as características, mais simples pode ser o classificador. Partindo dessa premissa foram realizadas quatro execuções nos mesmos moldes da seção 7.1.8, exceto pela substituição do MLP por um classificador de distância mínima. A primeira foi realizada com a SJM, a segunda com a SS, a terceira com a SSOC e a quarta com todas as características (tabela $7.2)$.

\begin{tabular}{|l|l|l|l|l|}
\hline método & SJM & SS & SSOC & conjunto completo \\
\hline \% acerto (treinamento) & 82,0 & 90,6 & 86,6 & 91,2 \\
\hline \% acerto (teste) & 70,0 & 86,7 & 75,3 & 25,1 \\
\hline
\end{tabular}

Tabela 7.2: Comparação das abordagens com classificador de distância minima: taxas de acerto para treinamento e teste. Não há desvio padrão por ser um processo determinístico.

Pode-se notar que o melhor subconjunto segundo a lógica da simplicidade do classificador é o da SS. A taxa de acerto se equiparou à taxa média de acerto obtida com um classificador MLP. Outro dado importante é a taxa de acerto do classificador de distância mínima quando todas as características estavam presentes, que é muito próxima da classificação aleatória dos padrões (25\%). Esse resultado extremo indica o quão prejudicial pode ser a presença de características ruins, ou mesmo da alta dimensionalidade, e reforça a necessidade da etapa de seleção de características num sistema de reconhecimento de padrões. 


\subsubsection{Exemplo de seleção de características sem redução da taxa de acerto}

Foi realizada outra seleção de características para demonstrar um caso sem aumento no erro de classificação. Foi ponderado que uma redução significativa na quantidade de características possivelmente não impactaria negativamente na taxa de acerto quando comparada com todas as 71 entradas presentes. Cinco execuções foram feitas com todas as características e cinco execuções foram feitas sem as 29 primeiras características descartadas pela SS. A escolha do tamanho do subconjunto foi arbitrária, pois é apenas para fins ilustrativos. A taxa de acerto no treinamento, em ambos os casos, foi de 100,0\%. No primeiro caso, a taxa de acerto no teste foi de $95,8 \%$ (desvio padrão de 0,4 ) e, no segundo caso, 95,7\% (desvio padrão de 0,6). Assim, o experimento confirmou o que se supôs: mesmo uma redução de $40 \%$ no total das características não teve impacto negativo significativo na classificação.

\subsection{CMET: Aplicação}

Foram realizados testes com fotos de paisagens praianas, seguindo a mesma estrutura do experimento controlado, exceto pelas seguintes mudanças (adotadas para aproveitar o menor custo computacional apresentado pelos novos problemas): treinamento mais prolongado na etapa de seleção, com encerramento depois de 1000 ciclos sem redução de pelo menos $1 \%$ na soma de erros quadráticos para as duas primeiras imagens; encerramento depois de 10 ciclos na etapa de treinamento das duas últimas imagens; camada oculta de tamanho 10, 20, 2 e 2 para a etapa de treinamento, respectivamente, da primeira, primeira com mais classes, segunda e terceira imagens.

O tempo de extração das características para o teste se manteve constante em todos os casos e foi de 50s. De cada imagem foram extraídas regiões retangulares que correspondem às classes de interesse, por exemplo, água, areia e céu. Dessas áreas foi coletada a amostra que constituiu o conjunto de treinamento. Os píxeis restantes cumpriram o papel do conjunto de teste, pois não foram usados nem no treinamento, nem na seleção de características. Na etapa de seleção escolheu-se, de três execuções, o subconjunto de menor tamanho com erro de treinamento inferior a $2 \%$ (escolhido por ser uma taxa bastante superior àquelas atingidas na tabela 7.2, porém ainda suficientemente inferiores a $100 \%$ de forma que uma quantidade considerável de características pudessem ser descartadas). Logo, o tamanho do subconjunto variou de experimento para experimento. 


\subsubsection{Cena natural 1}

O primeiro teste foi feito com uma imagem com texturas e níveis de cinza próximos e considerando-se apenas duas classes, como se pode notar na figura 7.7.

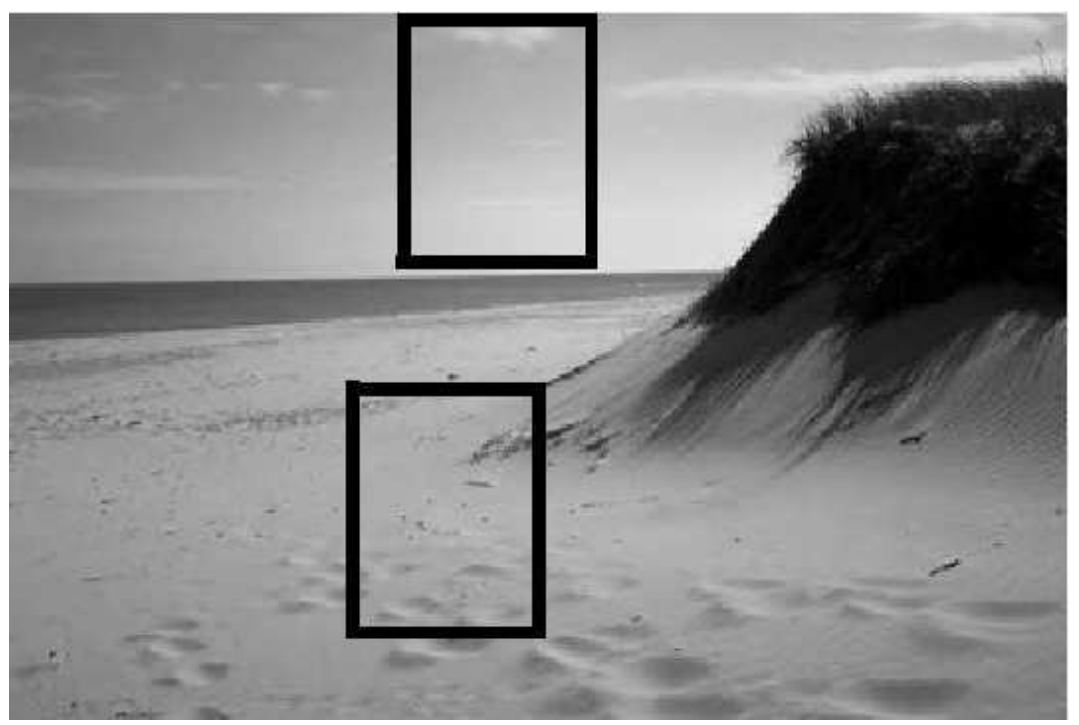

Figura 7.7: Cena natural 1: os retângulos indicam as duas regiões tomadas para treinamento (amostra de 8.512 píxeis).

Excetuando-se o fato de que o morro e o mar foram classificados como areia, enquanto que o ideal seria como classe desconhecida (cor preta), a segmentação pode ser considerada satisfatória, dada a dificuldade da cena. O subconjunto selecionado foi de tamanho sete: 13, 14, 18, 47, 69, 70 e 71; abrangendo estatísticas de primeira ordem, Matrizes de Coocorrência e transformada de Fourier bidimensional. Na figura 7.8 é apresentada a segmentação resultante.

Mais classes foram adicionadas ao treinamento (figura 7.9), cujo resultado é apresentado na figura 7.10. As características selecionadas foram: 11 e 13 (média e mediana dos píxeis).

Mais dois testes foram feitos com outras duas imagens: cenas naturais 2 e 3 .

\subsubsection{Cena natural 2}

Na figura 7.11 é apresentada a imagem original em tons de cinza, cuja segmentação é mostrada na figura 7.12. As características selecionadas foram: 11 e 13 (média e mediana dos píxeis).

\subsubsection{Cena natural 3}

No último teste foi usada a imagem ilustrada na figura 7.13. Ele apresentou o resultado exibido na figura 7.14. As características selecionadas foram 12 e 18 (desvio padrão 


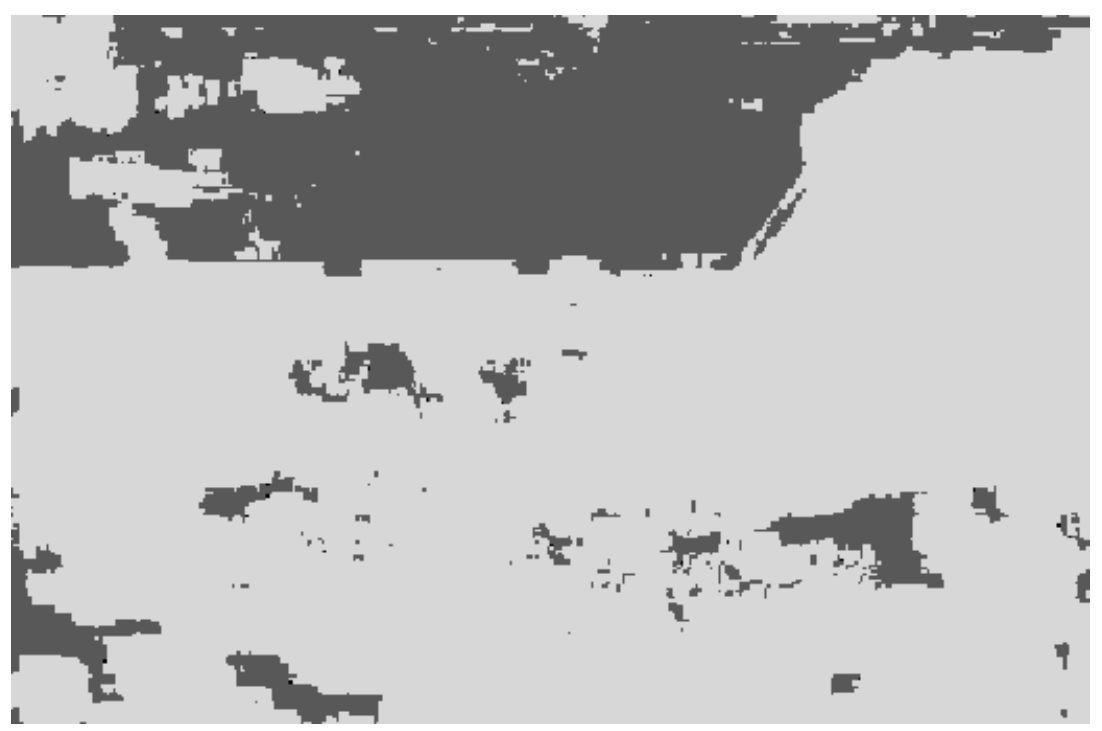

Figura 7.8: Cena natural 1 segmentada: cada nível de cinza representa uma classe.

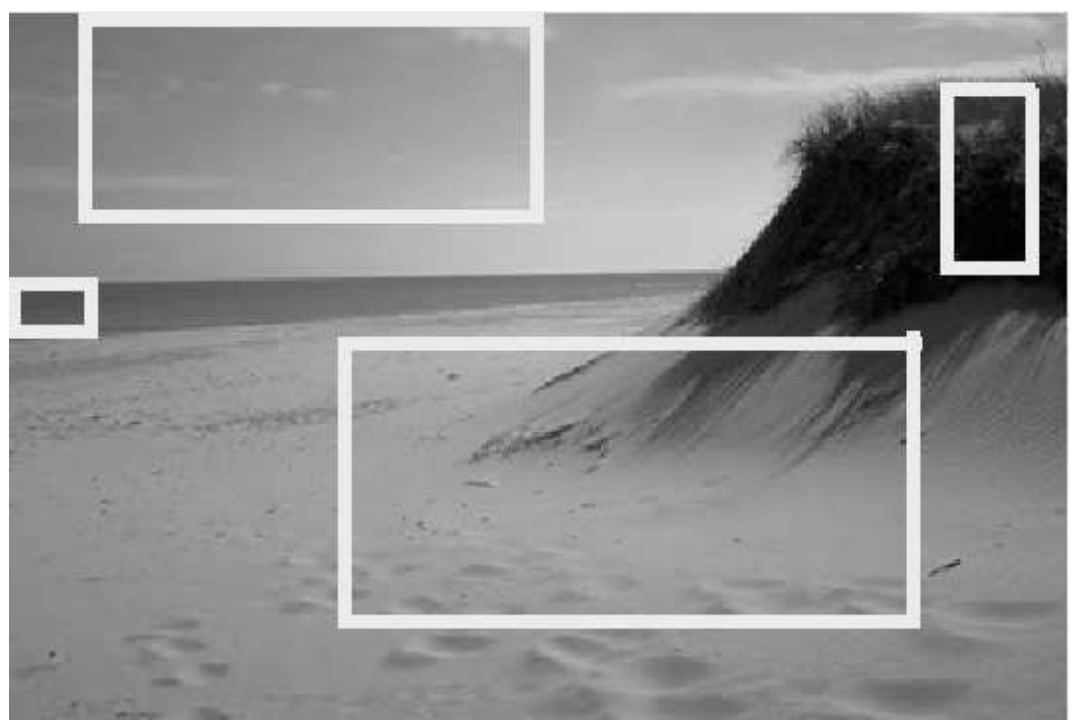

Figura 7.9: Cena natural 1 com mais classes: os retângulos indicam as áreas tomadas para treinamento (amostra de 30.800 píxeis).

dos píxeis e a média da característica variance das Matrizes de Coocorrência para o comprimento 2).

Os tempos de seleção, treinamento e segmentação são apresentados na tabela 7.3

Pode-se notar que o tempo de treinamento dos dois últimos testes foi bastante inferior aos demais. Essa diferença e mesmo a topologia de apenas 2 neurônios na camada oculta indicam que se tratam de problemas mais simples. O predomínio de estatísticas de primeira ordem nos subconjuntos finais e também o pequeno número de características selecionadas corroboram essa hipótese. É possível, por inspeção visual observar que o nível de cinza das regiões de interesse é, em grande parte, determinante. 


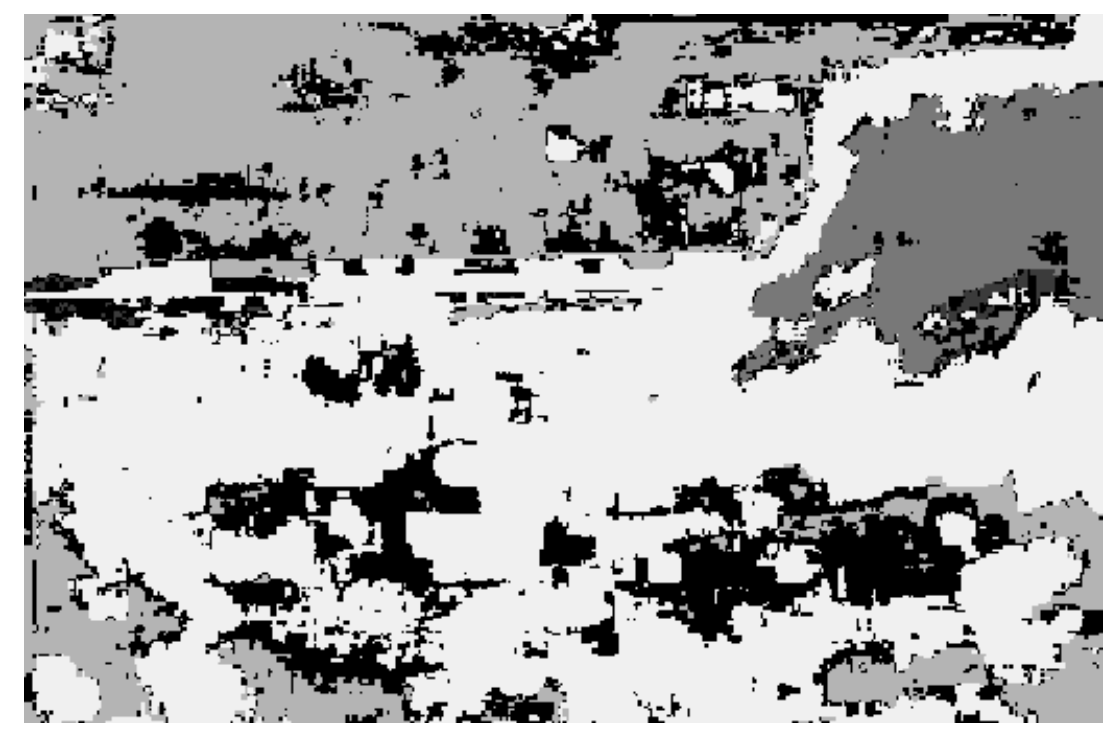

Figura 7.10: Cena natural 1 segmentada em quatro classes: cada nível de cinza representa uma classe, a cor preta indica classe desconhecida.

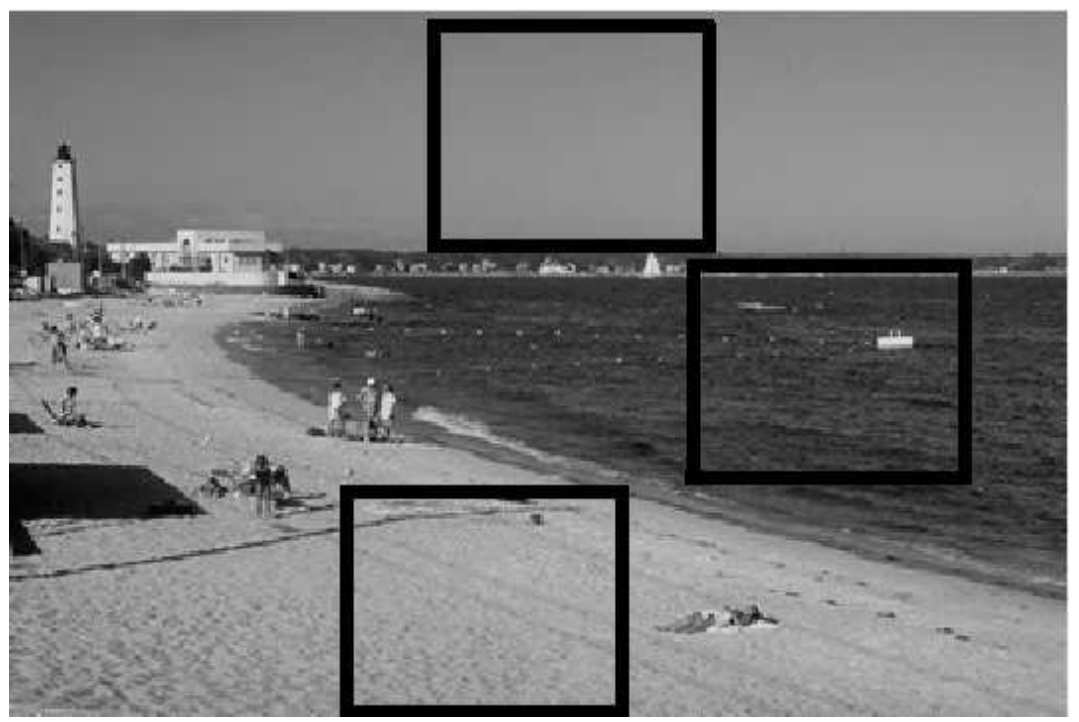

Figura 7.11: Cena natural 2: os retângulos indicam as áreas tomadas para treinamento (amostra de 17.952 píxeis).

\begin{tabular}{|l|l|l|l|l|}
\hline número da cena natural & $\mathbf{1}$ & $\mathbf{1}$ com mais classes & $\mathbf{2}$ & $\mathbf{3}$ \\
\hline tempo de seleção & 70.200 & 70.200 & 120.000 & 9.180 \\
\hline tempo de treinamento & 3.500 & 4.260 & 84 & 26 \\
\hline tempo de segmentação & 0,39 & 0,75 & 0,16 & 0,16 \\
\hline
\end{tabular}

Tabela 7.3: Comparação dos resultados para as diferentes imagens: os tempos são dados em segundos. O tempo de seleção é a soma das três execuções.

Pode-se concluir que a SS também identifica o total de características necessárias, dependendo da complexidade do problema. 


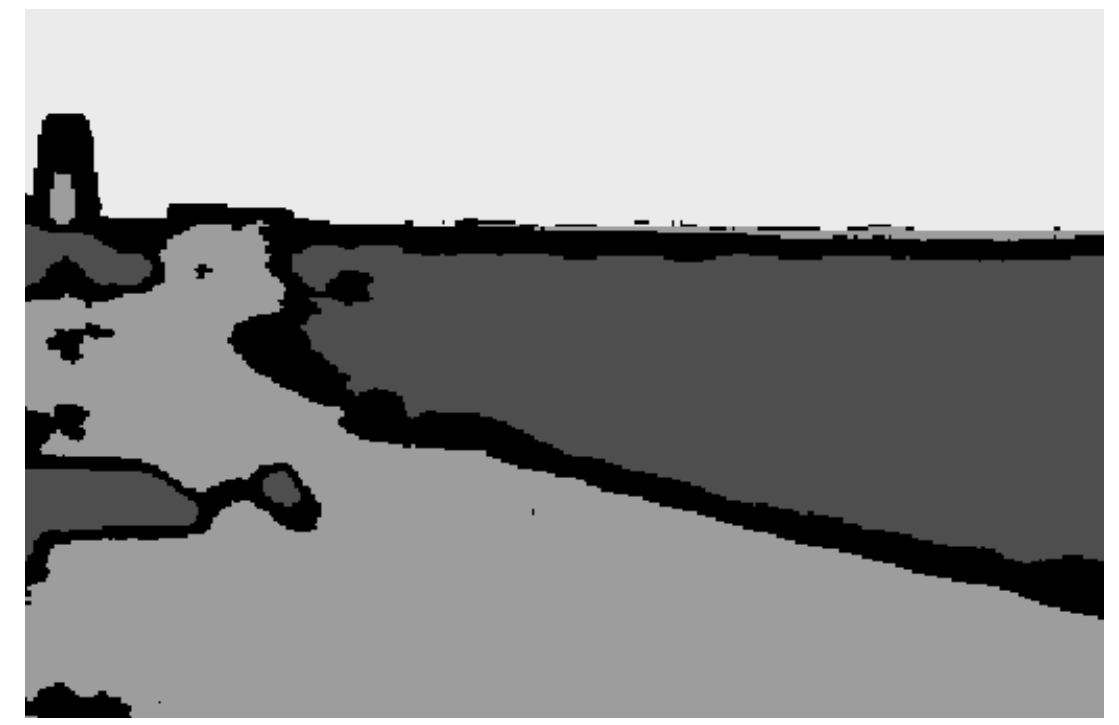

Figura 7.12: Cena natural 2 segmentada: cada nível de cinza representa uma classe, a cor preta indica classe desconhecida.

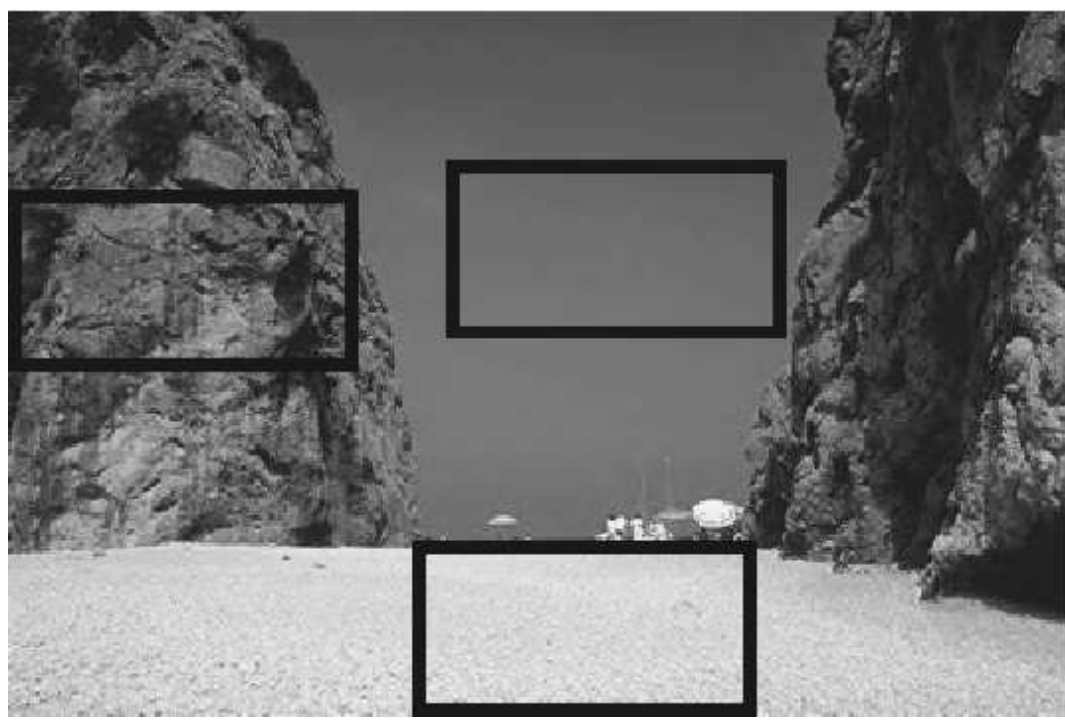

Figura 7.13: Cena natural 3: os retângulos indicam as áreas tomadas para treinamento (amostra de 15.552 píxeis).

\subsection{DMET - descarte de métodos de extração de tex- tura}

Para comprovar a capacidade do MLP de lidar diretamente com a textura sem tratamentos prévios (SANTOS, 2006), foi criado um mosaico apresentado na figura 7.15.e cujas áreas de treinamento são demarcadas na figura 7.15.a. Um classificador MLP foi treinado com estatísticas de primeira ordem e outro com Matrizes de Coocorrência para fins de comparação. Na figura 7.15.d, a segmentação por estatísticas de primeira ordem tem o 


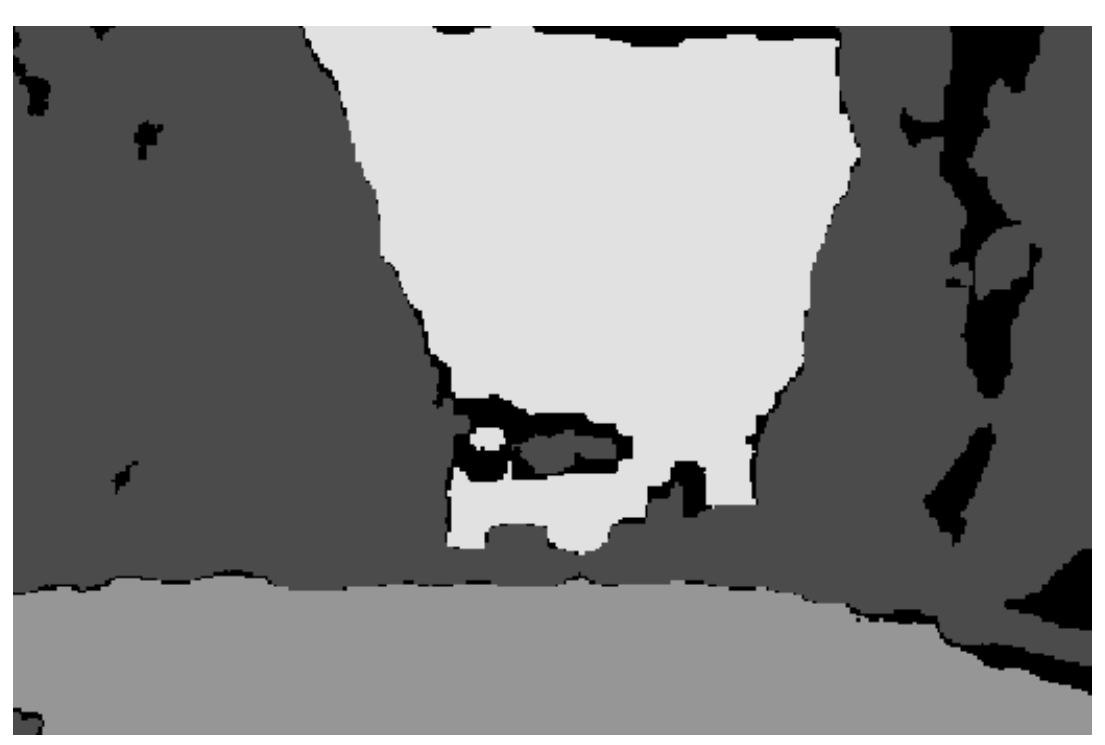

Figura 7.14: Cena natural 3 segmentada: cada nível de cinza representa uma classe, a cor preta indica classe desconhecida.

intuito de confirmar que apenas os níveis de cinza isoladamente não são suficientes para um bom resultado. A implicação direta dessa constatação é que o DMET foi capaz de inferir algo mais complexo para atingir um melhor desempenho (figura 7.15.b), ou seja, ele foi capaz de apreender a textura. Na comparação com as Matrizes de Coocorrência (7.15.c), o DMET retornou mais ruído, porém classificou melhor as fronteiras, onde rotulou os píxeis como classe desconhecida (cor preta).

Conforme explicado na seção 6.3, a topologia da rede foi de 169 entradas, 29 neurônios na camada oculta e 7 neurônios de saída. O critério de parada do treinamento foi o mesmo da CMET e consumiu aproximadamente 200.000s. É possível que, em grande parte, o tempo de treinamento tenha aumentado com relação ao CMET por causa da escolha de aproximadamente 5 vezes mais padrões de treinamento.

Duas conseqüências imediatas de se delegar a tarefa de apreensão da textura diretamente ao MLP é a necessidade de uma topologia maior e de um tempo de treinamento em torno de 20 vezes superior à abordagem que adotou as Matrizes de Coocorrência. Porém, por ter um custo de aquisição de características praticamente nulo, seu tempo de segmentação é 10 vezes menor.

Assim, em situações em que o tempo de treinamento não é crítico, o DMET apresentase como o mais rápido na segmentação supervisionada - uma vez que a etapa de treinamento já esteja encerrada. Isso o torna um método valioso para aplicações de tempo-real e mesmo para situações nas quais não se dispõe de recursos computacionais suficientes para os cálculos complexos envolvidos nos métodos tradicionais. 

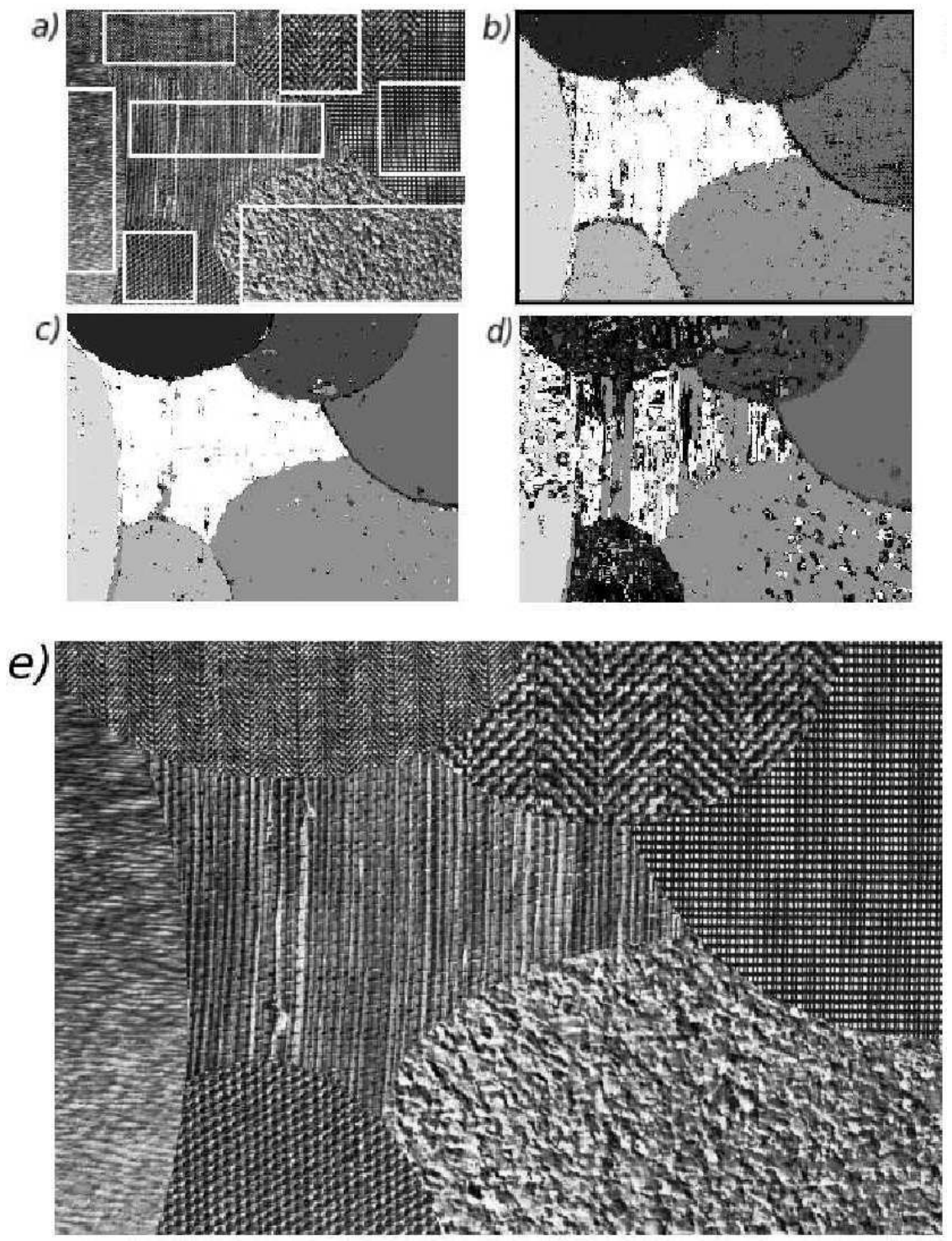

Figura 7.15: Segmentação do mosaico por três abordagens: a) conjuntos de treinamento (amostra de 122.316 píxeis); b) segmentação por DMET; c) segmentação por Matrizes de Coocorrência; d) segmentação por média e variância do nível de cinza; e) imagem utilizada.

\subsection{Considerações}

Este capítulo apresentou os resultados da seleção ótima, de diferentes variações do método de seleção por saliência e do método baseado no descarte de características de textura. Os contextos dos experimentos foram mosaicos de texturas e imagens de cenas naturais. Foi também realizada uma análise crítica sobre o desempenho das diversas abordagens. As conclusões finais deste trabalho são apresentadas no próximo capítulo. 


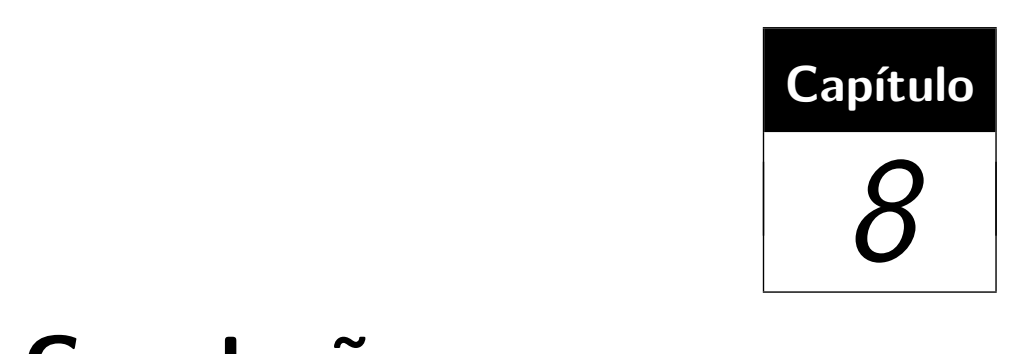

\section{Conclusões}

Este trabalho explorou a seleção de características por meio de uma rede neural MLP utilizando a medida de saliência. Diferentes variações dessa abordagem foram comparadas com um método estatístico ótimo.

Uma das dificuldades da abordagem estatística tradicional é sua complexidade. Se comparado à busca exaustiva baseada em um MLP, o método proposto reduz a quantidade de treinamentos de $2^{n}$ para $n$, com a vantagem de serem treinamentos parciais. Os resultados da seção 7.1.8 aliados aos cálculos da seção 6.2.3 mostraram que para subconjuntos de tamanho superior a 4 características, de um total de 71 , o método proposto é mais eficiente que a busca exaustiva baseada na distância JM.

Foi constatado que quando se trata de um sistema cujo classificador é um MLP, a seleção de características não aumenta a taxa de acerto do sistema. Isso é devido à seleção que ocorre internamente no MLP quando todas as características estão presentes. E é justamente essa propriedade que foi explorada na criação da medida de saliência. Sendo assim, quando se trata de selecionar características para um MLP, as principais vantagens são a redução no custo de aquisição de características e a diminuição da complexidade do sistema. No caso do classificador de distância mínima e outros classificadores pouco complexos, há ainda a vantagem de se aumentar a taxa de acerto do classificador.

Além da seleção que ocorre internamente, outras formas de inteligência, como a extração de características de textura, podem ser constatadas em um MLP. Isso foi comprovado no experimento baseado no DMET, que, inclusive, se mostrou, a princípio, uma boa opção para sistemas de tempo-real que não tenham restrições quanto ao tempo de treinamento.

Concluiu-se, pelos resultados obtidos, que a SSOC é mais indicada para classificadores MLP por ser mais rápida e por retornar bons resultados com esse tipo de classificador. 
Por outro lado, a SS é mais indicada para classificadores mais simples ou que tenham problemas com a alta dimensionalidade. De qualquer forma, a técnica de equalização da entrada sugerida se revelou de grande valia em ambos os casos. Vale ressaltar que a SSOC, embora envolva o longo treinamento de um MLP, é considerada de ordem constante, pois uma busca exaustiva baseada no acerto de classificação de um MLP precisaria de $2^{n}$ também longos treinamentos.

Uma constatação importante neste trabalho foi a qualidade do seletor de características por saliência. Ele foi capaz de produzir, independentemente da natureza da imagem, um subconjunto apropriado de características. O bom desempenho do classificador de distância mínima frente ao MLP, que é mais sofisticado, é uma evidência do sucesso da SS em termos qualitativos.

Por fim, é fundamental ressaltar o papel da técnica de equalização que aumentou consideravelmente a taxa de acerto da segmentação, independentemente da variação do método de seleção por saliência adotado.

\subsection{Contribuições}

A principal contribuição deste trabalho foi o desenvolvimento da técnica de equalização da entrada e respectiva avaliação. O autor acredita que essa é uma contribuição original para a área de pesquisa. Outras contribuições foram:

- comparação da heurística de saliência (SS, SSOC) com um método ótimo;

- demonstração do sucesso da SS com imagens reais;

- implementação do sistema extrator de características de textura e do sistema de seleção e classificação, ambos para processamento paralelo;

\subsection{Publicações oriundas do trabalho}

Foi publicado em um congresso local um artigo sobre a apreensão artificial da textura pelo MLP (SANTOS, 2006). Há também a intenção de se publicar a respeito da técnica de equalização da entrada.

\subsection{Desdobramentos futuros}

Uma conseqüência imediata deste trabalho seria a experimentação de um método de ordem $O\left(\log _{2} n\right)$ que seria um meio termo entre a SS e a SSOC. Ele consistiria da eliminação de apenas metade das características por iteração. Quando restasse uma quantidade próxima à desejada, por exemplo $2 n$, o processo continuaria como na SS convencional. Outro 
critério de seleção possível seria adotar um limiar: a cada iteração eliminam-se todas as características com valor de saliência abaixo de determinado limite. Uma desvantagem dessa abordagem seria a imprevisibilidade da complexidade do processo.

Outro desdobramento possível é a criação de uma SS não-supervisionada por meio de um MLP autoassociativo (AANN). 


\section{Referências Bibliográficas}

ABBADENI, N.; ZIOU, D.; WANG, S. Computational measures corresponding to perceptual textural features. In: ICIP. [S.l.: s.n.], 2000.

AMADASUN, M.; KING, R. Textural features corresponding to textural properties. IEEE Transactions on Systems, Man, and Cybernetics, v. 19, p. 1264-1274, 1989.

BACHOO, A. K.; TAPAMO, J.-R. Texture detection for segmentation of iris images. In: SAICSIT '05: Proceedings of the 2005 annual research conference of the South African institute of computer scientists and information technologists on IT research in developing countries. Republic of South Africa: South African Institute for Computer Scientists and Information Technologists, 2005. p. 236-243. ISBN 1-59593-258-5.

BALlARD, D. H.; BROWN, C. M. Computer Vision. [S.1.]: Prentice Hall Professional Technical Reference, 1982. ISBN 0131653164.

BANKS, S. Signal processing, image processin and pattern recognition. [S.l.]: Prentice Hall, 1990.

BATTIATO, S.; GALlO, G.; NICOTRA, S. Perceptive visual texture classification and retrieval. In: ICIAP. [s.n.], 2003. p. 524-529. Disponível em: <http://csdl.computer.org/comp/proceedings/iciap/2003/1948/00/19480524abs.htm>.

BECK, J.; SUTTER, A.; IVRY, R. Spatial frequency channels and perceptual grouping in texture segregation. Comput. Vision Graph. Image Process., Academic Press Professional, Inc., San Diego, CA, USA, v. 37, n. 2, p. 299-325, 1987. ISSN 0734-189X.

BISHOP, C. M. Neural Networks for Pattern Recognition. [S.l.]: Oxford, 1995.

BLOSTEIN, D.; AHUJA, N. Shape from texture: Integrating texture-element extraction and surface estimation. IEEE Trans. Pattern Anal. Mach. Intell., IEEE Computer Society, Washington, DC, USA, v. 11, n. 12, p. 1233-1251, 1989. ISSN 0162-8828.

BRADLEY, A. et al. Visual orientation and spatial frequency discrimination: a comparison of single neurons and behavior. Journal of Neurophysiology, v. 57, n. 3, p. $755-772,1987$.

BRIGHAM, O. The Fast Fourier Transform. [S.l.]: Prentice-Hall, 1974. 
BRODATZ, P. Textures: A Photographic Album for Artists and Designers. NY: Dover, 1966.

BRUZZONE, L. R.; SERPICO, S. B. F. An extension of the jeffreys-matusita distance to multiclass casesfor feature selection. Geoscience and Remote Sensing, IEEE Transactions on, v. 33, n. 6, p. 1318-1321, 1995.

CASTELLANO, G.; FANELLI, A. M. Variable selection using neuralnetwork models. Neurocomputing, v. 31, n. 1-4, p. 1-13, 2000. Disponível em: $<$ http://dx.doi.org/10.1016/S0925-2312(99)00146-0>.

CHAUDHURI, B. B.; SARKAR, N. Texture segmentation using fractal dimension. IEEE Trans. Pattern Anal. Mach. Intell, v. 17, n. 1, p. 72-77, 1995. Disponível em: $<$ http://www.computer.org/tpami/tp1995/i0072abs.htm>.

CHAUDHURI, B. B.; SARKAR, N.; KUNDU, P. Improved fractal geometry based texture segmentation technique. IEE Proceedings-Vision Image and Signal Processing, v. 140, p. 233-241, 1993.

CHAUVIN, D. E. R. Y. Backpropagation: Theory, architectures, and applications / edited by yves chauvin and david e. rumelhart. [S.l.]: Lawrence Erlbaum Associates, 1995.

CHEN, X. wen. An improved branch and bound algorithm for feature selection. Pattern Recogn. Lett., Elsevier Science Inc., New York, NY, USA, v. 24, n. 12, p. 1925-1933, 2003. ISSN 0167-8655.

CLARK, M.; BOVIK, A. C.; GEISLER, W. S. Texture segmentation using gabor modulation/demodulation. Pattern Recogn. Lett., Elsevier Science Inc., New York, NY, USA, v. 6, n. 4, p. 261-267, 1987. ISSN 0167-8655.

COMER, M. L.; DELP, E. J. The EM/MPM algorithm for segmentation of textured images: analysis and further experimental results. IEEE Transactions on Image Processing, v. 9, n. 10, p. 1731-1744, 2000. Disponível em: <http://dx.doi.org/10.1109/83.869185>.

DAI, Y.; NAKANO, Y.; MIYAO, H. Extraction of facial images from a complex background using SGLD matrices. In: International Conference on Pattern Recognition. [S.l.: s.n.], 1994. p. A:137-141.

DONG, P. Test of a new lacunarity estimation method for image texture analysis. International Journal of Remote Sensing, v. 21, n. 17, p. 3369-3373, nov. 2000.

DY, J.; BRODLEY, C. Feature Selection for Unsupervised Learning. The Journal of Machine Learning Research, MIT Press Cambridge, MA, USA, v. 5, p. 845-889, 2004.

FUKUNAGA, K. Introduction to Statistical Pattern Recognition. [S.l.]: Academic Press, 1990.

GALLOWAY, M. M. Texture analysis using gray level run lengths. Computer Graphics Image Processing, v. 4, p. 172-179, 1975.

GARSON, G. D. Interpreting neural net connection weights. AI Expert, v. 6, n. 4, p. 46-51, 1991. 
GONZALEZ, R. C.; WOODS, R. E. Digital Image Processing. 3rd. ed. [S.1.]: Addison-Wesley, 1992.

GOOL, L. V.; DEWAELE, P.; OOSTERLINCK, A. Texture analysis anno 1983. Computer Vision, Graphics and Image Processing, v. 29, p. 336-357, 1985.

HARALICK, A. Statistical and structural approaches to texture. Proceedings of the IEEE, v. 67, n. 5, 1979.

HARALICK, R. M.; SHANMUGAM, K.; DINSTEIN, I. Textural features for image classification. In: CMetImAly r7. [S.l.: s.n.], 1977. p. 141-152.

HAYKIN, S. Neural Networks: A comprehensive foundation. [S.l.]: Prentice Hall, 1999.

HE, D.-C.; WANG, L. Texture features based on texture spectrum. Pattern Recogn., Elsevier Science Inc., New York, NY, USA, v. 24, n. 5, p. 391-399, 1991. ISSN 0031-3203.

HE, D.-C.; WANG, L.; GUIBERT, J. Texture discrimination based on an optimal utilization of texture features. Pattern Recogn., Elsevier Science Inc., New York, NY, USA, v. 21, n. 2, p. 141-146, 1988. ISSN 0031-3203.

HESKES, T.; WIGERINCK, W. A theoretical comparison of batch-mode, on-line, cyclic, and almost-cyclic learning. Neural Networks, IEEE Transactions on, v. 7, n. 4, p. 919-925, 1996.

HUBER, R.; DUTRA, L. Feature Selection for ERS 1/2 InSAR Classification: High Dimensionality Case. 1998. Disponível em: <citeseer.ist.psu.edu/huber98feature.html>.

JAIN, A. K.; BHATTACHARJEE, S. Text segmentation using gabor filters for automatic document processing. Mach. Vision Appl., Springer-Verlag New York, Inc., Secaucus, NJ, USA, v. 5, n. 3, p. 169-184, 1992. ISSN 0932-8092.

JAIN, A. K.; DUIN, R. P. W.; MAO, J. Statistical pattern recognition: A review. IEEE Trans. Pattern Anal. Mach. Intell, v. 22, n. 1, p. 4-37, 2000.

JAIN, A. K.; FARROKHNIA, F. Unsupervised texture segmentation using Gabor filters. Pattern Recognition, v. 24, n. 12, p. 1167-1186, 1991.

JAIN, A. K.; ZONGKER, D. Feature selection: Evaluation, application and a small sample performance. IEEE Transactions on PAMI, v. 19, p. 153-158, 1997.

JANSSEN, I. et al. Skeletal muscle mass and distribution in 468 men and women aged 18-88 yr. Journal of applied physiology, v. 1, n. 89, p. 81-88, 2000.

JULESZ, B. Visual pattern discrimination. IRE Trans. Inform. Theory, v. 8, n. 2, p. 84-92, 1962.

KELLER, J. M.; CHEN, S. S.; CROWNOVER, R. M. Texture description and segmentation through fractal geometry. CVGIP: Image Understanding, v. 45, n. 2, p. 150 166, fev. 1989. Disponível em: <http://www.sciencedirect.com/science/article/B7GXG4CRRMNF-X/2/48eb41193cdec36220edea19dff0b923>.

KOHONEN. Self-Organizing Maps. [S.1.]: Springer, 1995. 
KORN, F.; PAGEL, B.-U.; FALOUTSOS, C. On the 'dimensionality curse' and the 'self-similarity blessing'. IEEE Transactions on Knowledge and Data Engineering, IEEE Educational Activities Department, Piscataway, NJ, USA, v. 13, n. 1, p. 96-111, 2001. ISSN 1041-4347.

KRAMER, M. Autoassociative neural networks. Computers $\&$ Chemical Engineering, v. 16, n. 4, p. 313-328, 1992.

KRAMER, M. A. Nonlinear principal component analysis using autoassociative neural networks. AICHE Journal, v. 37, p. 233-243, 1991.

KUDO, M.; SKLANSKY, J. Comparison of algorithms that select features for pattern classifiers. Pattern Recognition, v. 33, n. 1, p. 25-41, 2000. Disponível em: <http://dx.doi.org/10.1016/S0031-3203(99)00041-2>.

LAAR, P.; GIELEN, S.; HESKES, T. Input selection with partial retraining. Lecture Notes in Computer Science, v. 1327, p. 469-476, 1997b. ISSN 0302-9743.

LAAR, P.; HESKES, T.; GIELEN, S. Partial retraining: A new approach to input relevance determination. 1997. Disponível em: $<$ citeseer.ist.psu.edu/vandelaar99partial.html $>$.

LEFEBVRE, L.; POULIN, P. Analysis and synthesis of structural textures. In: Graphics Interface. [s.n.], 2000. p. 77-86. Disponível em: <http://www.graphicsinterface.org/proceedings/2000/119/>.

LERAY, P.; GALLINARI, P. Feature selection with neural networks. Behaviormetrika (special issue on Analysis of Knowledge Repr, v. 26, n. 1, 1998.

LERNER, B. et al. Feature selection and chromosome classification using a multilayer perceptron neural network. IEEE World Congress on Computational Intelligence, v. 6, 1994.

MALLAT, S. A theory of multiresolution signal decomposition: the wavelet representation. IEEE Transactions on Pattern Analysis and Machine Intelligence, v. 11, p. 674-693, 1989.

MARTINEZ, A. M.; ZHU, M. Where are linear feature extraction methods applicable? IEEE Trans. Pattern Analysis and Machine Intelligence, v. 27, n. 12, p. 1934-1944, 2005. Disponível em: <http://dx.doi.org/10.1109/TPAMI.2005.250>.

MASTERS, T. Signal And Image Processing with Neural Networks. New York: John Wiley \& Sons, Inc., 1994.

MATERKA, M. S. A. Texture analysis methods: A review. COST B11 report, 1998.

MESSER, K.; KITTLER, J. Choosing an optimal neural network size to aid search through a large image database. Proc British Machine Vision Conference BMVC98, p. 235-244, 1998.

MUNEESWARAN, K. et al. Texture image segmentation using combined features from spatial and spectral distribution. Pattern Recogn. Lett., Elsevier Science Inc., New York, NY, USA, v. 27, n. 7, p. 755-764, 2006. ISSN 0167-8655. 
NATH, R.; RAJAGOPALAN, B.; RYKER, R. Determining the saliency of input variables in neural network classifiers. Computers $\&$ OR, v. 24, n. 8, p. 767-773, 1997. Disponível em: <http://dx.doi.org/10.1016/S0305-0548(96)00088-3>.

PELEG, S. et al. Multiple resolution texture analysis and classification. IEEE Trans. Pattern Analysis and Machine Intelligence, v. 6, n. 4, p. 518-523, 1984.

PICARD, R. W.; ELFADEL, I. M.; PENTLAND, A. P. Markov/Gibbs Texture Modeling: Aura Matrices and Temperature Effects. [S.1.], 1991. Disponível em: <http://www-white.media.mit.edu/vismod/publications/techdir/TR-164.ps.Z>.

PRESS, W. H. Numerical Recipes in C. Cambridge: Cambridge University Press, 1990. $735 \mathrm{p}$.

PSTER, M.; ROJAS, R. Hybrid learning algorithms for neural networks: The adaptive inclusion of second order information. Zeitschrift fur Angewandte Mathematik und Mechanik, v. 76, n. 1, p. 215-218, 1996.

QIN, L. et al. Unsupervised texture classification: Automatically discover and classify texture patterns. icpr, IEEE Computer Society, Los Alamitos, CA, USA, v. 2, p. 433-436, 2006. ISSN 1051-4651.

RICHARDS, J. A. Remote sensing digital image analysis. [S.l.]: Springer-Verlag, 1995.

RIEDMILLER, M.; BRAUN, H. A direct adaptive method for faster backpropagation learning: The RPROP algorithm. Proceedings of the IEEE International Conference on Neural Networks, New York: IEEE Press, v. 1993, 1993.

RIEDMILLER, M.; BRAUN, H. A Direct Adaptive Method for Faster Backpropagation Learning: The RPROP Algorithm. 1993.

RUCK, D. W.; ROGERS, S. K.; KABRISKY, M. Feature selection using a multilayer perceptron. Journal of Neural Network Computing, v. 2, n. 2, p. 40-48, 1990.

SANTOS, D. P. dos. Texture extraction capabilities of multi-layer perceptron. Anais do II Workshop de Visão Computacional, Departamento de Engenharia Elétrica, São Carlos, SP, Brasil, v. 1, p. 123-130, 2006.

SARKAR, N.; CHAUDHURI, B. B. An efficient approach to estimate fractal dimension of textural images. Pattern Recognition, v. 25, n. 9, p. 1035-1041, 1992. Disponível em: <http://dx.doi.org/10.1016/0031-3203(92)90066-R>.

SCHIFFMANN, W.; JOOST, M.; WERNER, R. Comparison of Optimized Backpropagation Algorithms. 1993.

SCHÜRMANN, J. Pattern classification: a unified view of statistical and neural approaches. [S.l.]: John Wiley \& Sons, Inc. New York, NY, USA, 1996.

SIEW, L. H.; HODGSON, R. M.; WOOD, E. J. Texture measures for carpet wear assessment. IEEE Transactions on Pattern Analysis and Machine Intelligence, v. 10, p. 92-105, 1988.

SONKA, M.; HLAVAC, V.; BOYLE, R. Image Processing, Analysis, and Machine Vision. [S.l.]: Chapman \& Hall, 1993. 
TANENBAUM, A. S. Modern Operating Systems. [S.l.]: Prentice-Hall, 1992. ISBN 0-13-588187-0.

THEODORIDIS, S.; KOUTROUMBAS, K. Pattern Recognition. [S.l.]: Academic Press, 1999.

TUCERYAN, M.; JAIN, A. K. Texture segmentation using voronoi polygons. IEEE Transactions on Pattern Analysis and Machine Intelligence, PAMI-12, n. 2, p. 211-216, fev. 1990.

TUCERYAN, M.; JAIN, A. K. Texture analysis. Handbook of Pattern Recognition and Computer Vision, p. 235-276, 1998.

USHIZIMA-SABINO, D. M. et al. A texture approach to leukocyte recognition.

Real-Time Imaging, v. 10, n. 4, p. 205-216, 2004.

VANMARCKE, E. Random fields: analysis and synthesis. Princeton, NJ, USA: MIT Press, Cambridge MA, 1983.

VANMARCKE, E. Random Fields: Analysis and Synthesis. Rare Book Services, 1998. Acessado em 30/01/2007. Disponível em: $<$ http://www.princeton.edu/ evm/randomfields.html>.

VERMA, B.; KULKARNI, S. Texture feature extraction and classification. In: CAIP. [s.n.], 2001. p. 228-235. Disponível em:

<http://link.springer.de/link/service/series/0558/bibs/2124/21240228.htm>.

WANG, J. Z. James Z. Wang's Research Group. 2003. Acessado em 30/01/2007.

Disponível em: <http://wang.ist.psu.edu/docs/home.shtml>.

WANG, L.; HE, D. C. Texture classification using texture spectrum. Pattern Recognition, v. 23, n. 8, p. 905-910, 1990. Disponível em: <http://www.sciencedirect.com/science/article/B6V14-48N52VJ$\mathrm{R} / 2 / 34704 f 547270 f 9 c 3 f 304 f f 8 c d 5884025>$.

WARE, C.; KNIGHT, W. Using visual texture for information display. ACM Trans. Graph, v. 14, n. 1, p. 3-20, 1995. Disponível em: $<$ http://doi.acm.org/10.1145/200972.200974>.

YOUNG, T. Y.; FU, K. S. (Ed.). Handbook of Pattern Recognition and Image Processing. Orlando, FL: Academic Press, 1986.

ZEGARRA, J. A. M.; LEITE, N. J.; TORRES, R. da S. Wavelet-based Feature Extraction for Fingerprint Image Retrieval. [S.1.], 2006.

ZHANG, J.; TAN, T. Brief review of invariant texture analysis methods. Pattern Recognition, v. 35, n. 3, p. 735-747, 2002. Disponível em: <http://dx.doi.org/10.1016/S00313203(01)00074-7>.

ZHOU, F.; FENG, J. F.; SHI, Q. Y. Texture feature based on local fourier transform. In: ICIP (2). [s.n.], 2001. p. 610-613. Disponível em: <http://dx.doi.org/10.1109/ICIP.2001.958567>. 


\section{Apêndice A}

Este apêndice apresenta a numeração das características utilizada nos capítulos 6 e 7 . Detalhes de implementação são dados na seção 6.1.1.

1: Run Lengths short runs emphasis (média)

2: Run Lengths long runs emphasis (média)

3: Run Lengths gray level nonuniformity (média)

4: Run Lengths run nonuniformity (média)

5: Run Lengths run percentage (média)

6: Run Lengths short runs emphasis (desvio padrão)

7: Run Lengths long runs emphasis (desvio padrão)

8: Run Lengths gray level nonuniformity (desvio padrão)

9: Run Lengths run nonuniformity (desvio padrão)

10: Run Lengths run percentage (desvio padrão)

11: valores dos píxeis (média)

12: valores dos píxeis (desvio padrão)

13: valores dos píxeis (mediana)

14: valor do píxel

15: Matrizes de Coocorrência comprimento 2 - angular second moment (média)

16: Matrizes de Coocorrência comprimento 2 - contrast (média)

17: Matrizes de Coocorrência comprimento 2 - correlation (média)

18: Matrizes de Coocorrência comprimento 2 - variance (média)

19: Matrizes de Coocorrência comprimento 2 - inverse difference moment (média)

20: Matrizes de Coocorrência comprimento 2 - sum average (média)

21: Matrizes de Coocorrência comprimento 2 - sum variance (média)

22: Matrizes de Coocorrência comprimento 2 - sum entropy (média)

23: Matrizes de Coocorrência comprimento 2 - entropy (média)

24: Matrizes de Coocorrência comprimento 2 - difference variance (média)

25: Matrizes de Coocorrência comprimento 2 - difference entropy (média)

26: Matrizes de Coocorrência comprimento 3 - angular second moment (média)

27: Matrizes de Coocorrência comprimento 3 - contrast (média)

28: Matrizes de Coocorrência comprimento 3 - correlation (média)

29: Matrizes de Coocorrência comprimento 3 - variance (média)

30: Matrizes de Coocorrência comprimento 3 - inverse difference moment (média)

31: Matrizes de Coocorrência comprimento 3 - sum average (média)

32: Matrizes de Coocorrência comprimento 3 - sum variance (média) 
33: Matrizes de Coocorrência comprimento 3 - sum entropy (média)

34: Matrizes de Coocorrência comprimento 3 - entropy (média)

35: Matrizes de Coocorrência comprimento 3 - difference variance (média)

36: Matrizes de Coocorrência comprimento 3 - difference entropy (média)

37: Matrizes de Coocorrência comprimento 2 - angular second moment (desvio padrão)

38: Matrizes de Coocorrência comprimento 2 - contrast (desvio padrão)

39: Matrizes de Coocorrência comprimento 2 - correlation (desvio padrão)

40: Matrizes de Coocorrência comprimento 2 - variance (desvio padrão)

41: Matrizes de Coocorrência comprimento 2 - inverse difference moment (desvio padrão)

42: Matrizes de Coocorrência comprimento 2 - sum average (desvio padrão)

43: Matrizes de Coocorrência comprimento 2 - sum variance (desvio padrão)

44: Matrizes de Coocorrência comprimento 2 - sum entropy (desvio padrão)

45: Matrizes de Coocorrência comprimento 2 - entropy (desvio padrão)

46: Matrizes de Coocorrência comprimento 2 - difference variance (desvio padrão)

47: Matrizes de Coocorrência comprimento 2 - difference entropy (desvio padrão)

48: Matrizes de Coocorrência comprimento 3 - angular second moment (desvio padrão)

49: Matrizes de Coocorrência comprimento 3 - contrast (desvio padrão)

50: Matrizes de Coocorrência comprimento 3 - correlation (desvio padrão)

51: Matrizes de Coocorrência comprimento 3 - variance (desvio padrão)

52: Matrizes de Coocorrência comprimento 3 - inverse difference moment (desvio padrão)

53: Matrizes de Coocorrência comprimento 3 - sum average (desvio padrão)

54: Matrizes de Coocorrência comprimento 3 - sum variance (desvio padrão)

55: Matrizes de Coocorrência comprimento 3 - sum entropy (desvio padrão)

56: Matrizes de Coocorrência comprimento 3 - entropy (desvio padrão)

57: Matrizes de Coocorrência comprimento 3 - difference variance (desvio padrão)

58: Matrizes de Coocorrência comprimento 3 - difference entropy (desvio padrão)

59: Transformada de Fourier unidimensional 1

60: Transformada de Fourier unidimensional 2

61: Transformada de Fourier unidimensional 3

62: Transformada de Fourier unidimensional 4

63: Transformada de Fourier unidimensional 5

64: Transformada de Fourier unidimensional 6

65: Transformada de Fourier unidimensional 7

66: Transformada de Fourier unidimensional 8

67: Transformada de Fourier bidimensional - energia do espectro - raio 0

68: Transformada de Fourier bidimensional - energia do espectro - raio 1

69: Transformada de Fourier bidimensional - energia do espectro - raio 2

70: Transformada de Fourier bidimensional - energia do espectro - raio 3

71: Transformada de Fourier bidimensional - energia do espectro - raio 4 


\section{Apêndice B}

Este apêndice apresenta o experimento preliminar sobre a validade do retreino parcial.

Para assegurar que a adoção do retreino parcial não prejudica demasiadamente os resultados e realmente diminui o tempo de processamento, foram comparadas as versões com e sem o mesmo.

Na figura 8.1, é possível observar a evolução do erro de treinamento dependendo da quantidade remanescente de características. O tempo total sem o retreino parcial foi 12400s. O tempo total com o retreino parcial foi 8700 s (treino inicial: 3200, subconjuntos: $4500 \mathrm{~s}$ ). As taxas de acerto são semelhantes, porém o custo computacional 1, 4 vezes menor favorece o uso do retreino parcial. Devido à divergência de soluções, os subconjuntos selecionados não são apresentados.

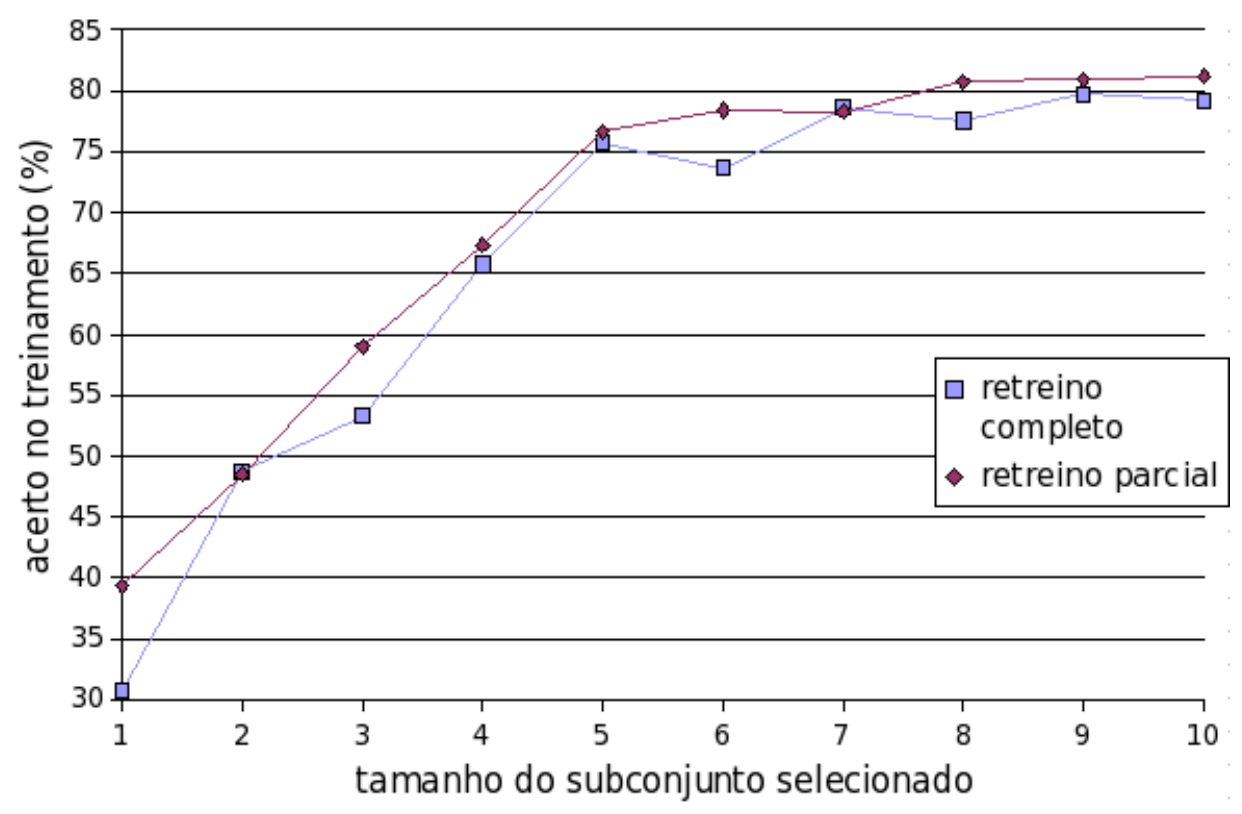

Figura 8.1: Comparação entre as taxas de acerto com e sem retreino parcial: taxas de acerto muito próximas 


\section{Apêndice C}

Como foi assunto de um artigo publicado no mestrado e é um importante método bioinspirado, a teoria do mapa auto-organizável de Kohonen é apresentada neste apêndice em detalhes.

Quando o SOM é de uma dimensão, os neurônios encontram-se ao longo de uma linha; para duas dimensões, dispõe-se num plano quadrado ou hexagonal (com os neurônios dispostos como num favo de mel). Raramente encontram-se arranjos de três dimensões. No caso de duas dimensões, a camada pode ser representada por uma matriz quadrada. Cada neurônio da matriz possui um número de pesos igual ao número de características sob análise. Inicialmente, todos os pesos têm seus valores definidos aleatoriamente dando seqüência a um longo processo iterativo. A cada iteração, um novo padrão é apresentado à rede e localizado o neurônio cujos pesos sejam mais parecidos com as características do padrão. Esse neurônio, chamado de vencedor, e os que estiverem mais próximos são alterados de forma a ficarem ainda mais parecidos com o padrão. Essa alteração é proporcional à distância do neurônio vencedor e aos parâmetros que decaem durante o processo. O grupo de neurônios afetados é regulado por uma função de vizinhança conforme ilustrado na figura 8.2: a configuração dos pesos dos neurônios e a configuração de características do padrão são ambas simbolizadas pela direção de uma seta; observar que o neurônio selecionado tem a orientação mais parecida com o padrão sob análise no momento; e, finalmente, os neurônios sob influência do neurônio vencedor são reorientados de forma a se aproximar do padrão apresentado.

Cada peso e padrão são denotados por $\mathbf{w}_{i, j}(t)$ e $\mathbf{x}_{l}$, respectivamente, onde $i, j$ é a posição do neurônio sobre o mapa, $t$ representa o número da iteração e $l$ é o número do padrão de um total de $L$ padrões. O neurônio vencedor $\mathbf{w n}_{i, j}(t)$ é aquele que for mais parecido com o padrão $\mathbf{x}_{l}$ segundo o critério:

$$
\mathbf{w n}_{i, j}(t)=\arg \min \left\|\mathbf{x}_{l}-\mathbf{w}_{i, j}(t)\right\|, \quad i, j=1, \ldots, M .
$$

onde $M$ é a largura do mapa. Depois que o neurônio vencedor é encontrado, a função de vizinhança pode ser calculada e usada na expressão abaixo para atualizar os pesos da rede neural:

$$
\mathbf{w}_{i, j}(t+1)=\mathbf{w}_{i, j}(t)+\eta(t) h_{i, j}(t)\left(\mathbf{x}_{l}(t)-\mathbf{w}_{i, j}(t)\right) .
$$

As funçoes $\eta(n)$ e $h_{i, j}(n)$ são, respectivamente, o parâmetro de aprendizado e a função de vizinhança:

$$
\eta(t)=\eta_{0} \exp \left(-\frac{t}{\tau_{2}}\right) .
$$



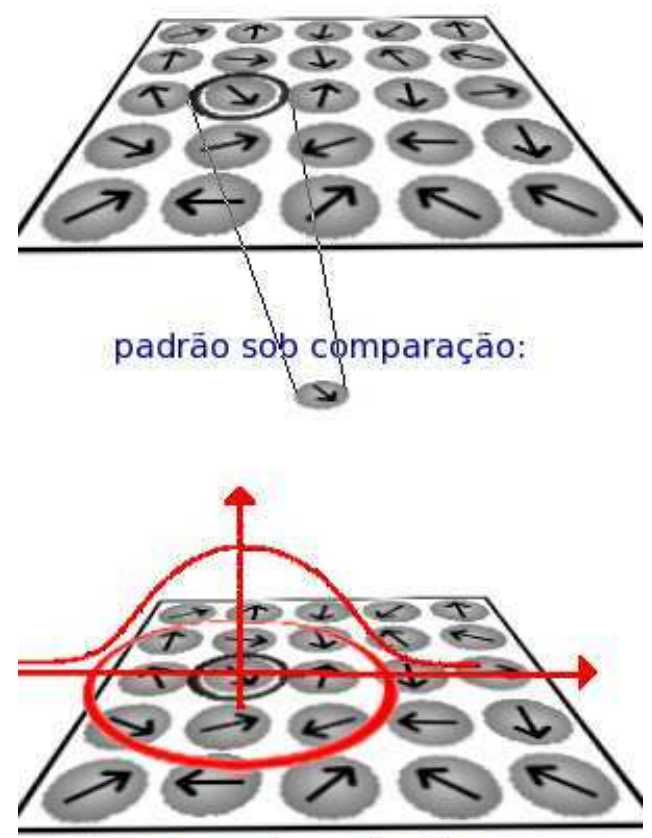

comportamento da funçāo de vizinhança numa dada iteraçäo

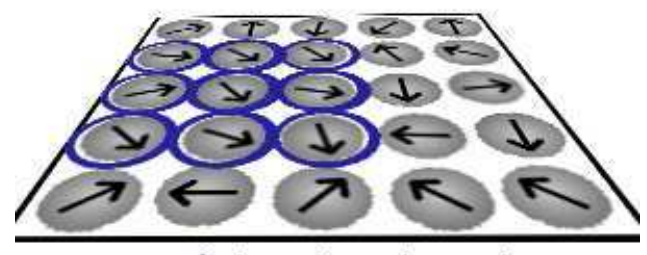

neurônios alterados pelo reajuste de pesos

Figura 8.2: Mapa de Kohonen: em cima: é localizado o neurônio mais parecido com o padrão (neurônio vencedor); no meio: é calculada a área de influência do neurônio vencedor; em baixo: é feito o ajuste dos neurônios envolvidos

$$
h_{i, j}(t)=\exp \left(-\frac{d_{i, j}^{2}}{2 \sigma^{2}(t)}\right) .
$$

$\eta(t)$ decai com o aumento do número de iterações, conseqüentemente, as mudanças passam a ser cada vez menores e a rede tende a se estabilizar. A função de vizinhança regula a influência do vencedor sobre seus vizinhos. Essa influência diminui até que apenas o neurônio vencedor seja afetado. $d_{i, j}$ é a distância entre o vencedor e o vizinho na posição $i, j$, e $\sigma(t)$ determina o alcance da influência. O alcance varia conforme a iteração $(t)$ :

$$
\sigma(t)=\sigma_{0} \exp \left(-\frac{t}{\tau_{1}}\right)
$$

onde $\tau_{1}$ e $\tau_{2}$ são constantes ajustadas de acordo com o experimento e $\sigma_{0}$ pode ser definido 
como a metade da largura do mapa, isto é, inicialmente, o vencedor tem grande influência sobre todo o mapa.

Após 2,000,000 iterações (HAYKIN, 1999), a rede já está estabilizada. Algumas regiões do mapa terão se especializado em responder a certas classes, outras regiões permanecerão inativas. Após o treinamento, todos os padrões podem ser novamente apresentados à rede. A cada nova apresentação, é selecionado o neurônio mais parecido, dito ativado, e sua posição no mapa pode ser rotulada caso se deseje relacionar as regiões com classes definidas pelo usuário. Depois de treinado, o mapa retorna o neurônio vencedor (e eventual rótulo de classe) quase instantaneamente, com o custo computacional dependendo apenas das dimensões do mapa e do tamanho dos neurônios (quantidade de características). 
